\title{
"Coming full circle": Reviving Private Press Printing at the University of Otago.
}

\author{
by \\ Paula Jane Whitelock \\ Submitted to the School of Information Management, \\ Victoria University of Wellington \\ in partial fulfilment of the requirements for the degree of \\ Master of Library and Information Studies
}

October, 2009 


\section{Acknowledgements:}

My sincere thanks to all those who contributed to this study - your knowledge, experiences and perceptions of the Printer in Residence Programme have been invaluable. To my supervisor, Dr Sydney Shep, your guidance, support and prompt responses to all my queries were much appreciated. And finally, I would like to pass on my gratitude to Dr Donald Kerr for suggesting the Printer in Residence Programme as a research topic and for all his support during the process of completing this research. 


\section{Abstract:}

The Printer in Residence (PiR) Programme at the University of Otago has been running since 2003 and in that time nine private press publications have been produced. Each year the Programme commissions a skilled handprinter to produce a specific work (usually related to the University of Otago's art and literary history) in collaboration with local artists and printmakers. Although there is valuable research available in regards to New Zealand's print culture, this was an aspect of New Zealand's private press history yet to be investigated.

This study utilised an historical case study approach to document the recent history and development of the Printer in Residence (PiR) Programme through an investigation of its archives. The study also included guided interviews with eight individuals involved in different areas of the Programme (e.g. administration and general operations, Printers in Residence and contributing artists and printmakers) and written accounts by two others. Using these methods the study aimed to gain a holistic perspective of the PiR Programme.

This data was used as the basis of three PiR Programme case studies (2005, 2006 and 2007). These were used to highlight the common and unique characteristics of each PiR Programme and outline the process of producing a PiR publication.

The data gathered for this study also identified several key themes. The first was the strong collaborative component in all aspects of the PiR Programme; the second was the importance placed on outreach - on promoting the Programme as a teaching opportunity to the English, Art History and Design departments; Third was the importance those interviewed placed on the hand-crafted qualities of books produced by the handprinting / letterpress printing process in comparison to commercial publishing; and fourth was the perceived value of the PiR Programme for those involved in this study. In conclusion, the findings of this study identified the PiR Programme as a small but important aspect of New Zealand's private press culture worthy of further research. 


\section{Contents:}

List of figures $\quad \ldots \ldots \ldots \quad 7$

Introduction $\quad \ldots \ldots \ldots . .6$

Problem Statement $\quad \ldots \ldots \ldots . .10$

Literature Review $\quad \ldots \ldots \ldots . . .11$

What is meant by the term' book'? $\quad \ldots \ldots \ldots . . .11$

'Book history' or 'print culture'? $\quad$......... 12

A brief outline of New Zealand's early printing history $\quad \ldots \ldots . . .14$

The private press $\quad \ldots \ldots . . .615$

New Zealand's private press movement $\quad \ldots . . . . .16$

Fine printing and New Zealand's private presses $\quad \ldots \ldots . . .16$

Including images in private press works $\quad \ldots \ldots . . . \quad 17$

$\begin{array}{lll}\text { The University of Otago Library and its bibliographic press } & . . . . . . . & 17\end{array}$

The Printer in Residence Programme at the University of Otago $\quad$......... 18

Other Printer in Residence Programmes in operation $\quad$......... 18

Adopting a theoretical framework for this study $\quad \ldots . . . . \quad 19$

Models of book production $\quad \ldots \ldots . . . \quad 20$

Summary $\quad \ldots \ldots \ldots . .20$

The objectives of this study $\quad \ldots \ldots \ldots .22$

Methodology $\quad \ldots \ldots \ldots . .24$

Research paradigm $\quad \ldots \ldots . . .24$

Historical case study approach $\quad \ldots \ldots \ldots . .24$

Sources of data $\quad \ldots \ldots \ldots . . .24$

The PiR Programme as a case study $\quad \ldots \ldots . . . \quad 25$

Case studies within a case study $\quad \ldots \ldots . . .26$

Generating new data $\quad \ldots \ldots . . .26$

Selecting a sample for the interviews using purposive sampling $\quad \ldots \ldots \ldots . .26$

Profiles of the study's key informants $\quad \ldots . . . . . \quad 28$

The interview process $\quad \ldots \ldots \ldots . .31$

Data analysis $\quad \ldots \ldots \ldots . .33$

Themes that emerged during the data analysis phase $\quad \ldots \ldots \ldots . .33$

Reflections on the study's methodology $\quad \ldots \ldots \ldots . . .33$

The University of Otago' s bibliographic press and the $\quad \ldots \ldots \ldots .36$

Printer in Residence Programme

The Bibliography Room $\quad$......... 36

The Printer in Residence Programme $\quad$........ 39

The objectives of the Printer in Residence Programme $\quad \ldots \ldots . . .40$

The role of the Printer in Residence $\quad$......... 41

Selection criteria for the Printer in Residence $\quad \ldots . . . . \quad 42$

Choosing the subject matter $\quad \ldots \ldots \ldots . . .44$

Including images in Printer in Residence publications $\quad \ldots \ldots \ldots . .45$ 
Pricing of the publications

Copyright

Promotion of the Printer in Residence Programme $\quad$......... 47

The success of the Printer in Residence Programme $\quad$......... 48

From Bibliography Room to Otakou Press $\quad$........ 49

Now and then $\quad \ldots \ldots . . . \quad 40$

Summary $\quad \ldots \ldots . . . \quad 51$

Case study 1: The 2005 Printer in Residence Programme $\quad$......... 54

Introduction $\quad$......... 55

Access to Lilac by Joanna Margaret Paul $\quad$........ 56

PINE by Ralph Hotere and Bill Manhire $\quad$........ 59

Collaborative aspects of the 2005 PiR Programme $\quad$......... 65

The outreach components of the 2005 PiR Programme $\quad \ldots . . . . .67$

In hindsight: overall challenges for the 2005 PiR Programme $\quad$......... 68

Summary $\quad$........ 69

Case Study 2: The 2006 Printer in Residence Programme $\quad$......... 71

Introduction $\quad \ldots \ldots . . . \quad 72$

The concept behind the illustrations $\quad \ldots \ldots . . . \quad 72$

The design of the book $\quad \ldots \ldots . . . \quad 76$

A process of collaboration $\quad \ldots \ldots . . . \quad 78$

The overall success of the Hunting of the Snark (2006) publication $\quad$......... 80

The outreach component of the 2006 PiR Programme $\quad$......... 82

Summary $\quad \ldots \ldots . . . \quad 82$

Case study 3: The 2007 Printer in Residence Programme $\quad$........ 84

Introduction $\quad$......... 85

Background to the 2007 PiR Programme $\quad$........ 85

The poem selection process $\quad \ldots \ldots . . . \quad 87$

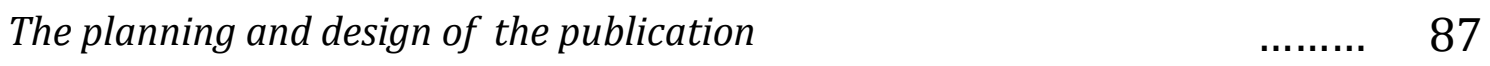

Making use of the Otakou Press during this Programme $\quad$........ 89

The process of interpretation $\quad$......... 90

The collaborative nature of the 2007 PiR Programme $\quad$........ 91

The outreach component of the 2007 PiR Programme $\quad$......... 93

Pricing this publication $\quad$......... 94

Promotion of the publication $\quad$......... 94

Summary $\quad$........ 95

What themes have emerged from the data gathered? $\quad$......... 97

Collaboration within the PiR Programme $\quad$........ 97

The outreach component of the PiR Programme $\quad$......... 99

The 'hand crafted' book vs. the mass produced book $\quad \ldots . . . . .102$

Art collector's edition or private press book? $\quad \ldots \ldots . . . \quad 104$

Future considerations for the PiR Programme $\quad \ldots . . . . .106$

Perceived success and value of the PiR Programme $\quad \ldots . . . . .110$ 
The lifecycle of PiR publications

…..... 114

A new model for the study of the book

........ 114

Summary:

…..... 119

Conclusion

References

......... 123

Appendix 1: List of PiR publications 2003-2009

Appendix 2: Study objectives outlined in the Research

Proposal

Appendix 3: Information provided to all interview participants

Appendix 4: Glossary 


\section{List of Figures:}

Figure 1:

A view of the Otakou Press room featuring the Vandercook Proofing Press, and the Albion press, made by Hopkinsons of London in 1845.

Figure 2:

A view into the Otakou Press room; note work of passed PiR publications (2006 and 2007) displayed. The Columbian Hand Press appears in the background.

Figure 3:

Cover of Access to Lilac (2005)

Figure 4:

Pages from Pine (2005)

Figure 5.

Cover of Pine (2005)

Figure 6.

Some elements of the Hunting of the Snark (2006) kit.

Figure 7:

The twelve characters of the Hunting of the Snark, as printed for the $2006 \mathrm{PiR}$

Programme.

Figure 8: Title page of Hunting of the Snark (2006).

Figure 9:

An example of the design and layout of the text for Hunting of the Snark (2006).

Figure 10: Title page for Twelve Poems (2007).

Figure 11: Olav Neilsen's interpretation of Hone Tuwhare's Rain. 


\section{Introduction:}

The Printer in Residence Programme at the University of Otago has been running since 2003 and in that time nine private press publications have been produced using the Otakou Press facility (formerly known as the Bibliography Room). Participants have included a number of well respected private press printers, illustrators and artist printmakers, many of whom have contributed to the Programme more than once. The subject matter for the publications has often been influenced by the history of the Bibliography Room and the publications $\mathrm{Dr}$ Keith Maslen produced for his Burns Fellow colleagues in the English Department (Bill Manhire, Hone Tuwhare, Brian Turner and Ruth Dallas), sometimes in collaboration with local artists, such as Ralph Hotere.

The objective of this study was to document the recent history and development of the Printer in Residence (PiR) Programme through; an investigation of its archives, interviews with eight of the Programme's participants and written accounts by two others. The study also aimed to gain a holistic perspective of the Programme by selecting participants from all areas of the Programme's operations.

In-depth case studies of the 2005, 2006 and 2007 Programmes were used in order to build a picture of how PiR Publications have been planned and produced. The common themes that emerged from the interviews and PiR documentation were also discussed in relation to the Programme's primary objectives. Finally, the PiR Programme and the publications produced were considered in relation to the Adams and Barker's (1997) model of the lifecycle of the book. 
The findings of this study indicate that overall, the PiR Programme has been very successful in achieving its primary objectives. Each Programme publicises the Otakou Press and the printing presses it houses; each Programme involves the opportunity for class visits to the Otakou Press and / or talks by the Printer in Residence (and any other contributors); and finally, each PiR Programme has produced publications that reflect the University press room's historical and literary associations and connection to the Otago region. With these factors in mind, the PiR Programme should be considered a small but important aspect of New Zealand's private press history. 


\section{Problem statement:}

There is evidence of much valuable research being conducted on the history of the book, or print culture, in New Zealand. Roderick Cave included a section on private presses in New Zealand and Australia in The Private Press (1983), and has written a number of papers on individual private presses in New Zealand (Cave, 2001). D. F. McKenzie (1983) has investigated his concept of the 'sociology of the text' in reference to the effect of print on Maori culture (an oral culture until the missionaries came to New Zealand) and the interpretations of the Treaty of Waitangi. Book and Print in New Zealand: a guide to print culture in Aotearoa (1997) and A Book in the hand: essays on the history of the book in New Zealand (2000) are excellent resources discussing different areas of New Zealand's print history. And since then, the University of Otago's English Department initiated Print Culture in New Zealand: The Otago Project (University of Otago, 2002), to encourage continued research in the area.

As outlined above, research into the many areas New Zealand's print culture is ongoing and often takes on the form of individual cases studies. Although this form of research is valuable, there is the potential for localised aspects of New Zealand's book history to be missed unless researchers are aware of them.

The idea for a Printer in Residence (PiR) Programme at the University of Otago was conceived by Dr Donald Kerr (the University Library's Special Collections Librarian) and continues to be managed by him with support from the English Department and the Design studies Department.

Although the objectives of the PiR Programme are rather localised, the success of the Programme's publications has spread much further than Dunedin and Otago - largely due to the quality of the publications and the prominent New Zealand printers, poets and artists involved in their production. 
The Programme's objectives, its participants and its popularity make it an important aspect of the New Zealand's recent private press history. However, at the time of this study, there was no evidence to suggest that any research on the University of Otago's PiR Programme had been conducted.

It is the aim of this study to document the development of the PiR Programme and encourage further research into this area of New Zealand's print culture. 


\section{Literature review}

The review of literature relevant to this study indicated that the PiR Programme needs to be studied within the context of New Zealand's private press (and bibliographic press) history - a history that was heavily influenced by the print culture of Britain and Europe.

Also of particular relevance was the bibliographic press, or teaching press, movement (beginning in the Universities of Britain and the United States in the 1900s) which by the late 1950s was visible in New Zealand. The University of Otago's bibliographic press was established in 1961 by Keith Maslen and David Esplin and named the Bibliography Room. In an unpublished essay, Maslen (2005) says that its primary purpose was to teach "... the processes by which the texts embodying our literary heritage were transmitted from author to the reader in the medium of print" (Maslen, 2005 2). Although the English Department still use this facitility as a teaching press, it is also the location of the PiR Programme for 6 weeks of the year.

Additional literature relevant to this study is the research and theory developed around the notion of 'the book', the concepts of 'book history and 'print culture' and methods of book production.

\section{What is meant by the term' book'?}

The English Dictionary describes the term book as any written material that is put together in a portable form ("book", 2009). The term 'material' is broad enough to encompass a range of items (such as cloth, leaves, paper or parchment) but it is the ability to make the text portable that defines it as a book.

Another term often used interchangeably with 'book' is 'codex'. However, this is a term describing a specific type of book with sheets of paper folded into pages and sewn along one edge (Brown, 1994). It is important to clarify these terms as not all PiR publications are in this codex form - some are also a collection of loose leaves wrapped in a folder or box. 
All of the interview participants in this study described the PiR publications as books. Loney (2009) argues that theorists often use the term 'book' when they are actually referring to the ideas it is transmitting, rather than the physical structure. However the term actually refers to the physical structure and the content (or subject matter).

\section{'Book history' or 'print culture'?}

The terms 'book history', 'history of the book' and 'print culture' are often used in the literature reviewed and sometimes interchangeably. Finkelstein and McCleery (2005) discuss the arguments for and against these terms by those involved in research on the history book and /or print.

In terms of the New Zealand literature (Cave 1983, 2001; Griffith, Harvey and Maslen 1997; McKenzie, 1983; and Traue, 2001), there seems to be a tendency to use the term 'print culture'. This is defined in the introduction of Book and Print in New Zealand: a guide to print culture in Aotearoa (1997) as as "the technology of printing and the impact it has had on New Zealand society and culture" (1997, p.11). Here the book is regarded as one aspect of a print culture that also includes a range of print ephemera, such as; invitations, menus, shopping lists, bus tickets and advertisements. As we can see, for some researchers 'book history' is considered too narrow to encompass the interests of all researchers studying in this area. Eisenstein's Printing press as an agent of change (1979) is a good example of this (Finkelstein and McCleery (2005).

Finkelstein and McCleery (2005) claim that the contemporary understanding of 'book history' is much broader and now includes the history of all written and printed communication in any medium - including all stages in the production and all the social, cultural, intellectual and economic aspects of human activity that impact upon it. 
Although is not the purpose of this study to determine which of these terms is more accurate, it is important to highlight them and the discussions surrounding their use. It is also necessary to highlight that contemporary research in this area is much broader in scope than an examination of a book's physical structure and how it was produced.

\section{A brief outline of New Zealand's early printing history:}

Traue (2001) describes New Zealand's print culture as running in two distinct paths; one directed at the indigenous Maori population (primarily the production of books) and the other for the colonial settler population (newspapers and ephemera).

When the missionaries came to New Zealand, they found that the Maori did not have a written version of their language and set about trying to produce one so that religious material could be produced for the Maori population. This involved the printing of small books that contained word lists and short sections from the bible as a means of teaching the Maori to understand the printed version of the their oral language (Maslen, 1993 and Traue, 2001). At first these books were printed back in England (or Australia) but since the printers did not recognise the language they were printing, the books produced often contained many errors. There was also a lengthy time frame involved because it could take weeks or months for the books to arrive by ship to New Zealand. As means of resolving this problem, the missionaries bought the printing press to New Zealand (Cave, 1983; Griffith, Harvey and Maslen, 1997; Traue, 2001). However, due to the problems involved in printing legible copies on printing presses, it was not until skilled printers settled in New Zealand that suitable publications were being produced in New Zealand to meet the missionary's purposes.

Traue (2001) states that the printed material produced for the colonial settlers reflected the British newspaper print culture they had left behind. Even before the colonial setters arrived in New Zealand, editions of 'local' newspapers were being produced for the New Zealand Company towns (Traue, 2001). When 
printing businesses were finally set up in New Zealand, they were primarily involved in producing regional newspapers and jobbing (producing the assorted ephemera needed for a mini Britain to operate). However, it was not until after the Second World War that local book publishing houses began to develop (Traue, 2001).

\section{The private press:}

The literature reviewed in this study makes a distinction between the commercial printing industry and private presses. Commercial printing tends to be characterised by the mass production of 'in demand' printed material, utilising the most cost effective resources, to ensure the highest profit margins (Greco, 2005).

In contrast, private presses tend to be owner-operated and focus on the production of limited edition poublications. The owner-operator has control over the choice of subject matter and all aspects of the production process. They also tend to be less concerned with generating a profit as they are with producing what they want, and for this reason, they tend to run on a cost recovery basis (McLeod, 2007, Ransom, 1929, Waite, 1997). Cave (2001) and McLeod (2006) point out that the term private is not necessarily an indicator of quality and suggest that a distinction should be made been those private presses with a focus for producing high quality works and 'hobby printers'. Editions of high quality are sometimes referred to as examples of fine printing.

Hughes's (2001) article, about the making of The love songs of Ibykos (1997) by Alan Loney, identifies the characteristics of a high quality private press production process: Loney was the printer and the publisher; he was responsible for all aspects of book design, manufacture and transmission, and many of these elements involved much networking and collaboration with colleagues involved in the book arts. This process is quite unlike commercial publishing which tends to separate the steps in the production process - often contracting them out to other companies in a bid to remain cost effective (Platt, 2001). 


\section{New Zealand's private press movement:}

Although is evidence of amateur, non-commercial, non-missionary printing in New Zealand from the 1870s and 1880s, a private press movement didn't begin to flourish until the 1930s (Cave, 1983, 2001). As was the case in England, the private press movement in New Zealand was not initiated by those working within Zealand's printing industry. Instead it was those with a more academic interest in the techniques of printing using the handpress who took up the challenge of printing and publishing privately (Cave, 1983 and McLeod, 2007).

An example of this is Caxton Press, set up by Dennis Glover and John Drew in a disused stable in Christchurch. Like Nags Head Press (also in Christchurch) and Pelorus Press (Auckland), Glover wanted this press to become a publishing outlet of high quality for New Zealand's growing literary talent (Cave, 1983).

It is not the aim of this literature review to provide a comprehensive list of New Zealand's private presses. However, it is important to highlight the desire among private printers to; publish items not being picked-up by the commercial publishers and produce publications of the highest quality their financial situations would allow (Cave, 1983; Hughes, 2000).

These ideals are also reflected in the objectives of the Printer in Residence Programme. The subject matter tends to be unpublished New Zealand poetry (with the intention of making this material more accessible), and the publications are produced to a high standard using quality materials.

\section{Fine printing and New Zealand's private presses:}

Editions of high quality hand printing are often referred to in the literature as examples of fine printing. Fine printing is seen to reflect the printers desire to: revive the craft of book making; become proficient in all areas of the book arts (paper making, printing, typesetting and design, binding etc) and create books that are as much an art object as they are functional in transmitting the ideas in the text (Hughes, 2001; McLeod, 2006; McLeod, 2007; Waite, 1997). 
In an age where desktop publishing, graphic arts software and computer typesetting can achieve innovative and near perfect results, McLeod (2007) views the handcrafted (and individualised) quality of private press books as another characteristic distinguishing commercial and private press publishing.

\section{Including images in private press works:}

A common characteristic of the PiR publication is the inclusion of images to accompany the text (with the exception of Open Sky, 2008).

Adamowicz (2009) discusses two reasons why images are included in books and the relationship between the two. In the first case, images are used to illustrate the text - to enchance the reader's understanding of the text. In this situation the images are considered subordinate because the creation of the image relies on the text (Adamowicz 2009, p. 189).

A less common situation is when images and text share equal importance and a good example of this are the books associated with the livre d'artiste (Adamowicz, 2009; Benton, 2007; and Drucker, 2000). The livre d'artiste is associated with a movement in book publishing in France during the twentieth century aimed at the art collector market. Publications included the works of well known poets such as Paul Verlaine and Pierre Bonnard and famous artists such as Pablo Picasso and Henri Matisse (Adamowicz, 2009).

\section{The University of Otago Library and its bibliographic press:}

In an article for the journal Script and Print, McLeod (2006) felt that the future of New Zealand's fine private press printing lay in the hands of the Universities three private presses (Wai-te-ata Press at Victoria University of Wellington; Holloway Press at the University of Auckland and Otakou Press at the University of Otago) becaue they have the funding and resources (and to an extent the captive audience) required to foster a continued interest in handprinting (McLeod, 2006). 
University presses like the Otakou Press are often referred to as Bibliographic Presses. The most predominant description of a bibliographic press was written by Philip Gaskell (1965, p.1);

“...by a 'bibliographical press' is meant a workshop or laboratory which is carried on chiefly for the purpose of demonstrating and investigating the printing techniques of the past by means of setting type by hand, and of printing from it on a simple press."

Dr Keith Maslen (a lecturer in the English Department) and David Esplin (the Reference Librarian) set up the University of Otago's bibliographic press (named The Bibliography Room) in 1961. It continues to operate from the University's Central Library as a teaching press for the English Department and is the site of the yearly PiR Programme (Maslen, 2005b).

\section{The Printer in Residence Programme at the University of Otago:}

Donald Kerr, Special Collections Librarian at University of Otago Library, came up with the idea for the PiR Programme in 2002. A pilot was run in 2003 and the Programme has continued since then on a yearly basis (Kerr, 2005). In collaboration with Dr Shef Rogers and Dr Noel Waite, a three way partnership was set up between the University of Otago Library, the English Department and the Design Studies Department to support and fund (if required) the PiR Programme (Kerr, 2005).

In its third year, the Programme produced its fifth publication PINE by Ralph Hotere and Bill Manhire (2005), and its launch was used to mark the renaming of the Bibliography Room to the Otakou Press.

\section{Other Printer in Residence Programmes in operation:}

Research showed that it was not uncommon for book arts organisations and tertiary institutions to offer residency programmes, especially in the United States. Most are referred to as 'artist in residence' programmes and offer the space, equipment and materials to work on their own projects, as well as an 
exhibition of recent work (Center for Book Arts, 2008; Hamilton Print Markers Arts Association, n.d.). However, some residencies also require the artist to assist with teaching or "execute special project work" for the organisation (Minnesota Center for Book Arts', 2008).

Although several Printer in Residence Programmes were found, most do not relate to the type of Programme run at the University of Otago Library. In most cases, 'Printer in Residence' refers to the employment of a qualified printer, on a contractual basis, to carry out the technical teaching aspects of letter press printing and any printing projects scheduled during that time (University of Iowa Center of the Book, n.d.; University of Rhode Island, n.d.). In New Zealand, Tara McLeod is the Printer in Residence at Holloway Press, Univerity of Auckland. However, there is no teaching role associated with thisposition (Kerr, 2007).

A Printer in Residence Programme more characteristic of the one at the University of Otago Library is run by Wai-te-ata Press, Victoria University of Wellington. Two interview participants in this study, John Holmes and Brendan O’Brien have been Printers in Residence there.

\section{Adopting a theoretical frame work for this study:}

Since the late 1980s, research interests relating to the study of books has broadened considerably. Research encompasses not only a book's production process and content, but also the social and cultural context and how this can impact on the meaning(s) given to a publication (McGann, 2002; McKenzie, 1983). D F McKenzie (1983) and McGann (2002) refer to this type of investigation as the 'sociology of the text' and the 'socialization of the text".

Peter Hughes (2001) used this type of approach when researching the publication of The love songs of Ibykos (1997) by Alan Loney. Hughes refers to "the human motives and interactions" (Hughes, 2001, p.99) involved in each stage of the book's production, which took 17 years (and three private presses) to complete. 


\section{Models of book production:}

In 1982, Robert Darnton published a model to help researchers investigate the book production process within a social and cultural context - the Communication Circuit Model (Adams and Barker, 1993; Finkelstein and McCleery, 2005; Howsam, 2006). The intention of the model was to outline the stages that printed information (in book form) went through as it was transmitted throughout a society (from author, to publisher, to printer, to distributer, retailer and consumer), and the cultural, political and social values that influence this process (Howsam, 2006, p.29).

Darnton's model was later modified by Adams and Barker (1993) to produce what they saw as a 'more book-centred model' (Howsman, 2006, p 33). They also added a new phase into the lifecycle of the book, the survival phase. If a book survives the phase of transmitting its information from author to reader, it can in time serve a new function as an artefact of the social, cultural, political and religious context of its publication (Adams and Barker, 1993; Finkelstein and McCleery, 2005; Howsam, 2006).

The stages outlined in Adams and Barker's model (Adams and Barker, 1993) have provided a useful structure to explore the lifecycle of the PiR publications. However, it is important to note that the model is designed to include all forms of book production, including commercial publishing, and in the private printing process many of these stages overlap because they undertaken by the same person, the printer (Finkelstein and McCleery, 2005 p.14).

\section{Summary:}

As outlined above, much research has been undertaken in the area of book history and print culture which is relevant to this study. The University of Otago's PiR Programme is deeply embedded in New Zealand's private press and bibliographic press history (which in turn has been influenced by New Zealand's wider print culture). 
An exploration of types of printing residency programmes offered in New Zealand and overseas indicated that:

a) The programmes in the UK and United States tend have a different focus and;

b) the printer in residence programme run through Wai-te-ata Press (Victoria University of Wellington) has the most similarities but doesn't have the same outreach objectives or operate on a yearly basis.

A review of the theory relating to print culture and book history, within the Social Sciences, Bibliography and History, highlighted Adams and Barker's (1993) book lifecycle model as a useful a structure for investigating the life cycle of the PiR publications. 


\section{The objectives of this study}

A review of New Zealand's private press history and discussions with Dr Donald Kerr indicated that no research had been conducted on the PiR Programme at the University of Otago.

Research objectives:

1. In the absence of prior research, the first research objective was to gain an overall picture of the PiR Programme's development - using the Programme's archives.

2. The second research objective was to include the perceptions of those involved in the PiR Programme by conducting interviews with the Programme's participants. In order to gain a holistic understanding of the Programme, interview participants were selected from all areas of the Programme operations, such as the; Printers in Residence, collaborating artists and printmakers, Programme partners, administrators and managers.

3. The third objective was to apply a case study approach to a selection of PiR publications in order to portray the "human motives and interactions" (Hughes, 2001 p.79) that bought them about.

4. And last, was to apply the data gathered to an appropriate research model to ensure all aspects of the Programme had been covered. The model developed by Adams and Barker (1993), to outline the stages in a book's lifecycle, was selected for this purpose. 
Research questions:

The following research questions were developed during the literature review phase of this study and became the focus of the interview and data analysis process:

- What is the historical context of the PiR Programme and the bibliographic press from which it is run?

- What are the objectives of the PiR Programme and are they being achieved?

- What is the process involved in producing a PiR publication?

- How is the PiR Programme regarded by those involved?

- What challenges / issues, if any, are facing the PiR Programme? 


\section{Methodology:}

\section{Research paradigm:}

As outlined in the research objectives, this study aimed to the gather data about the PiR Programme relating to its historical context, its development, and the perceptions of those involved.

The study was situated in the interpretivist research paradigm - regarding reality as an individual construction, based on experiences and perceptions which are embedded in a social context (Pickard, 2007). Qualitative data was sought because it was seen as the most effective means of informing the research objectives in an in-depth and meaningful way (Pickard, 2007 p.13).

\section{Historical case study approach:}

The definition of historical research given in Gall, Gall and Borg (2005) accurately describes the intention of this study in relation to the PiR Programme:

"[Historical research is] the process of systematically searching for data to answer questions about a past phenomenon in order to better understand the phenomenon and its likely causes and consequences." (Gall, Gall and Borg, 2005 p.413)

\section{Sources of data:}

Also in-line with historical research, this study investigated a variety of data sources relating to the PiR Programme.

Secondary sources relating to New Zealand's print culture and private press history were used to:

- clarify the study's research objectives and questions and;

- determine the types of primary sources needing investigation during the study (Gall, Gall and Borg, 2005). 
The primary sources targeted for this study included the initial proposal for a pilot PiR Programme; proposals for each new project; progress reports; selection criteria; lists of those who had purchased PiR publications; drafts of speeches and essays; organisational policy documents related to the PiR Programme and archived correspondence with the project's participants. Archived copies of PiR publications, as well as any proofs and / or plans, were also considered as primary information sources. In line with Adams and Barker's (1997) perception of books, the PiR publications were regarded as artefacts - physical representations of the human activity that produced them.

The validity of the primary and secondary sources was determined by a consideration of:

- the origin of the information source;

- "the reasonableness of the statements" included in the text (Gall, Gall and Borg, 2005 p.421) and;

- the credentials of the author in relation to this area of study (Gall, Gall and Borg, 2005; Shep, 2005).

\section{The Printer in Residence Programme as a case study:}

Since the PiR Programme had not already been the subject of research, it was decided to treat it as case study. This decision was informed by an investigation of the general characteristics of case study research which complemented the objective of this study. Like other case studies, this study:

- was concerned with developing an in-depth and holistic view of a phenomenon within its social context (Burns, 2000);

- was investigating a phenomenon with clear boundaries (its location and the relatively short span of time it had been in operation) that enabled it to be treated a unit of enquiry (Burns, 2000; Gall, Gall and Borg, 2005; Gorman and Clayton, 2005);

- would draw on a variety of information sources and information gathering techniques. 


\section{Case studies within a case study:}

Over the seven years that the PiR Programme has been operating, nine publications have been produced. During the process of exploring the PIR archives, it was decided that treating the PiR publications as units of enquiry in their own right was an effective way of gaining an in-depth understanding of the process involved in producing them. Due to the time constraints on the study, an in-depth investigation of a selection of PiR publications was chosen over a shallower investigation of all of them.

The 2009 PiR Programme did not begin until September and this was too late for it to be included as a case study in this research. However the publication produced, OLucky Man (2009), is included in the list of PiR publications provided in Appendix 1.

\section{Generating new data:}

Historical research often interprets existing forms of data in an attempt to understand a phenomenon. However, since the PiR Programme had not been the subject of research, there was little existing data to draw on in relation to the firsthand accounts from Programme participants. In-line with research methods literaure (Gorman and Clayton, 2005), in-depth guided interviews were conducted with participants involved in the PiR Programme to gather this type of information.

Selecting a sample for the interviews using purposive sampling:

Priori sampling techniques (Pickard, 2007) were used in the sense that the interview participants were selected on the grounds that they fitted defined criteria - in this case, first-hand involvement in the PiR Programme. It was also important to have a sample that enabled a holistic view of the Programme.

Each of the potential informants were contacted by email introducing the study and its objectives (the contact details of the selected sample were supplied by 
Donald Kerr). The following documents were also attached and are found in Appendix 3:

- A project information sheet that outlined the objectives of the study and any ethical considerations that needed to be considered (these were reiterated in the informed consent form).

- An interview question guide.

- An informed consent form (to be signed and returned if they wished to be involved).

Of those contacted for an interview, all responded except one. Of those that responded to the email invitation, all agreed to participate in the study in some guise or another. Of those who agreed to participate in the study, one was overseas during the interview phase for the study and wished to respond to the questions outlined on the guide via email rather than phone. Another informant did not wish to be interviewed or respond to the interview questions. However, this informant was willing to supply a written account of their involvement in the PiR Programme.

The high rate of participation in the study turned out to be a good indicator of the positive feelings these participants had for the PiR Programme. Many also saw involvement in this study as a means of expressing their continued support.

When all the responses to the study came back, it was found that the sample included only one printmaker. It was at this time that another printmaker was contacted (by recommendation from a key informant) and they agreed to participate. 


\section{Profiles of the study's key informants:}

\section{Dr Donald Kerr:}

Donald Kerr was the Special Collections Librarian at the Auckland Public Library before taking up a similar role at the University of Otago Central Library near the end of 2002. Having owned his own press, Kerr was keen to see the presses in the Bibliography Room (located in the Central Library) get greater use and developed the idea of a Printer in Residence Programme at the University of Otago. Gaining support and funding from the University Librarian, the English Department (who were the primary users of the Bibliography Room at the time) and Design Studies Department, the PiR Programme was piloted in 2003 and has continued on a yearly basis. Kerr continues to plan, manage, and co-ordinate the 4-6 week Programme every year (in consultation with representatives from its supporting partners) while also planning and constructing four exhibitions per year for Special Collections.

\section{Rosalind Andrew:}

Rosalind Andrew is the Commerce and Humanities Faculty Librarian at the University of Otago Central Library and she is part of the team that Kerr consults about ideas and proposals for each PiR Programme. Andrew also co-ordinated the 2007 Programme (while Kerr was on research leave) which was the production of Twelve poems by Hone Tuwhare; interpreted by seven Dunedin printmakers (2007). This Programme involved co-ordinating the efforts of the Printer in Residence, John Holmes, and seven local printmakers. Andrew continues to be a great supporter of the Programme.

\section{Tara McLeod:}

Tara McLeod has been a leading New Zealand printer since the 1980s with a wealth of knowledge in typography and printing design. He is the owner and operator of Pear Tree Press in Auckland and is also the resident printer for Holloway Press at the University of Auckland. McLeod and Kerr have known each other for several years and due to his experience using the larger printing 
presses, McLeod was the first Printer in Residence at the University of Otago in 2003. McLeod was also the Printer in Residence for the 2006 and 2009 Programmes.

\section{Dr John Holmes:}

John Homes started printing as a student with an Adana hand press 45 years ago and now publishes works under the imprint Frayed Frisket Press from his home in Dunedin. Holmes was the Printer in Residence at Otakou Press in 2004 and 2007 and has twice been a Printer in Residence eat Wai-te-ata Press, Victoria University of Wellington. Holmes has also been involved in other printing projects through the Otakou Press such as, the printing of James K Baxter's PINE trees in the key of $F$ and a rose in the key of $G$ (2004) in collaboration with artist printmaker Inge Doesburg, and a more recent publication for the University of Otago has been the printing of Three letters from Charles Darwin (2009) under his own private press imprint. The Otakou Press's Vandercook proofing press is actually owned by Holmes and on long term loan to the University.

\section{Inge Doesburg:}

Inge Doesburg studied at the Otago Polytechnic's Art School under Marilyn Webb and has become a respected Dunedin based printmaker. She has been teaching printmaking at Kings High School for 13 years and occasionally teaches at the Otago Polytechnic Art School. Doesburg is a great supporter of the PiR Programme having contributed to several Programmes in various capacities. She contributed her own work for Twelve Poems (2007) and O Lucy Man (2009), printed the work of another printmaker for Faces in the Water (2004) and helped turn the illustrations of David Elliot into 'printable' images for Hunting of the Snark (2006). 


\section{Brendan O’Brien:}

Brendan O'Brien is a respected printer based in Wellington who specialises in producing small pamphlets, usually of New Zealand poetry. Since dabbling in printing (on a holiday back from Australia) using his father's bench top hand press, he has produced a number of pamphlets which are primarily poetry. After returning to New Zealand from the UK in 1999, he became the Artist in Residence at the Rita Angus Cottage for almost two years - producing 20 pamphlets during that time, as well as a larger publication for the Holloway Press. O'Brien has twice been the Printer in Residence at Wai-te-ata Press and was the Printer in Residence at Otakou Press in 2005. He produced two publications during his extended residency in Dunedin; Access to Lilac (2005) and PINE (2005).

\section{David Elliot:}

David Elliot was a commercial designer and art teacher at Kings High School before becoming a full-time illustrator of books for children based in Dunedin. As an artist he sells his illustrations online and through the art gallery in Ashburton. Elliot has always appreciated the work of Lewis Carroll and he mentioned the Hunting of the Snark, a favourite of his, as a possible subject for the PiR Programme. Kerr later picked up on this idea and it became the text for the 2006 Programme, with Elliot as the illustrator and Tara McLeod as the Printer in Residence. The publication was sold out by the time it was finished and was purchased by a number of Lewis Carroll collectors overseas.

\section{Dr Shef Rogers:}

Shef Rogers is a senior lecturer in the University of Otago's English Department. After Dr Keith Maslen's retirement, Rogers took over the running of the Bibliography Room for the English Honours paper on descriptive and analytical bibliography. Part of this course involves students setting and printing a piece of verse using the letterpresses. Rogers has been a great supporter of the Printer in Residence Programme and is part of team consulted for approving PiR Programme ideas and proposals. Rogers, who was overseas during the period of 
interviewing for this study, kindly agreed to respond to the questions provided in the interview guide via email.

\section{Alan Loney:}

Alan Loney is well respected printer, poet and writer. In New Zealand he owned and operated Hawk Press and Black Light Press, and was the resident printer at Holloway Press, University of Auckland. He now lives in Melbourne where he continues to print and write. Loney is well recognised for his published works relating to book history, typography, book making and design. This year he is contributing a conference paper for the BSANZ Conference at the University of Queensland, Brisbane. Loney participated in the 2008 PiR Programme producing the publication Open sky: a homage to Ruth Dallas (2008).

\section{Olav Neilsen:}

Olav Neilsen completed a Bachelor of Fine Arts in Dunedin and it was in his second year that became interested in the texture that could be achieved from the etching and printmaking process. After three years of travelling, Neilsen became a full-time printmaker based in Dunedin. He was invited to become involved in the 2007 PiR Programme and its publication of poems from Hone Tuwhare's Come Rain Hail (1970) (1970). The publication was titled Twelve poems by Hone Tuwhare; interpreted by seven Dunedin printmakers (2007), and as the title implies, involved the work of six other Dunedin based printmakers.

\section{The interview process:}

This study used a guided interview approach which allowed the questions to act as a checklist or guide for the researcher and the informant. It also allowed the researcher flexibility to explore research themes further using additional questions if necessary (de Marris, 2004; Pickard, 2007). Appendix 3 includes some of the questions asked during the interview process. Since the informants were not necessarily involved in the PiR Programme in the same way, any questions irrelevant to their involvement were avoided during the interviews. An 
attempt was made to keep these questions broad and open-ended to encourage discussion.

The study's information sheet and informed consent form asked the informants whether it would be possible to retain recordings of the interviews as part of the PiR Programme archives. All the informants that were interviewed agreed to this option.

\section{Conducting the interviews:}

Although face-to-face interviews in a quiet location were preferred, telephone interviews were conducted with the two informants located in the North Island. The informants were only required to take part in one interview. However, they were asked if it was possible to ask follow up questions if clarification or further exploration of a theme was required at a later date. All the interviews were recorded, and permission to do so was asked in the informed consent form. Participants were able to request that recording be stopped at any point during the interview (Gorman and Clayton, 2005) or that comments made during the interview be edited before the recordings were stored as part of the PiR Programme archives.

\section{Transcription of the interviews:}

Due to the time constraints on this study, the recorded interviews were only partially transcribed. Notes and direct quotes were taken from the interview recordings so that any predominant themes and perceptions could be explored thoroughly.

This study accepts that in regards to oral history accounts, “...memory is never pure" (Shep, 2005 p. 171). During the interviews some informants were asked to describe their involvement in publications produced up to 6 years ago and experiences since then may have influenced their perception of that experience now. However, as is the case with all information sources used in this study (and 
indeed the study itself), the interviews are considered interpretations of the PiR as a phenomenon.

\section{Data analysis:}

An aim of this study was to identify patterns or themes from the data gathered that could contribute towards a greater understanding of the PiR Programme; its historical context, its development, and the production of its publications.

The study was not concerned with creating any generalisations that could be applied to other research or PiR Programmes, only with building a body of knowledge on this one phenomenon that could be utilised for further research.

Data analysis was carried out from the beginning of the data gathering process using descriptive, topic, and analytical coding techniques (Richard, 2005). The data was gathered from various sources (secondary and primary) and the coding process allowed this data to be categorised and reorganised in ways that would inform the research objectives, test their validity and highlight any emerging themes.

During the study, the data gathered was organised under general categories relating to the study's research objectives:

- History of the University of Otago's bibliographic press room

- The development of the PiR Programme

- Specific PiR publications

- Themes emerging from the interviews with the key informants and /or the PiR documentation

- Adams and Barker's (1997) model of the lifecycle of the book. 


\section{Themes that emerged during the data analysis phase:}

As the data gathered for this study was analysed, the following themes emerged:

- The collaborative nature of the PiR Programme

- The perceived importance of the outreach component in the PiR Programme

- The commitment towards producing high quality 'hand-crafted' work

- Perceived challenges and constraints facing the PiR Programme

\section{Reflections on the study's methodology:}

On reflection, this study may have benefited from a more comprehensive analysis of the primary data relating to the PiR Programme before the interviews were conducted. A greater knowledge of the publications the informants were involved in may have allowed for more probing questions about the production process.

The key informants selected for this study were contacted by email and all but one of these responded. However, it was later found that this individual did not have access to the internet at that time and could not access their email. It would have been prudent to have considered this scenario earlier; following up any email invitations to participate (which were not responded too) with an invitation by post.

Once the interviewing and transcription process was complete and the formal phase of analysis progressed, it became apparent that the some of the research objectives outlined in the study's proposal (see appendix 2) needed to be revaluated. A primary objective of the study was to investigate whether the Otakou Press was taking on a more book-arts focus through the PiR Programme, than under its original guise as the Bibliography Room. However, as the data was analysed this issue did not stand out in the research findings as was expected from the review of the literature. Although this issue is still discussed in the study, it no longer seemed appropriate to use as the study's focus. 
The interview process and $\mathrm{PiR}$ archives generated large quantities of rich data about the Programme. However, due to the tight time frame for this study, it became apparent that it was not possible to produce case studies for all the PiR publications. It also became apparent that more information was being gathered about some publications relative to others, and as a result, it was decided to concentrate on developing case studies of the 2005, 2006 and 2007 PiR Programmes. These Programmes had aspects to them that were unique to the others, yet they also displayed enough similarities, in terms of the Programme objectives and general procedures, to make them representative to the other PiR Programmes on a general level. 


\section{The University of Otago's bibliographic press and the Printer in Residence Programme.}

\section{The Bibliography Room:}

Establishing a bibliographical press at the University of Otago was the vision of Dr Keith Maslen, a lectuerer in the the English Department. In 1961, with the help of David Esplin, the University's Reference Librarian, support and funding was garnered from the English Department and the University Library to set up a letterpress room that would give senior students in English "...the fundamentals of the processes by which the texts embodying our literary heritage were transmitted from author to the reader in the medium of print." (Maslen, 2005 p. 2).

Maslen and Esplin's teaching objectives were focused on "....introducing literary students to matters bibliographical rather than to make then connoisseurs of 'fine' printing" (Maslen, 2005 p.3).

Up until the 1940s and 1950s, letterpresses and metal type were still predominant in New Zealand's printing industry (Maslen, 2005) and this made it relatively easy to access the presses, type, and other equipment necessary to establish a basic press room.

The Bibliography Room, as it came to be known, started off with an Albion hand press (foolscap size) "begged from the Otago Museum" (Maslen, 2005 p.3) and type donated from John McIndoe and the Otago Daily Times. Over time a range of Monotype Garamond (10 to 36 point) roman and italic was built up as well as a small quantity of Bodini, Plantin and Albertus Titling. Although the Bibliography Room was limited in the range of type it had available, Maslen (2005) felt that this was not necessarily a bad thing because "many many fine faces can seduce the beginner" (Maslen, 2005 p.3). 
In November 1961, a grant from the University Council of 100 pounds and annual funding of 10 pounds allowed the bibliographic press to get underway (Maslen, 2005) and shortly afterwards, the 1961 English honours bibliography class set and printed an "unpublished poem in the De Beer Collection by John Hoadly" (Maslen, 2005, p.3). The press room was located with the English Department in Cameron House and operated from a washhouse at the back for four years.

In 1965 the Bibliography Room relocated to the new University of Otago Library building and was used to commemorate the Library's opening (Maslen 2005). With the new location came some additional printing presses. An early nineteenth century Columbian Hand Press of American design, which was bought to Dunedin in the 1860s by Henry Wise, was donated by Laing and Matthews Printers (Maslen, 2005). A Phoenix treadle-platen press came from Dunedin Print and "a small Adana table-top hand press was purchased for smaller printing jobs on paper not larger than quarto-size" (Maslen 2005 p.4).

In an unpublished essay written by Maslen (2005) on the history of the Bibliography Room, he outlines the three classes of work produced in this space: “...student exercises, works by New Zealand writers on sale (which students very often helped with), and pieces of jobbing printed for and by an interesting cross-section of the University community and a few outsiders....I resolutely saw every job as having a teaching and learning component, and for this reason I welcomed newcomers who simply wanted to try their hand." (Maslen, 2005 p.4).

In the late 1960s and early 1970s few commercial outlets existed for printing and publishing New Zealand literature and poetry. During this time, Maslen used the Bibliography Room to produce small runs of New Zealand poetry written by some of his literary colleagues in the English Department, many of whom were Burns Fellows (Maslen, 2005). Publications under The Bibliography Room Press imprint included James K Baxter's The Lion Skin (1967) and Jerusalem Sonnets 
(1970); Ruth Dallas's Ragamuffin Scarecrow (1969) and Hone Tuwhare's Come Rain Hail (1970). Although the text was often typed, the presses were used to print the covers and title-pages (Maslen, 2005). The University Bookshop, and equivalents throughout New Zealand, provided the retail outlets for the publications.

A relationship was also built with artist printmakers such as Ralph Hotere, Els Noordhoff, and Michael Smither who contributed wood blocks or linocuts for the covers of these publications (Maslen, 2005):

"I printed the title and author's name in black on a dummy leaf and Ralph Hotere inscribed a perfect circle between them. His idea was to echo Hone's words in his poem 'Hotere': "when you score a superb orange/ circle on a purple thought-base/ I shake my head and say: hell, what/ is this thing, called love" (Maslen 2005 p.6).

After Maslen's retirement from the English Department in 1991, Shef Rogers took over operations in The Bibliography Room and he continues to use it for "instruction in descriptive and analytical bibliography" (Roger, August, 2009). "The English Dept uses the room to teach the students the significance of hand-set typography and printing in forms. Each year the students of ENGL 368 print a single-sheet quarto text in verse. The precise number of lines varies depending on the number of students enrolled, with each student setting 4 lines of verse. Occasionally post-grad students have also used the room to print various keepsakes" (Rogers, personal communication, August 2009).

From 1999 to late 2001 the University of Otago's ISB building, which houses the Central Library, was completed. It is here on the first floor that the Bibliography Room was relocated. Michael Wooliscroft, the University Librarian at the time, was keen to contrast the history of the ornate presses with the contemporary design of the building and the cutting-edge electronic access that it offered (R. Andrew, personal communication, July, 2009). For this reason, one wall of the 
print room was made of glass to allow any printing activity to be viewed by visitors to the Library.

During the Bibliography Room's relocation to the University's ISB building it gained a Vandercook proofing press from Dr John Holmes (owner and operator of Frayed Frisket Press) which he rescued from becoming a ships anchor. The press was still in good condition, "although it has lost its original inking rollers" (J. Holmes, personal communication, June, 2009).

In 2002, Dr Donald Kerr was employed as the first full-time Special Collections Librarian at University of Otago Library. Kerr, a "lapsed member of the Hand Printing Association" and owner-operator of his own private press, was aware of the history and activities of The Bibliography Room and was excited by the prospect of utilising the presses more than they were at the time (D. Kerr, personal communication, 2009).

“Here's this wonderful facility and it's being underutilised, and perhaps, under promoted. And I started to think about some sort of Programme, like the Printer in Residence" (D. Kerr, personal communication, June 30, 2009).

\section{The Printer in Residence Programme:}

In 2003, the Printer in Residence Programme (PiR Programme) was launched and this seems to mark a more direct involvement by the University Library in the operations of the Bibliography Room.

Tara McLeod took up the first four week residency in 2003. During this time two publications were produced: '... a great warm feather-bed' (2003) which was an unpublished letter written by Charles Brasch in February 1958 (40 copies printed), and A Haggis of Verse (2003); a volume written by seven poets with an association with Dunedin (50 copies). 
Although both publications were viewed as trial runs to test whether the presses were in good enough condition, they proved very popular and all copies were sold. This, coupled with the positive feedback on seeing the Bibliography Room in operation, led to the support of the PiR Programme by the University Librarian. (D. Kerr, personal communication, June 30, 2009)

\section{The objectives of the Printer in Residence Programme:}

The Printer in Residence Programme Contract (2005) states that the aim of the Programme is to:

- raise the profile of this facility amongst library staff, academic staff and students, and the general public;

- hold seminars and practical sessions with English, Design and Art History students, and other interested parties such as librarians, booksellers, designers and artists by the end of the Programme and;

- produce a specified publication by the end of the Programme.

For Kerr and Wooliscroft, the PiR Programme was less about the items produced as it was about creating an awareness of the letterpress printing process and its role in the history of book production - objectives that are very much in line with Maslen's reasons for setting up the Bibliography Room in the first place.

"The [PIR] publications are a commodity that we are able to 'capitalise' on but they are the outcome of a greater purpose which is the process of educating and building awareness" (D. Kerr, personal communication, June 30, 2009).

From the Programme's inception, Wooliscroft was keen that it had outreach to academic departments, University staff and students, and also the wider community (D. Kerr, personal communication, 30 June, 2009). For this reason, seminars and class visits to the press room became an important part of the Programme and the Printer in Resident's role. 
For Kerr, another objective of the Programme is to provide wider access to texts of local relevance and importance which have yet to be published. As a not-forprofit enterprise run by an academic institution, the PIR Programme is an ideal vehicle for producing publications that may never be made otherwise, especially by commercial publishers.

\section{The role of the Printer in Residence:}

It is the overall responsibility of the Printer in Residence to produce a limited edition publication of good quality (Kerr, 2005 p.2). It is usually the printer who determines the overall plan for the publication: its layout, size and type of paper required, what inks to use and the use of colour, the type of housing (binding or an enclosure) and the typesetting (type faces, size and spacing).

"They [the printers] are given an idea of what to do and then they can print it anyway they like really..... they have full rein over the printing and design. I don't pretend to be an expert. They have their own notions of what they want to do but they have to grapple with what we've got. We've got limited typefaces and blocks and types of paper available so the printer who comes here has to work through those problems" (D. Kerr, personal communication, 30 June, 2009).

"[the Printer is] the underpinning thread that is common to all of it. John [Holmes] had very definite views on the design, how it [Twelve Poems, 2007] should be housed and what colours should be used" (R. Andrew, personal communication, July.... 2009).

That said, the role of the printer is slightly different with each publication depending on how much collaboration they are involved in with other participants. If the publication is to incorporate images, the printer may also need to collaborate with a printmaker (sometimes an artist/illustrator and a printmaker) to determine the best way to display the text and image. 
Despite the Printer's relative control over the production process, all of the participants in this study (printers, artists and printmakers) felt there had been some level of group collaboration into the design and production process of the PiR publications they had been involved in (Doesburg, personal communication July 15, 2009; Elliot, personal communication, July 31, 2009; Holmes, personal communication June 30, 2009; McLeod, personal communication July 6, 2009; Neilson, personal communication July 31, 2009; O’Brien, personal communication July 8, 2009).

Outreach to the University and wider community is also part of the Printer in Residence's role. Seminars and tutorials are used as a means for the printer (and any associated printmakers or artists) to discuss the Programme underway and increase people's awareness of the Otakou Press and the process of letterpress printing in general.

"Each candidate is required to talk to students and staff of the University, and those interested parties in the wider community. The most convenient way to do so is through seminars and lectures to the various departments, with some practical sessions in the Press Room. Scheduling is done in consultation with library and departmental staff" (D. Kerr, personal communication, June 30, 2005 p.2).

\section{Selection criteria for the Printer in Residence:}

All of those interviewed for this study described an informal process of becoming involved in the PiR Programme. Most seemed to have either 'meet up with,' 'run into' or 'bumped into' or 'phoned up by' Donald, or have 'known him for years.'

"I think it all happens in conversation, and if an interest is expressed further information is given. It sort of grows from there and becomes part of a proposal" (R. Andrew, personal communication, July 9, 2009). 
Rosalind Andrew, the Reference Librarian at the University of Otago Library, believes there is a need to establish a formal selection criteria "that can give an indication of what is expected and required of a Printer in Residence" (R. Andrew, personal communication, July 9, 2009). She also felt that establishing "robust procedures that can stand up to scrutiny" could be advantageous to its future support (R. Andrew, personal communication, July 9, 2009).

At present, PiR documentation states that a candidate must be:

- "a handcraft printer with established skills and knowledge of presses and press work" (Kerr,2005 p.1);

- able to collaborate with Donald Kerr and any other PiR project partners (including printmakers) to produce a limited edition publication of good quality, to a deadline;

- able, and willing, to undertake the outreach component of the Programme - presenting seminars or tutorials to communicate their work as printers and the project they are undertaking;

- able to commit themselves to a 4-6 week residency in Dunedin - usually in early August to coincide with the second semester teaching (Kerr, 2005). The printer is paid a printer fee for their work over the 4-6 week period and their accommodation, meals and airfare are also paid.

At present, only four printers have been involved in producing the PiR Programme's nine publications. As stated by Kerr (2005; D. Kerr, personal communication, June 30, 2009), McLeod (personal communication, July 6, 2009), Holmes (personal communication, June 30, 2009) and O’Brien (personal communication, July 8, 2009), there are few skilled handcraft printers in New Zealand and this puts a strain on the quantity of printers in New Zealand that are available for selection. Although Kerr (2005) referred to other possible New Zealand printers, they were viewed as 'untested' and this makes their candidacy difficult. At present there is no selection criteria in regards to the printmakers or artists involved in the PiR Programme. 


\section{Choosing the subject matter:}

In virtually all cases, Kerr recommends the subject matter for the PiR Programmes. A proposal for each Programme is put forward to an advisory group for discussion and approval. This group is made up of Sue Pharo (University Librarian); Rosalind Andrew (Reference Librarian); Maureen Miller (Library Services Manager); Prof. Lyn Tribble (English Dept); Dr Shef Rogers (English Dept); Dr Noel Waite (Design Studies) and Prof. Thomas Bley (Design Studies).

Kerr feels that the 'readability' of the text, whether or not it has already been published (virtually always favouring unpublished material with a local literary connection), originality, and size are the primary concerns when choosing subject matter for a PiR project (D. Kerr, personal communication, 30 June, 2009). Future material of interest to Kerr includes unpublished historical narratives held in the Hocken Library.

Relevance to current events is also factor in the choice of texts. It is not uncommon for Kerr to select texts associated with upcoming events or anniversary's linked to the University of Otago. The unpublished Brasch letter was printed in the year that the embargo was lifted from his papers (the University of Otago Library's Special Collections also holds the Brasch collection), and the 2009 project, $O$ Lucky Man (a series of poems about Brasch written by New Zealand poet Riemke Ensing), helped mark the Centenary of Brasch's birth. In a couple of cases Kerr referred to a desire to have the PiR publications completed whilst the author is still able to view them. Sadly Ruth Dallas passed away before Open Sky (2008) was completed, but Hone Tuwhare was able to view Twelve Poems (2007) which utilised his collection of poems from Come Rain Hail (1970) produced in The Bibliography Room. 


\section{Including images in PiR publications:}

The third PiR publication, Faces in the water (2004), incorporated woodcut images by John Mitchell. Since then, including print-makers in the production of the PiR publications has become a constant. Kerr felt that this trend emerged from Michael Wooliscroft's intention to encourage community involvement in the Programme (D. Kerr, personal communication, 30 June, 2009). Kerr and Wooliscroft saw the appeal of "mixing text with image" and were aware that "Dunedin had a wealth of excellent print-makers, and we thought this was a great opportunity to tap into that resource" (D. Kerr, personal communication, 30 June, 2009). Since then, printmakers such as Inge Doesburg, Kathryn Madill and Jenna Packer have become regular contributors of their own work, as well as printing that of other artists.

However, even though images are included in the majority of the PiR publications, Kerr still sees the text as "driving the look and feel of the book" (D. Kerr, personal communication, 30 June, 2009). The images take on an illustrative function and are used to enhance the reader's understanding of the text (D. Kerr personal communication, June 30, 2009; I. Doesburg, personal communication, 15 July, 2009; 0. Neilsen, personal communication, July 31, 2009).

"I suppose as a saleable item, you always consider the image. But to be honest, I still see the print process as being the most important" (D. Kerr, personal communication, 30 June, 2009). 


\section{Pricing PiR publications:}

Virtually all the participants interviewed for this study said that the prices for the PiR publications were very reasonable considering the work and craftsmanship involved in producing them.

“... as people have said, 'where can you find a Mary McFarlane and a Marilyn Webb for $\$ 250.00$ ?'” (J. Holmes, personal communication, 30 June, 2009).

Kerr has no plans to raise the price of the publications because he wants them to remain accessible to a wide variety of people (D. Kerr (personal communication, June 30, 2009). Although the publications may contain the work of well known New Zealand printmakers and artists, the publications are not aimed at the art market and are not intended, in Kerr's view, to be treated as art works.

"From the beginning, Michael Wooliscroft made it clear he did not want these publications aimed at the art market. They were not to be marketed as top-notch items at top-notch prices for the art collector out there - it was to be aimed at the people who just liked books and want to own a limited edition item" (D. Kerr, personal communication, 30 June, 2009).

As was pointed out by Andrew (personal communication, July 9, 2009), Elliot (personal communication, July 31, 2009) and Kerr (personal communication, June 30, 2009), the PiR Programme is insulated from the market competition of the commercial publishing sector because it is run by an educational institution. The sale of the publications don't have to generate a profit (nor are they supposed to) and are priced to cover production costs only.

\section{Copyright:}

Once a text is selected for a PiR publication, Kerr must gain approval from the author (or their Estate) to use it for publication by the University of Otago Library. 
When a PiR publication is complete, the University of Otago owns the copyright of the publications and the printed matter. However, the printmakers retain intellectual property rights on their images (Kerr, personal communication, April $26,2007)$ and this allows them the opportunity to reproduce the images for individual sale.

\section{Promotion of the PiR Programme}

"Donald is pretty proactive in getting the message out as far as promoting the press and choosing good subject matter that seems to sell" (T. McLeod, personal communication, July 6, 2009).

"...... the promotion of each Programme through the Marketing and Communications Department at the University of Otago, departmental email list groups, national list groups (LIANZA, ExLibris), and other media: radio, television, newspaper" (Kerr, 2005a, p.3).

Kerr said that he can spend up to $1 \frac{1}{2} 2$ days emailing libraries (national and international) or using library list-servs to promote the publications being produced. Kerr said he likes the idea of local libraries "creating their own special collection of New Zealand produced limited edition items" (D. Kerr, personal communication, 30 June, 2009), and it is a good way of making a small run of publications more accessible to the public. Kerr will also target literary societies or groups (such as the American and British Lewis Carroll Societies) that might be interested in a particular publication.

The PiR Programme is also promoted via:

- the University of Otago Library website;

- the seminars promoted as part of the Programme's out-reach component and;

- local press are often invited to each wazgooze in an attempt to raise awareness of the PiR Programme in the local community. 


\section{The success of the Printer in Residence Programme}

Since the Printer in Residence Programme's inception in 2003, it has produced at least one publication a year utilising the Otakou Press facility.

“.... we occasionally joke that we pride ourselves in not having a book launch because by the time the item is sewn up and finished they are all sold" (D. Kerr, personal communication, 30 June, 2009).

The popularity of the PiR publications has made the Programme self-funding and the three way financial partnership to support the Programme has not yet been required. However, Kerr felt that the interest and the support for the Programme expressed by the English and Design Departments still contributed to the continuation of the Programme (D. Kerr, personal communication, 30 June, 2009).

Although degrees of outreach vary, all of the Programmes have involved some formof outreach in the form of class and individual visits to the press room and seminars (J. Holmes, personal communication, 30 June, 2009; I. Doesburg, personal communication, 15 July, 2009; D. Kerr, personal communication, 30 June, 2009; B. O’Brien, personal communication, July 8, 2009; T. McLeod, personal communication, July 6, 2009).

Despite the popularity of the PiR publications, the success of the Programme should not be measured purely in terms of sales. Another measure of its success is the overwhelming support for the Programme by those who participated in this study. Surrounding the PiR Programme is a team of people that assist on a regular basis (John Holmes, Tara McLeod, Inge Doesburg, Jenna Packer, Kathryn Maddill and John Mitchell). When asked about the existence of this support team Kerr agreed saying that, "they want to be involved and you can't beat that enthusiasm" (D. Kerr, personal communication, 30 June, 2009). All of the study's participants acknowledged the significant the role of Kerr in determining the subject matter for the publications, as well his ability to pull together printers, printmakers, artists and authors so that the publications can actually happen. 


\section{From Bibliography Room to Otakou Press:}

"... the name change had to be ratified by the University in consultation with Te Tumu and was also supported by Keith Maslen" (D. Kerr, personal communication, June 30, 2009).

In an email in response to Kerr about the success of the first PiR Programme, Keith Maslen reiterated the notion of renaming The Bibliography Room. Maslen's suggestion for the new name was the Otakou Press Room, with Otakou Press as the imprint name (K. Maslen, personal communication, December 4, 2003).

In 2005, the PiR Programme's fifth publication, PINE by Ralph Hotere and Bill Manhire (2005), was used to mark the renaming of the Bibliography Room to the Otakou Press. In a speech to celebrate the completion of PINE (2005) and mark the renaming, Maslen had this to say about the PiR Programme:

"Yesterday's modest venture has found renewed vigour, and this renaissance, this fresh out flowing of creativity deserves to be marked with a change of name" (Maslen, 2005, p. 2).

Shef Rogers recalls the decision to rename the press room as part of a need to more "accurately reflect the functions of the press room" (S. Rogers, personal communication, August 3,2009$)$. The new name was also seen to have both historical and geographical significance:

"The name was suggested in recognition of the probable provenance of the oldest press in the room, the Hopkinson and Cope Albion, which was probably first used to print the Otakou News" (S. Rogers, personal communication, August 3, 2009). 
The launch of PINE (2005) was used to mark the name change because Ralph Hotere and Bill Manhire have strong links to Otago, and one of the original Pine series was printed in the Bibliography Room (B. O’Brien, personal communication, July 8, 2009).

"Pine is a significant publication to mark that change - that it is not just a bibliography room - it has a bigger impression than that - it's also an Otakou/Otago imprint" (D. Kerr, personal communication, 30 June, 2009).

As far as Kerr and Rogers are concerned, the name change does not indicate a change in the function or direction for press room, instead it clarifies the room's functions which were never solely bibliographic. While Maslen (2005) was running the Bibliography Room, he took the opportunity to use the facility as a means of making unpublished New Zealand poetry (by his Burns Fellow colleagues) accessible to the wider community. A number of those interviewed highlighted this connection between the PiR Programme and the publications produced by Maslen in the Bibliography Room, and saw the PiR Programme as a means of revitalising the press room's literary function. (I. Doesburg, personal communication, July 15 2009; J. Holmes, personal communication, 30 June, 2009; B. O’Brien, personal communication, July 8, 2009).

\section{Now and then:}

Characteristics of the PiR publications that differentiate them from those produced by Maslen are as follows:

- The PiR publications are produced as part of a structured Programme with set aims and objectives; supported and funded by the University Library, English Department and Design Studies Department.

- The subject matter for the PiR publications goes through a formal proposal process and must be approved by a panel of representatives from the University Library, English and Design Studies Departments. 
- The PiR publications have been produced by printers from New Zealand and Australia, and each printer is paid produce and communicates the publication they are working on to a wider audience.

- Images are often incorporated throughout the PiR publications.

- The entire publication is printed on a letter-press and smaller edition runs are produced because of this.

- The publications are only sold through Special Collections at the University of Otago.

- The University Bindery has been involved in providing enclosures / covers for many of the PiR publications (although the degree of this involvement has varied from publication to publication).

\section{Summary:}

With the backing of the University of Otago English Department and Library, Maslen and Esplin set up a bibliographic press named the Bibliography Room. The intention of the press was to teach English student's the process of letterpress printing, but at a time when it was difficult to get the works of New Zealand literature published commercially, Maslen also utilised the Bibliography Room to produce the work of his Burns Fellow colleagues.

An inventory of the items printed by the Bibliography Room was created by Keith Maslen in 2006 for the Special Collection's exhibition, The Black Art: Handprinting in the Bibliography Room, 1961-2005. Many of these items can be viewed online as part of the Library's online Special Collections exhibition: http://www.library.otago.ac.nz/exhibitions/blackarts/index.html

Kerr was aware of the history of the Bibliography Room and the role it played as a teaching press and a private press. The PiR Programme seems to have revitalised both functions to some extent. The outreach aspects of the Programme complement the press room's use a teaching facility (which has been extended to the Design Studies and Art History departments), and the 
publications produced reflect the historical objective of making unpublished local material accessible utilising the handpress.

Although the launch of a PiR publication was used to mark the renaming of the Bibliography Room, the idea to rename the press room was originally that of Keith Maslen. Rather than marking a change in direction for this bibliographic press, the renaming seems to mark a connection between the press room and the Otago region. 


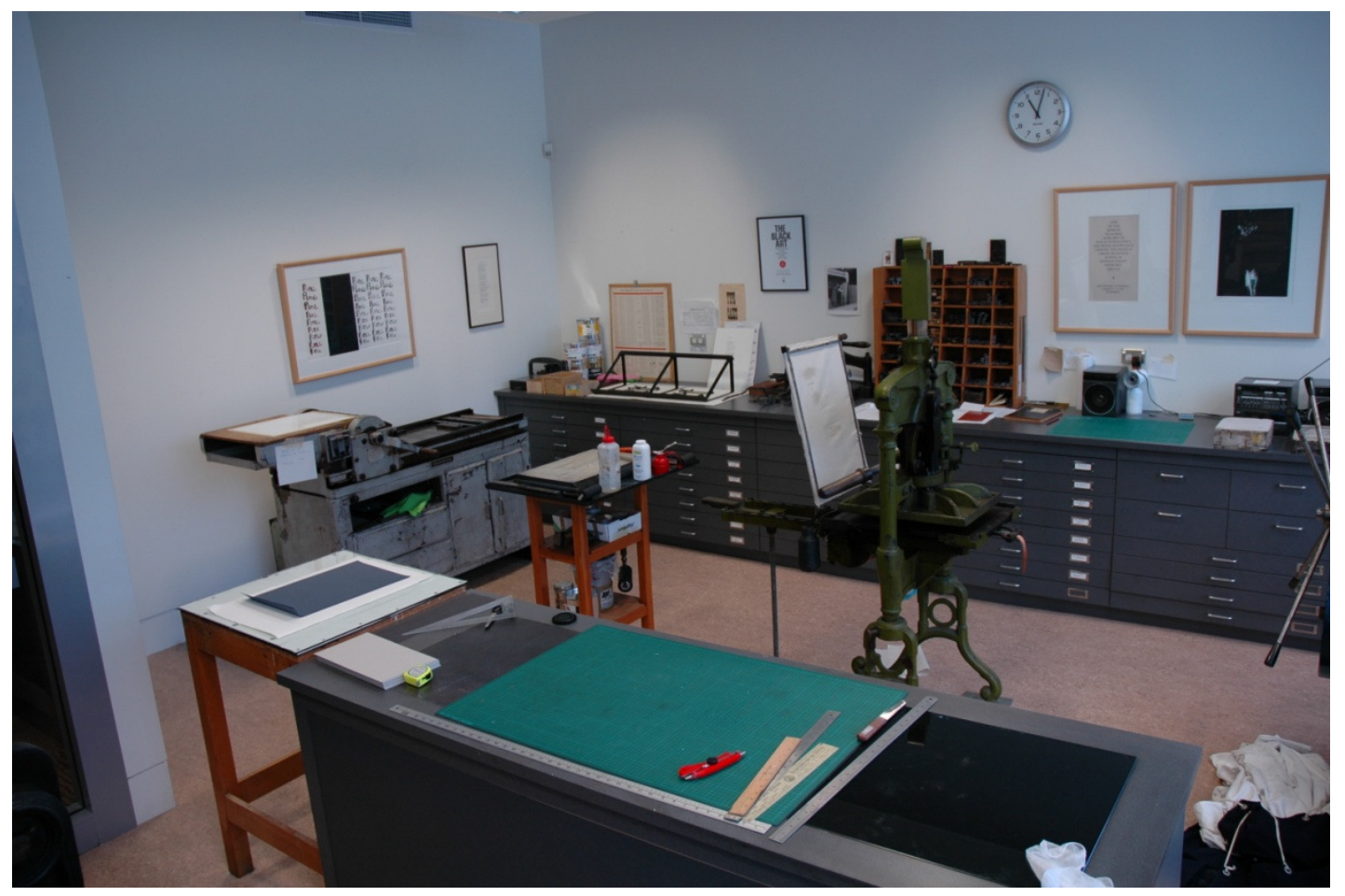

Figure 1: A view of the Otakou Press room featuring the Vandercook Proofing Press, and the Albion press, made by Hopkinsons of London in 1845.

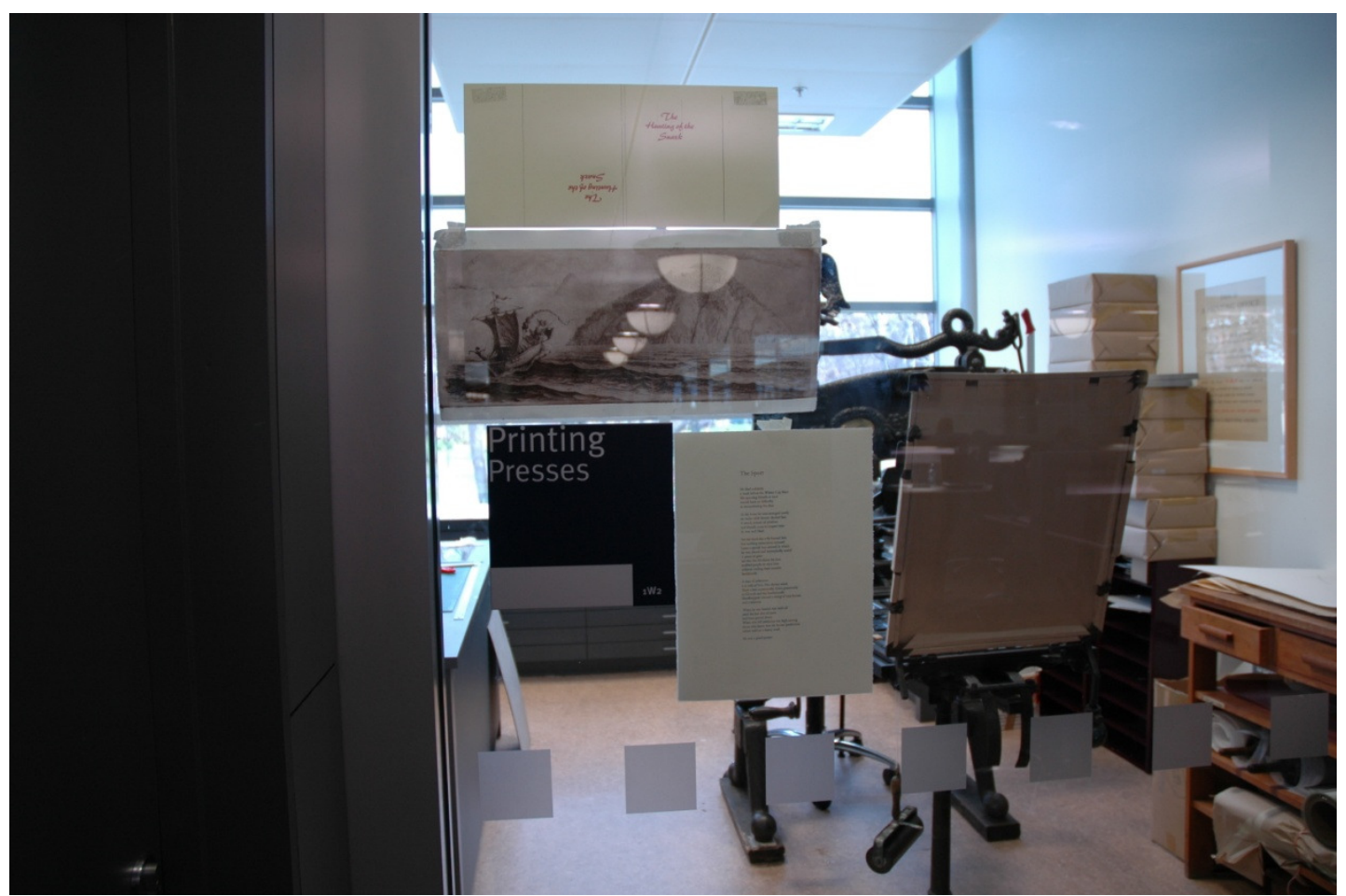

Figure 2: A view into the Otakou Press room; note work of passed PiR publications (2006 and 2007) displayed. The Columbian Hand Press appears in the background. 
Case study 1:

The 2005 Printer in Residence Programme 


\title{
The 2005 Printer in Residence Programme:
}

\author{
Access to Lilac by Joanna Margaret Paul
}

PINE by Ralph Hotere and Bill Manhire

2005 was a busy year for the Bibliography Room at the Otago University. Before the 2005 PiR Programme began, the Bibliography Room had already been used for a sideline project; a limited edition printing of the previously unpublished James K Baxter poem, PINE trees in the key of $F$ and a rose in the key of $G$, with $\mathrm{Dr}$ John Holmes as printer and Inge Doesburg as the illustrator/printmaker.

The PiR Programme began in August 2005 and was meant to run "for 20 working days; spread over one month, from $1^{\text {st }}$ to $28^{\text {th }}$ August" (Kerr, 2005a p.1). During this time, two publications were to be produced. The first was a collection of Joanna Paul's poetry titled "Access to Lilac" and the second "was a first time printing of Ralph Hotere's and Bill Manhire's PINE" (Kerr, 2005 p.5). The process of producing "Access to Lilac" was a relatively smooth. In contrast, there were times when it looked as though the Hotere and Manhire publication would not happen at all.

2005 was also the year that the Bibliography Room was renamed the Otakou Press; a name with a strong historical association with Otago's printing history. PINE (2005) was seen as the ideal publication to mark the renaming due to its historical connection to the Bibliography Room and Otago.

Brendan O'Brien was the Printer in Residence for the 2005 PiR Programme. A Wellington based printer who specialises in printing small runs of high quality pamphlets of New Zealand poetry; O'Brien follows a history of this type of publication by likes of Dennis Glover and the Caxton Press, Don McKenzie in the early years of the Wai-te-ata Press and Dr Keith Maslen in the Bibliography Room. 
Kerr was familiar with O'Brien's work from his years working as the Rare Books Librarian at Auckland City Library and invited him to participate in a PiR Programme. In discussions between Kerr and O'Brien, the possibility of producing two publications arose; a book of poetry by Joanna Paul as well as a publication involving collaboration with Ralph Hotere and Bill Manhire.

\section{Access to Lilac by Joanna Margaret Paul}

Joanna Paul is probably best known as a New Zealand painter but she is also recognised for her poetry. O'Brien formed a friendship with Joanna Paul and her mother Janet while he was printing (under the Fernbank Studio imprint) from the Rita Angus Cottage in Wellington as an Artist in Residence in from 20002002. Paul had also been an artist in residence at the Rita Angus Cottage and Janet, who O'Brien spoke of having a great knowledge of typography, had been a good friend of Rita Angus (B. O’Brien, personal communication, June, 9, 2005).

It was during this time that Paul gave O'Brien some of her unpublished poetry which he has used in previous publications, The Cherry Now (2001). It was not only O'Brien's association with Paul but also Paul's connection to Dunedin, especially Port Chalmers (Ireland, 2003), that made a publication of her poetry an ideal project for the PiR Programme.

On request, Bernadette Hall, the executor of Paul's estate along with Charles Bisley, provided Kerr with a sheaf of unpublicised poems with the series title "Access to Lilac".

"The series I have in mind has been arranged by Joanna with colour photographs and colour paintings that she seems to have made to go with the text" (B. Hall, personal communication, March 1, 2005).

Kerr contacted Peter Ireland, the executor of Paul's art work, by letter for permission to use the images Paul had included with the poetry series. However in another letter to Ireland (June 20 2005), Kerr refers to a joint decision between Charlotte Paul, Hall and O'Brien to use some of her line drawings 
instead because they could be reproduced more successfully using the printing process (D. Kerr, personal communication, June 20, 2005). The line images chosen were made into three polymer blocks of varying size by Wickliffe Press. An image of Joanna was also provided by Charlotte Paul so that copies could be "tipped into each volume of verse" (Kerr, personal communication, June 20, 2005). Around this time the decision was also made to use Zerkall Apecail Edition paper for the Paul publication, for the page size to be "approximately 265-195 mm," and for the edition to sell for between $\$ 75$ and $\$ 85.00$ (B. O'Brien, personal communication, July, 9, 2009).

O'Brien began his residency August 1, 2005 and spent the first three of the four weeks on the Paul project. O'Brien felt that his friendship with Paul and his appreciation of her poetry and art, informed the design of the book (B. O'Brien, personal communication, July, 9, 2009).

"At the time, there was no work of Joanna's in print, so it was great to make Access to Lilac accessible" (B. O'Brien, personal communication, July, 9, 2009).

O'Brien also spoke of being inspired by Alan Loney's Imogen (1978), another limited edition publication of Paul's poetry.

Having more experience using small bench-top platen presses, O'Brien found using the print room's Vandercook proofing press quite "a jump up in scale" (B. O’Brien, personal communication, July, 9, 2009).

"I had used a Vandercook before but it still had its inking rollers and that makes a huge difference to the speed and quality of the printing because it takes away that inking problem. It took a bit of time adjusting to this [the hand inking] and getting used to the fine tuning the press required" (B. O’Brien, personal communication, July, 9, 2009). 
As well as determining the design and layout of the publication, O'Brien was also responsible for creating the cover and sewing in all the pages. He chose a soft cover binding similar to what he used for his own private press editions.

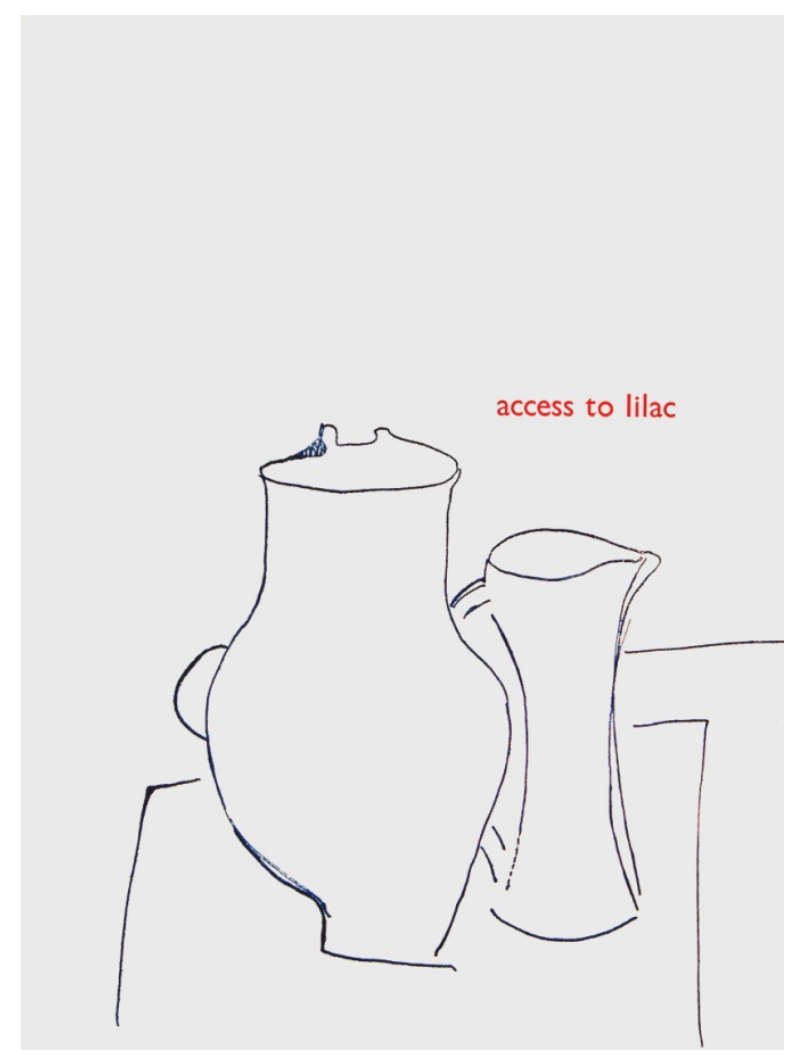

Figure 3: Cover of Access to Lilac (2005)

In terms of type, O'Brien was limited to the resources available in the print room. “there wasn't enough type to set the whole book at once which is what you would usually do, so I had to set about quarter at a time; print it and then pull it to bits so I could use it again" (B. O'Brien, personal communication, July, 9, 2009).

However, O'Brien didn't mind working in an environment of limited resources because he had to "make do with what is available" in his own studio. If anything, he said it "helps him work" (B. O'Brien, personal communication, July, 9, 2009). "... for example, the type on the cover of Access to Lilac. I would have done that much larger but the type just wasn't available, and in the end, I was really happy with what I had done. I ended up using type I wouldn't have 
usually chosen but in the end it fitted the project" (B. O'Brien, personal communication, July, 9, 2009).

One hundred copies of Access to Lilac were printed and by "December 2005, and with little promotion, only 27 copies remained for sale... The executors of Joanna Margaret Paul and family were overwhelmed by the excellent production of the Paul poetry book" (Kerr, 2005, p.5).

The national bibliographic database, Te Puna, indicated that nine New Zealand libraries (public and tertiary) purchased this item for their collections. Invoice lists for this publication also indicate that a copy was purchased for Special Collections at University of Melbourne Library and the rest were sold to individuals.

\section{PINE by Ralph Hotere and Bill Manhire}

In the draft of a letter to Ralph Hotere and Mary McFarlane (February 2, 2005) Kerr outlines a plan for the 2005 PiR Programme. At this time Kerr says that "on Brendan's [0'Brien] suggestion" Bill Manhire has been contacted "in the hope he can supply a long poem, or a number of poems for printing... Brendan has also suggested that you might want to be involved in some way on this project, perhaps as the illustrator of Manhire's poetry" (D. Kerr, personal communication, February 2, 2005). In an email response by Manhire, it is suggested that "Ralph might like to have another go at a text he's worked on in the past. Maybe the PINE series might become a book - some of the PINE prints were done in the Otago Bibliography Room" (B. Manhire, personal communication, February 10, 2005).

In Hotere - out of the black window (1997), Gregory O'Brien describes the two series of PINE prints produced by Hotere in the early 1970s. “.... the first a group of 1972 watercolours which are among Hotere's most lyrical works" (O'Brien, 1997 p. 49) and the second are "a more robust-looking sequence" using woodblock letters from 1973-1974 (O’Brien, 1997 p. 49). 
“...these banner-like-configurations of words, which the artist printed on the Royal Columbian handpress at the Bibliography Room at the University of Otago" (O’Brien, 1997 p. 49).

The text for the PINE works was written by Bill Manhire when he was living in London in the early 1970s. In an account by Manhire (O'Brien, 1997), he spoke of sending a postcard every so often to Hotere "with the word PINE on it and a line of poetry" (O'Brien, 1997, p. 49) and it was these that Hotere included in his series of works.

O'Brien and Kerr were keen on Manhire's suggestion to print the PINE series in book format and approval was gained by Hotere. O'Brien had seen the large woodblock PINE prints Hotere had produced in the Bibliography Room for the 1973-1974 series and planned to print the publication in a similar style (B. O'Brien, personal communication, July, 9, 2009). Manhire's text from the postcards was to be printed in Hotere's handwriting using polymer plates.

"The design for the book came from discussions with Ralph back in June. I made dummy sheets and took them out to Ralph to show him the idea and we talked about how he did the large scale prints and his unconventional methods of inking the wooden type" (B. O'Brien, personal communication, July, 9, 2009).

“... when it came to getting a copy of the poems from Bill [Manhire], he actually found two others that he hadn't sent to Ralph. We gave these to Ralph and the book grew a bit larger than first thought" (B. O'Brien, personal communication, July, 9, 2009).

Due to Hotere's age and recent ill health, O'Brien and Kerr felt that PINE should be the priority of the Programme. O'Brien met with Hotere in June 2005 to discuss the idea of the project and Hotere was keen to be involved (B. O'Brien, personal communication, July, 9, 2009). Kerr was hopeful that Hotere would 
actively participate in the project when he wrote the proposal for $2005 \mathrm{PiR}$ Programme:

“Ralph Hotere is perhaps New Zealand's most well-known living artist. He is very keen to work with the presses, and on the suggestion of Bill Manhire, is likely to produce another PINE sequence. Although Hotere is confined to a wheel-chair, there is hope that a technician will be on hand to aid the artistic process. O'Brien of course will be present" (Kerr, 2005a, p.2).

However, between June and August “Ralph's assistant died, Ralph wasn't in the best of health, and he was also in the middle of moving house; it began to look as though the project wasn't going to happen .... It took his energies elsewhere" (B. O'Brien, personal communication, July, 9, 2009). As a result, when O'Brien started his residency in August, he got started on the Joanna Paul project and carried on trying to negotiate a time to meet Hotere.

Even though O'Brien didn't begin working on PINE (2005) until the last week of his residency, he was still confident that he could get it completed in time.

"I imagined the PINE book would be a speedier process [compared with Access to Lilac] because I didn't have to set as much text, and that can be a slow process if you haven't been trained in setting it" (B. O'Brien, personal communication, July, 9, 2009).

However, as the project progressed, O'Brien found that he was going to need more time.

"I had taken an extra week's leave from work to travel in the South Island, but decided to add that to my residency to get the extra time" (B. O'Brien, personal communication, July, 9, 2009). 
Although the text was limited, O'Brien was finding that "the inking [of the wooden type] was very time consuming in order to get the desired effect" (B. O’Brien, personal communication, July, 9, 2009).
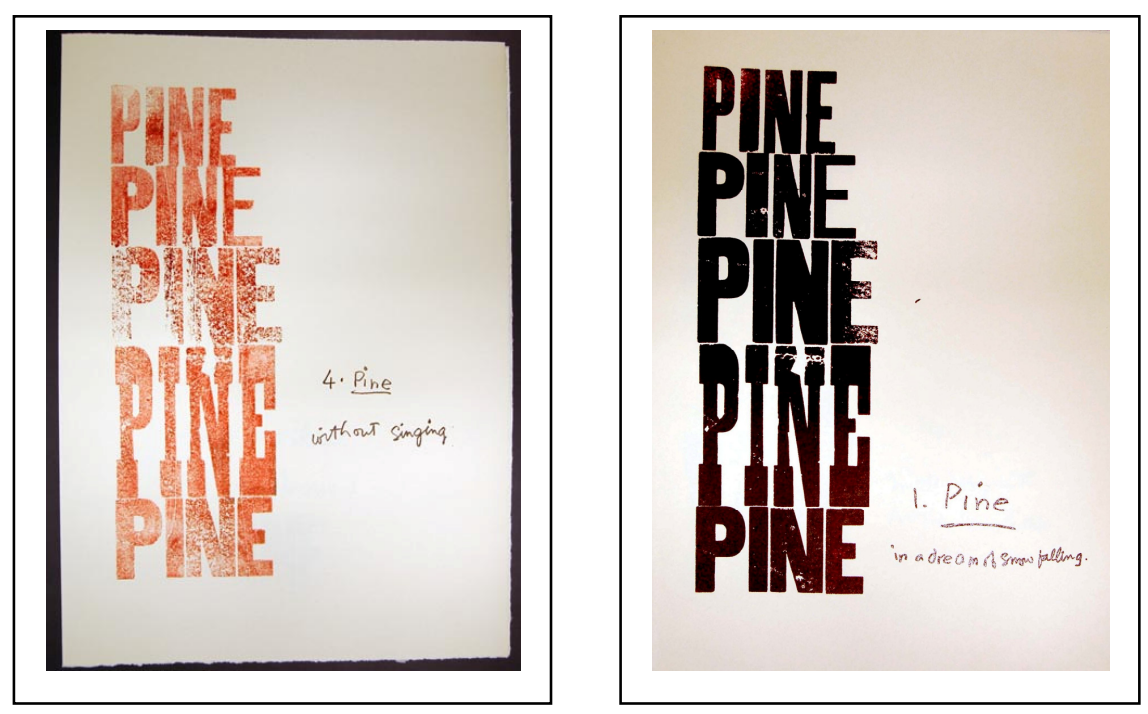

Figure 4: Pages from PINE (2005)

The publication was also taking more time than expected due to the amount of ink needed and the extended drying time required.

"...we had pages drying all over the press room and the meeting room next door" (B. O’Brien, personal communication, July, 9, 2009).

By the end of the five weeks O'Brien had to return to work in Wellington but he returned "two or three times" to get the publication finished.

Like Access to Lilac (2005), O'Brien created the cover for PINE (2005). The design for the cover came from O'Brien's knowledge of the covers Hotere had created for books such as Malady by Bill Manhire (1970), Sap-wood \& milk: poems by Hone Tuwhare (1972) and The elaboration: poems by Bill Manhire; drawings by Ralph Hotere (1972).

"I gave him [Hotere] a couple of rough ideas and we settled on a simple black cover with PINE in white ink" (B. O'Brien, personal communication, July, 9, 2009). 
"The cover chosen for PINE kind of fits with some of the other things Bill and Ralph have done together," and in this respect, O'Brien felt that the publication could "join that family" of publications, rather than turning out as a "stray orphan" (B. O'Brien, personal communication, July, 9, 2009).

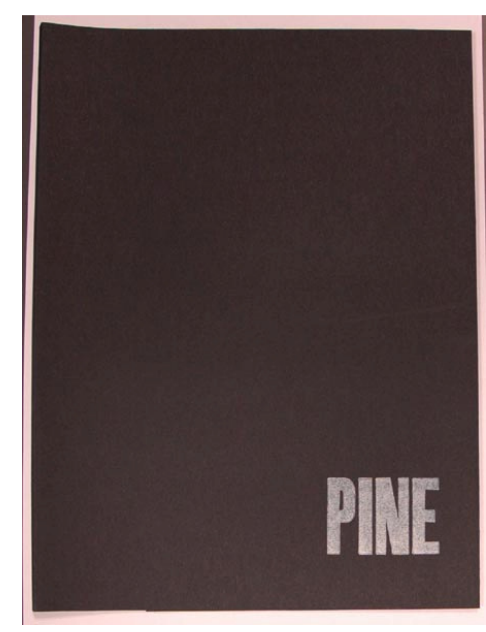

Figure 5. Cover of PINE (2005)

The reception PINE (2005) was very positive. "Both Hotere and Mary McFarlane were very pleased with O'Brien's printing of the PINE book. Bill Manhire and Victoria Timpany (Hotere's art dealer) commented favourably also" (Kerr, 2005, p.5).

The pricing of PINE (2005):

The Proposal for the Printer in Residence Programme (2005a) indicates that the 74 "trade" (unsigned) editions were originally priced at \$175 and the "deluxe" (signed) editions at $\$ 350$. However once known, the pricing of the publication soon became challenging issue for Kerr:

"The charging of the book $[P I N E]$ caused a furore throughout the Library system. Ralph's an artist, so we couldn't sell off the PINE printing without recognising his artistic work .... we have to do right by everyone involved. That was the year that we charged more than we would have usually done and it didn't sit well with the Library administrators; it raised the question of whether we could be viewed as commercial entity, and we are not. 
That's why we align ourselves with academic departments and have that outreach component" (D. Kerr, personal communication, 30 June, 2009). "That pricing issue is such a complex one - particularly as even the most minor of Ralph's work fetches such high prices and I suspect such an animal as the "Hotere collector-investor" exists...... It is going to be very hard to not undersell the book but also to have Ralph, etc happy with the price and the purchasers too..." (B. O'Brien, personal communication, October, 2005).

"...when we did the Hotere/Manhire publication people were adamant that those sets would be broken up immediately and sold off separately for inflated prices and it was a rip-off and sacrilege and we should not be doing this" (R. Andrew, personal communication, July 9, 2005).

To help ensure that the prints would not be separated once the book was sold, a message was tipped into each publication stating that is was the intention of the artist, poet and printer that "the shape and integrity of this project be respected and that copies of this book--in its current bound form--remain intact" (Hotere \& Manhire, 2005).

As it turned, Ralph Hotere and Mary McFarlane were happy to leave the pricing of the publication to Kerr (D. Kerr, personal communication, October 11, 2009) and were happy with the final decision to price the 26 copies signed by Hotere, Manhire and O'Brien at $\$ 800$ and the remaining unsigned copies at $\$ 350$.

Marking the press room's name change with PINE (2005):

When asked about the change in name of the Bibliography Room to the Otakou Press Kerr said that "it was something that had been mentioned previously and I thought, let's make it significant. Brendan was down that year and he knew Ralph, he had worked with him before and it just seemed to be appropriate" (D. Kerr, personal communication, 30 June, 2009). 
The promotion and recipients of the PINE publication:

In a report outlining the PiR Programme's activities from 2003-2005, Kerr states that "much time was allocated on advising libraries and research art galleries of its availability" before PINE (2005) was released for sale to individuals (Kerr, 2005, p.5). As well as utilising the University's Marketing and Communications Department, PINE (2005) was also promoted using internal and national email list groups such as, LIANZA, ExLibris and the Arts Foundation of NZ (Kerr, 2005, p.5). Promotional materials were also sent to local newspapers amd radio and television stations.

By December 2005, four New Zealand Libraries had purchased signed copies of PINE (2005) and unsigned copies were sold to a further fourteen, including Te Papa and Monash University Library in Melbourne.

The launch of PINE (2005) and the renaming of the Bibliography Room were combined in one event on December 6, 2005 in the University of Otago Central Library. The importance placed on the occasion was reflected by the guest list which included the University of Otago's Vice Chancellor, Deputy Vice Chancellors, Pro Vice Chancellor for Humanities, the Marketing Director, Maori Affairs Advisor and senior staff from the University of Otago Library. Dr Keith Maslen, the founder of the Bibliography of Room, presented a speech marking the occasion.

\section{Collaborative aspects of the 2005 PiR Programme:}

Creating Access to Lilac (2005) and PINE (2005) were collaborative processes for O'Brien, and his association with Ralph Hotere and Joanna Paul previous to these projects may have helped shape the success of both publications.

The production of Access to Lilac (2005) required collaboration with Kerr and the executor's of Paul's poetry and artwork. The PiR archives for Access to Lilac (2005) indicate that Bernadette Hall was impressed with O'Brien's previous publications of Paul's poetry and was happy for him to be involved in another. "It 
sounds like a really lovely project. Charles [Bisley] and I would want to be as helpful to you as we can be" (B. Hall, personal communication, March 1, 2005). In regards to PINE (2005), O'Brien spoke of how positive he felt about being able to work with Hotere and Manhire on the project and how valuable it was to him personally.
"It was wonderful be able to do something with Ralph Hotere. I think artists that use language can teach printers and designers a lot, especially how to look at language and how to look at space and colour on a page because this can be very different to someone trained in design. It was wonderful to talk to him about his work and learn from him - it was a privilege really.... Ralph did come into the print room several times to see what was going on. He was not in the best of health so he didn't take full part in using the press, although he did try using the old press [Columbian] a bit - he was more looking over our shoulders as we did the work which was great... It was also great to have Bill Manhire involved because he helped me at the start of my printing - putting me on to a friend of his for type... and he was always keen on making small pamphlets and books of poetry" (B. O'Brien, personal communication, July, 9, 2009).

O'Brien also explained how programmes such as this, which are organised by an institution, are excellent opportunities for private printers to collaborate with others - especially since it can be a difficult process to organise such projects on an individual basis.

“...working on your own, you can be reluctant to involve other artists or professional binders because you often can't afford to pay them for their collaboration and still make the projects affordable" (B. O'Brien, personal communication, July, 9, 2009). 
Programmes like this can provide the infrastructure required to carry out such collaborative projects; taking that financial pressure off the printer and possibly allowing room for more creative freedom (B. O'Brien, personal communication, July, 9, 2009).

Completing one publication, let alone two, during a five week residency requires the assistance of many helpers, and these included the Dunedin Public Library's Bindery staff who came in to sew the publications together (D. Kerr, personal communication, 30 June, 2009; (B. O’Brien, personal communication, July, 9, 2009).

"When we did the Hotere book and the Joanna Paul book we all pitched in. We had students and staff helping and that's all part and parcel of making a book like this" (D. Kerr, personal communication, 30 June, 2009).

\section{The outreach components of the 2005 PiR Programme:}

One of the three outcomes outlined in the Proposal for the Printer in Residence Programme (2005a) was "to hold seminars and practical sessions with English, Design and Art History students, and other interested parties such as librarians, booksellers, designers and artists by the end of the Programme" (Kerr, 2005 p. 1).

As part of his residency obligations, O'Brien held two sessions in the print room for classes of English and Design students:

"Some were very interested in what I was doing while others may have seen it as something from the past that they didn't really know" (B. O’Brien, personal communication, July, 9, 2009).

His residency was also "punctuated by encounters" with students, University staff and interested individuals such as Keith Maslen (B. O'Brien, personal communication, July, 9, 2009).

"I had quite a number of visitors to the print room that were just interested in what was going on. It was nice to meet them. It was nice to 
talk to people about how the project was unfolding" (B. O'Brien, personal communication, July, 9, 2009).

\section{In hindsight: overall challenges for the 2005 PiR Programme}

The challenges relating to getting the PINE project off the ground and the subsequent challenges relating to the pricing of the publication have already been outlined above. However, some of the other challenges faced are listed below:

- As with all the PiR projects, the Printer in Residence is expected to make do with the limited type available in the print room. O'Brien was happy to take on this challenge when it came to the Joanna Paul publication but he bought some wooden type down for PINE (2005).

- As outlined previously, O'Brien was not used to operating large presses like the Vandercook and it took a bit of time to adjust - especially since it had no inking rollers.

- The biggest challenge for O'Brien was to complete two publications during one four week residency and this was a challenge he may have underestimated.

"I was maybe a bit ambitious with the size of the editions and I could have made it easier if I had done fifty copies. However, for me, the slow part is the type-setting, so another fifty copies [of the Joanna Paul publication] is not so much of a hassle. However, it was different with the PINE (2005) and all the inking involved... It would have been easier if I had had a couple more weeks [for the PINE publication]. I was so rushed most of the time that I couldn't do as much quality control on things. There were some slightly roughly printed sheets but that didn't really matter as it added to the effect of things... I did make the recommendation of extending the residency period, although I acknowledged the pressure it would put on 
those who work outside printing. In an ideal world, the printer would be there all year" (B. O’Brien, personal communication, July, 9, 2009).

\section{Summary:}

2005 was a significant year for the PiR Programme. Two PiR publications were produced, one of which was used to mark the renaming of the Bibliography Room to the Otakou Press. Despite the time pressure involved in producing two publications, the objectives set out for the 2005 PiR Programme were achieved, including class visits to the print room.

Access to Lilac (2005) involved much collaboration with Joanna Paul's family and the executors of her estate to gain the poems and drawings necessary to create the publication. This process of collaboration was as smooth as the production process and the publication was completed three weeks into the four week residency.

In contrast, the process of producing PINE (2005) was more challenging. Circumstances had changed since O'Brien had met with Hotere in June 2005 and it was not until the last week of his residency that O'Brien could begin work on the project. Although O'Brien was initially quite optimistic about the possibly of completing the publication in the time remaining, it proved to be impossible. The process of inking the wooden type of get different effects on page was more time consuming than first thought, as was the time expected for the paper to dry. However, O'Brien was willing to add an extra week to his residency and made two more visits to Dunedin to complete the publication.

Access to Lilac (2005) and PINE (2005) were well received by the poets, artists, executors and/or family contributing to the publications. And although O'Brien was under much pressure to get PINE (2005) finished, he spoke of how rewarding it was to be involved in both publications. He found the opportunity to collaborate with Hotere on PINE (2005) and learn new skills and new ways of 
viewing language as part of a design process very rewarding (B. O’Brien, personal communication, July, 9, 2009). 
Case study 2:

The 2006 Printer in Residence Programme 


\section{The 2006 Printer in Residence Programme: \\ The Hunting of the Snark: an agony, in eight fits by Lewis Carroll}

"Finally here's a chance to do the Snark after all these years."

(D. Elliot, personal communication, July 31, 2009).

\section{Introduction:}

Thirty illustrated versions of Lewis Carroll's Hunting of the Snark (1874) have been produced worldwide but the 2006 PiR publication was the New Zealand's first handprinted edition. The Printer in Residence was Tara McLeod and the illustrations were created by David Elliot. Local printmakers Inge Doesburg, Jenna Packer and Kathryn Madill used the solar-plate etching process to print Elliot's images. The 'Snark project' ran for six weeks, $1^{\text {st }}$ August - $7^{\text {th }}$ Sept.

Unlike the other PiR Programmes:

1. Control over the planning and design of the publication was shared between the Printer in Residence and the Artist.

2. It utilised material that had already been widely published and had no connection to Dunedin.

\section{The concept behind the illustrations:}

When Elliot began illustrating and writing books on a full-time basis, one of the things he always wanted to do was to illustrate Lewis Carroll's Hunting of the Snark. At one stage the project was almost underway with a commercial publisher in New Zealand but fell through when it came to getting an overseas publisher.

"I've always loved the blackness of the poem, and also, it fitted with where I wanted to go in illustration" (Elliot, personal communication, July 31, 2009).

Elliot met Kerr through his wife (a colleague of Kerr's at the University of Otago Library) and on hearing about the PiR Programme suggested the Carroll poem as 
a possible subject. Kerr responded positively to this idea and took it on as a PiR project:

"I probably suggested that the Snark would be a wonderful thing to do and Donald picked up on it, to his credit" (Elliot, personal communication, July $31,2009)$.

In correspondence with McLeod, Kerr speaks of meeting with Elliot and Doesburg to discuss the images and their plans to have "perhaps 8 full size images - one per fit. And perhaps 2-3 other ones interspersed throughout the text; a maximum of 32-34" (D. Kerr, personal communication, July 2006).

The initial idea was to use "raised metal plates, like those used for printing advertisements in newspapers" (D. Elliot, personal communication, July 31, 2009) because "you could get incredible detail with them and they could be printed together with the text" (D. Elliot, personal communication, July 31, 2009). However, after having no luck locating any printmakers who had used this technique, it was decided to use solar-plate etching instead. Doesburg often used solar-plate etching as part of her own work and found that it produced a similar level of detail. However, a disadvantage of solar-plate etching was the time consuming and expensive nature of the process, and as plans for the Programme progressed, it became apparent that was not feasible to print thirty plus illustrations for 101 editions (D. Elliot personal communication, July 31, 2009).

Through a process of elimination the plan for the illustrations began to change, as did the format for the whole publication. Instead of a single book, the publication morphed into a 'Snarkopack' (D. Kerr, personal communication, June 30, 2006) made up of a book of the hand-printed text and a separate set of illustrations of varying sizes encased in a tri folder. 


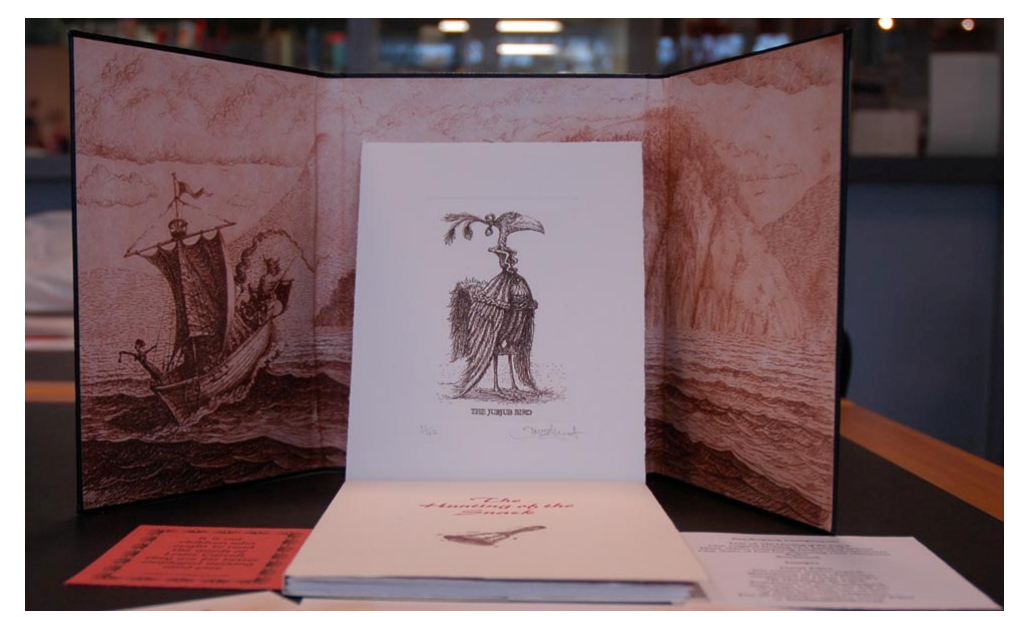

Figure 6: Some elements of the Hunting of the Snark (2006) kit.

The new design reflected Elliot's vision of the poem and how he conceptualised the illustrative process. For example, the folder became a scene-setting element for the story, a theatrical back-drop in which to set the poem:

"The Snark always reminded me of a game of sorts, a very black and pointless kind of exercise, but nevertheless a game. And also, in illustration, I tend to think of the story as a theatre, a stage upon which the characters move around...... this manifested into the idea of having the backdrop of the theatre and having individual cards as characters... I've always had a 3-d thing, may be it comes from being a kid. I always liked comics, with the parts you could cut out, and this has translated in to my picture books" (D. Elliot, personal communication, July 31, 2009).

The scene-setting backdrop is based on a view from Port Chalmers that Elliot always felt matched the poem's description, and “....when you think about stories you tend to set them in your own environment anyway" (D. Elliot, personal communication, July 31, 2009).

The other illustrations are representations of the poem's twelve characters. They were printed four to a sheet and made up as cards that could be punched out and set on feet. This allowed the characters to be moved around the landscape adding to the game or theatrical quality of the publication. Elliot felt that this 
format not only worked well with the poem but also reflected the way he felt about illustration:

"[In the Hunting of the Snark] Carroll is almost taking the characters out in front of you and introducing you to them in that way anyway" (D. Elliot, personal communication, July 31, 2009).

In terms of representing the characters, Elliot selected poses and body language that would portray their personalities and "how they would play out on the stage" (D. Elliot, personal communication, July 31, 2009).

Inge Doesburg, with the assistance of Jenna Packer and Kathryn Madill, turned Elliot's illustrations into solar-plate etchings that could be handprinted using the the newly acquired etching press. While printing the illustrations, Elliot and Doesburg found that the different types of acetate used for the background and the smaller images created different effects. The landscape came out quite "soft and atmospheric" (D. Elliot, personal communication, July 31, 2009) while the smaller images were sharper. These "happy accidents" (D. Elliot, personal communication, July 31,2009 ) worked well - adding to the 3D quality of the publication.

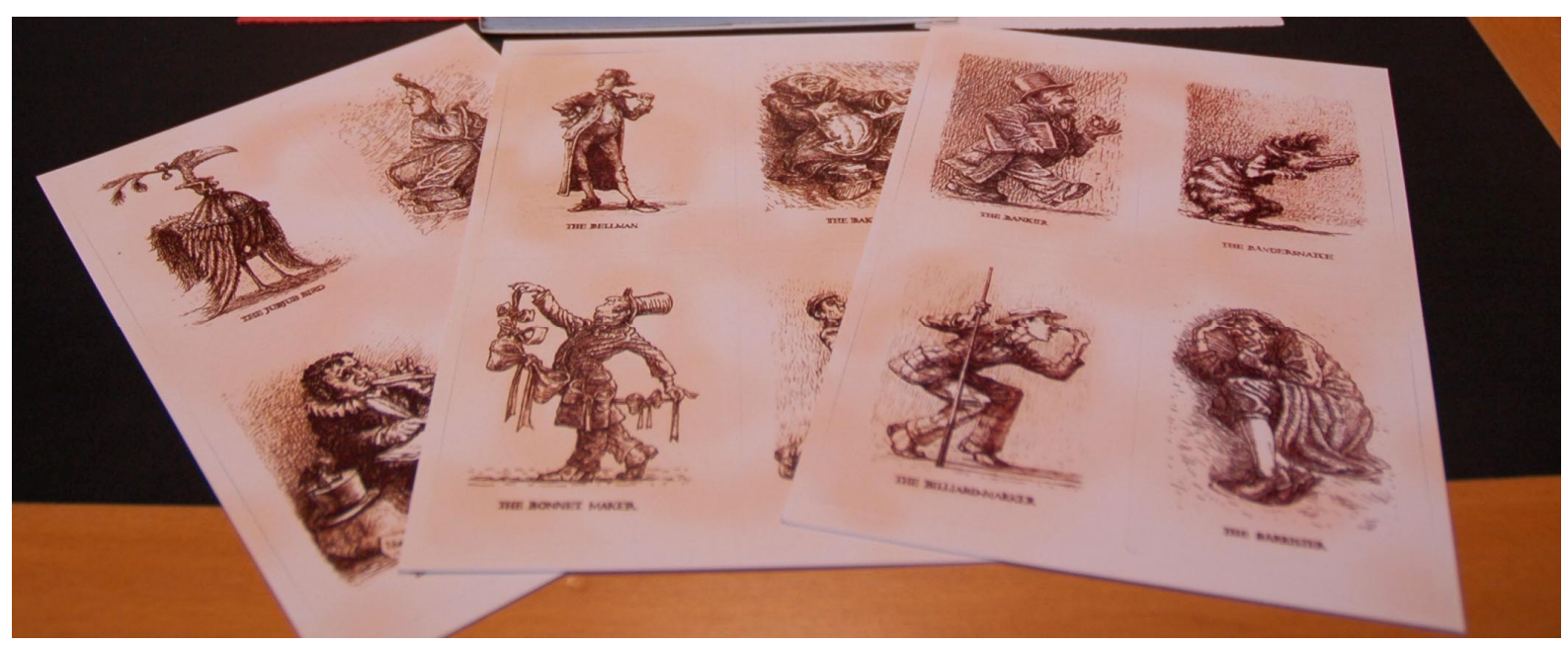

Figure 7: The twelve characters from the Hunting of the Snark, as printed for the $2006 \mathrm{PiR}$ Programme. 
Once printed, the card characters (see Figure 7) were sent to a commercial printer to be reproduced as a set of punch-out cards:

“.... there was also the concession to technology by having to take David's illustrations to Wickliffe Press who scanned and reduced them and made a dye so they could be made into playing card images. They also made feet for the cards" (D. Kerr, personal communication, 30 June, 2009).

In addition to the card series, a larger solar plate etching of one of the Snark characters was included in each publication:

"I made the compromise of including one print in a random sort of way. I wanted them [the buyer] to almost become the character they get. So if you got the Beaver then you are the Beaver for evermore, you are part of

the Beaver Club as it were" (D. Elliot, personal communication, July 31, 2009).

\section{The design of the book:}

While Elliot and Doesburg were working on the images, McLeod worked on the design and printing of the text. The book was printed on the Vandercook proofing press using $12 \& 14$ pt Garamond Roman (newly purchased). The paper used was off-white Zerkall, with terracotta Bugra used for the endpapers.

McLeod felt that Palette Script type "had a snarkish feel to it" and used his own for the book cover and title page, printed in red ink (T. McLeod, personal communication, July 7,2009 ). The cover also includes an image of a ringing bell. McLeod also printed a quote on the terracotta Bugra paper to be used as a bookmark. 


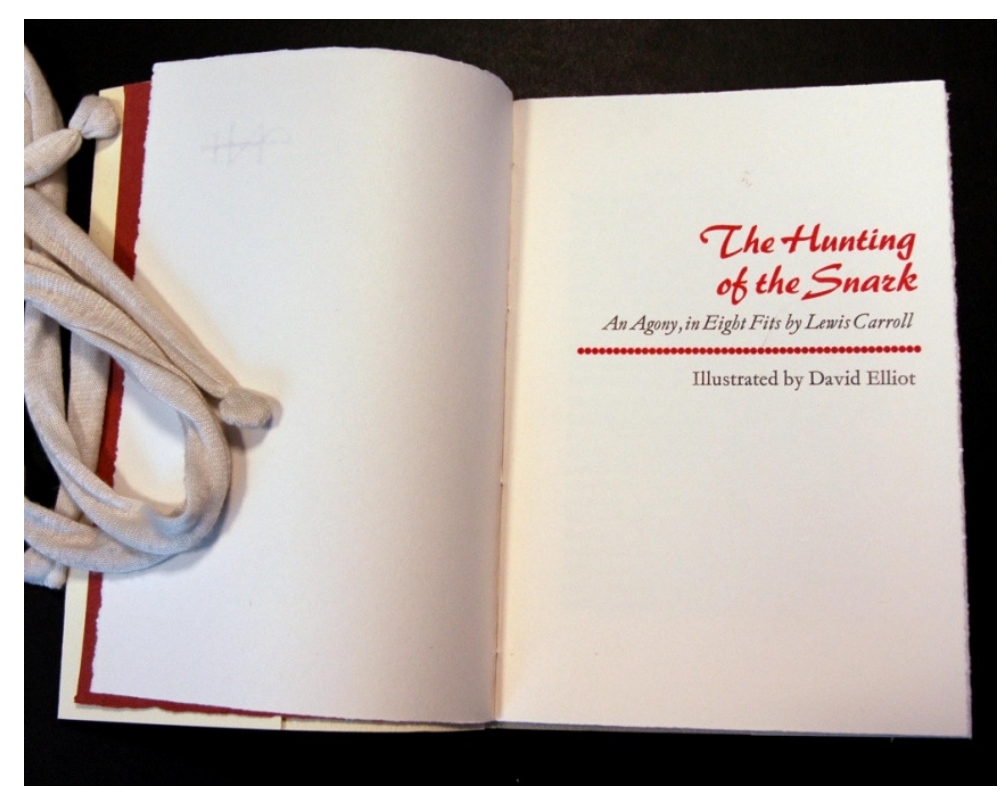

Figure 8: Title page of Hunting of the Snark (2006).

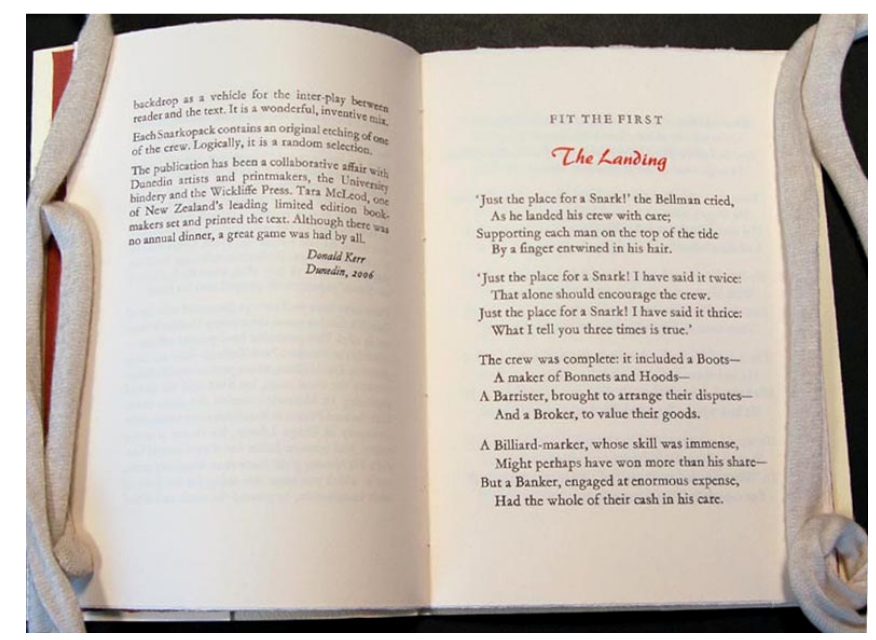

Figure 9: An example of the design and layout of the text for Hunting of the Snark (2006).

In a written account of the 2006 PiR Programme, Kerr (2006) jokes about the instance when proofing error was discovered but only after 101 copies of a double-sided sheet were printed:

"At the end of the first week, as I was dissing type from a completed double sided sheet of text, Tara said: 'Often when distributing type, you notice small blemishes that are not picked up on the printed sheet.' I looked at the lines I was distributing and said: 'Oh you mean like 'the the Butcher'. Silence. Panic. Silence. Read. Check. Panic. Silence. Swearing! And there it 
was - a great gaping 'the the' mistake that we had missed. This was a tough lesson learnt." (Kerr, 2006, p. 2).

The tri folder cover was produced by Don Tobian at the University of Otago Bindery and the titling is embossed silver. This was the first PiR Programme to use the Bindery to produce the publication's cover. Previous to this, the Bindery had only provided the materials.

In regards of the overall design of the folder, Kerr talked of some long discussions between Elliot and the team of printmakers:

"... and the printmakers and the artist must have spent two hours talking about whether the paper should be ragged or straight edged. And Tara [McLeod] who is a rather pragmatic man was saying, 'why don't they just get on and make a decision?' And in fact the decision was made for them because when the item went to the Bindery it was cut with a straight edge and slapped in the folder" (D. Kerr, personal communication, 30 June, 2009).

Kerr also referred the difficulties of finding enough black shoe-lace to tie the folders:

“.....it seemed like an endless chore to obtain 140 metres of the right sort of shoelace at the right price. There was no stock in New Zealand and it had to be ordered from Australia. The usual long wait, constant phone calls, including out-sourced 0800 numbers to Melbourne, finally secured the desired amount. A gleeful time was had cutting the shoelace and wrapping each Snarkopack." (Kerr, 2006, p. 2).

\section{A process of collaboration:}

It was clear from the interviews that Elliot, Doesburg, McLeod and Kerr felt the publication was essentially a group effort involving much collaboration. 
"With the Snark it was more of a group effort in terms of the overall concept with the folder and prints" (T. McLeod, personal communication, July 6, 2009).

Doesburg, who already knew Elliot, found the process of working with him very rewarding:

"That was great fun and David Elliot, he works at Kings also, is a great guy and a wonderful artist and it was wonderful working with him.

We had to fine tune what he wanted the prints to be like and we ended up using the solar-plate etching technique, which was foreign to him and things like the reversal of the image was also foreign to him - as it is for many artists who are not printmakers. The whole process was a good experience for me because I got to hone my teaching.... it was definitely a collaboration with David. It was interesting to see how he worked and what was important to him - handling his lovely drawings was great fun and it worked out well. It is a beautiful, beautiful work" (I. Doesburg, personal communication, 15 July, 2009).

Elliot enjoyed the opportunity to be directly involved in the book-making process and work with others with a similar passion for what they do. He was particularily struck by the respect and attention the printmakers paid to the process of printing his illustrations.

“...I was involved with other people - a team - and saw all the care and respect everyone had for the whole process. Most of the time, as an illustrator and writer, you put everything in the mail and six months later a book comes back. There's an ongoing process but it is not near as handson as this. You don't get to see it being made or go down to the Bindery and talk about embossing silver on the cover" (D. Elliot, personal communication, July 31,2009 ). 
The one disappointment for Elliot was the limited time he was able to spend learning about, and engaging in, the handprinting process; the topography, the type setting and the printing (D. Elliot, personal communication, July 31, 2009).

“In terms of the process of producing the book, I didn't get nearly enough time as I wanted learning. I only really go to met Tara a couple of times.... We worked quite separately, Tara and I - he had his agenda of what he wanted to do and I was just really working pictorially on my own set of stuff. It would have been nice to mix and match that a little more but it just couldn't happen at the time" (D. Elliot, personal communication, July 31, 2009).

\section{The overall success of the 2006 PiR Programme:}

In terms of saleability, the Hunting of the Snark (2006) was a great success with all copies sold before the project was complete. Kerr promoted the publication on a series of library and book collecting list-servs, as well as targeting Lewis Carroll societies overseas. Kerr has always been keen to have the PiR publications purchased by libraries and in this case they included; the Dunedin Public Library, Auckland Museum Library, University of Illinois Library, Eames Collection of Rare Books in San Francisco and Monash University Library. Copies were also sold to members of the Lewis Carroll Society in the United Kingdom and the United States, including Andrew Sellon, the President of the Lewis Carroll Society of North America (D. Kerr, personal communication, 30 June, 2009).

For Kerr, the 2006 Programme stood out because "the concept and the content was something different, something out of the bag. It went through so many permutations of what David [Elliot] wanted and what could be done physically on the presses, which are quite conservative. It was a package of problems that were overcome" (D. Kerr, personal communication, 30 June, 2009). 
Although McLeod saw the publication as a "definite success," in hindsight he wondered whether the collaborative process would have benefited from a more structured approach. He felt that at times there were so many people involved in the production and design of the publication (including the Bindery and Wickliffe Press) that it started to feel 'bitsy' (T. McLeod, personal communication, 6 July, 2009).

“...it may have evolved too much as it went along without enough structure behind it to keep the ideas it check. The overall design of the Snarkopac 'happened' rather than there being an overall design concept" (T. McLeod, personal communication, 6 July, 2009).

Elliot was pleased with the finished product and for him this is a significant achievement:

“Well I like it and I don't usually like the stuff that I do. I like the process of making it, but at the end I always end up thinking that I could have done some part of it better, but I can still open this and like what's inside which is not that common" (D. Elliot, personal communication, 31 July, 2009).

One aspect of the publication that does dismay Elliot is its lack of use (as intended) by those who have purchased it. He's found that purchasers are especially reluctant to pop-out out the card characters (D. Elliot, personal communication, 31 July, 2009).

"No one punches the bloody cards out in case they damage them. I said to Donald, 'we've got to get hold of these people and send out an extra set', and I've done this but they still won't do it, they just have another set. Some people have rung up and complained because they wanted an illustrated book and I tell them 'pop the bloody cards out... The best sensation is when you open it out, get the book out, pop out the cards one by one and stand them up and start reading the story. It becomes a wee performance. But of course you can only do that once" (D. Elliot, personal communication, 31 July, 2009). 
In his review of the Hunting of the Snark (2006) for the North American Carollian Society, Andrew Sellon (2006) felt that producing the publication as a game was a clever idea but questioned whether a collector would be willing to dismantle the parts of a limited edition work to use it in that way. Elliot also acknowledged this issue in hindsight (D. Elliot, personal communication, 31 July, 2009).

\section{The outreach component of the 2006 PiR Programme:}

McLeod, Doesburg and Elliot were involved in the outreach aspect of the 2006 Programme which included presentations to Design Studies, English and Art History classes. The proposal for the 2006 Programme refers to an intention to hold workshops for these classes but this did not happen due to constraints. Despite this, Kerr was happy with the outreach that was achieved and said that several groups visited the Otakou Press while McLeod and Doesburg were working - giving them the opportunity to see the "process of setting type, inking type and printing" (D. Kerr, personal communication, 30 June, 2009).

\section{Summary:}

The documentation and interviews relating to the 2006 PiR Programme indicated a creative process in which the format of the publication was ever evolving, and as decisions over the form of the illustrations changed, so did the overall format of the publication. Another unique aspect of this PiR Programme was the equal input into the design and layout of the publication by the Printer in Residence and the illustrator. However, as the format of the publication took shape and the text and illustrations were separated, printer and artist ended up working quite separately from each other.

In terms of the PiR objectives, the 2006 Programme seems to have fulfilled all of them. A publication of high quality was produced to deadline and the Programme's participants were involved in some form of outreach to promote the publication and the handprinting process. The poem's popularity generated 
great success in terms of sales, including overseas libraries and individual collectors. 
Case study 3:

The 2007 Printer in Residence Programme 


\section{The 2007 Printer in Residence Programme:}

Twelve poems by Hone Tuwhare; interpreted by seven Dunedin printmakers.

\section{Introduction:}

So far, the 2007 PiR Programme is the only one to have involved so many printmakers in illustrative process, and the only Programme that hasn't been overseen by Kerr.

The printer in Residence was Dr. John Holmes and the contributing artist printmakers were; Marilyn Webb, Mary McFarlane, Inge Doesburg, Simon Kann, Kathryn Madill, Jenna Packer and Olav Neilsen. Each printmaker was given the opportunity to choose and interprete a poem from Hone Tuwhare's Come Rain Hail (1970), which was orginal published in the Bibliography Room.

Rosalind Andrew, with the assistance of Dr. Shef Rogers, was responsible for managing the Programme. Like the 2005 Programme, it overran its initial deadline (August 6th - September 10th) and was not completed till mid-October due to the "complexities of participant's schedules and the difficulties in sourcing some materials" (Andrew, 2008, p.1). Despite some challenges, the publication was produced to a high standard and all copies were sold by the middle of November 2007.

\section{Background to the 2007 PiR Programme:}

An etching press was purchased for the Otakou Press in 2006 and the 2007 Programme "was going to be its big workout" (R. Andrew, personal communication, 9 July, 2009).

Correspondence between Kerr and Roger Steele (of Steele Roberts Publishing Ltd) indicates that the original plan was to use some of Tuwhare's unpublished material for the $2007 \mathrm{PiR}$ publication (D. Kerr, personal communication, January 12, 2007). However, in a subsequent letter to Tuwhare, Kerr says that the decision had been made to "come full circle and create images from Come Rain 
Hail (1970), which was originally published in the Bibliography Room" (D. Kerr, personal communication, April 24, 2007). In this letter, Kerr also refers to the possibility of including Ralph Hotere as one of the participating artists but this was not to be.

The goals for the Programme were developed by Kerr, in collaboration with the Printer in Residence, Dr John Holmes, and the seven local printmakers:

- To produce a limited edition, printed on the Vandercook Proofing Press;

- To provide seminars and practical sessions/workshops for English, Design and Art History students, and other interested parties such as librarians, booksellers, designers and artists;

- To give lectures to classes in Design Studies English and Art History. "Dr Holmes will also give an open lecture for other interested parties" (Kerr, 2007, p.2).

From mid June Kerr was on reserach leave, and the running and monitoring of the Programme was taken over by Rosalind Andrew, the Library's Reference Librarian, and Dr Shef Rogers from the English Department. Catherine Robertson, the Acting Special Collections Librarian, was also a point of contact and assistance for the Printer in Residence and the printmakers (Kerr, personal communication, 7 June, 2007).

Two meetings were held with Andrew, Holmes and the seven printmakers to determine: the format and design of the publication; the selection of the Tuwhare poems; how the publication would be contained and to develop a schedule for the use of the Otakou Press Room by all participants (Kerr, 2007; R. Andrew, personal communication, 9 July, 2009).

"At the end of these meetings we [Andrew and a library assistant] ended up with a long list of things that I had never even heard of and then we had to go off and source them, although many of the printers could tell us 
where.... The specialised inks were some of the most difficult things. I know that I had a library assistant trying to obtain a particular ink and they spent about half a day trying to source it" (R. Andrew, personal communication, 9 July, 2009).

\section{The poem selection process:}

Andrew described the selection process as "not a particularly organised

procedure - based more on first dibs than anything - but nevertheless, it worked out ok and no one seemed to choose the same poems" (R. Andrew, personal communication, 9 July, 2009).

Olav Neilsen was not familiar with Hone Tuwhare's poems at the time but felt that this was "a nice way to approach the project because everything was fresh to him" (O. Neilsen, personal communication, 31 July, 2009). He ended up selecting Rain because it was his partner's favourite poem (which she had written inside a journal as a Christmas present to him the previous year) but had no idea that the poem had been written by Tuwhare or how popular it was in New Zealand. Once he realised its popularity, he admitted that "it did put a bit of pressure on" ( 0 . Neilsen, personal communication, July 31, 2009).

The poems selected by the other printmakers from Come Rain Hail (1970) were: Haiku - Marilyn Webb

Ru-au-moko - Mary McFarlane

Flood - Inge Doesburg

Tangi-hanga - Simon Kaan

Hotere - Kathryn Madill

Child coming home - Jenna Packer

\section{The planning and design of the publication:}

Holmes played a leading role in determining the design, format, layout, colours and enclosure for the publication (R. Andrew, personal communication, 9 July, 2009). 
“... we got the twelve poems and some were short like Haiku and others were much longer - and it was a matter of working out how big a piece of paper we could get them on because I wanted to keep the same type face and size for every poem" (J. Holmes, personal communication, 30 June, 2009).

During the interview, Holmes described how spreadsheet software can help with type-setting; making it easier to determine the spacing between letters, words and lines, as well as visualising the overall layout of the text (J. Holmes, personal communication, 30 June, 2009). In terms of his printing style, Holmes believes that text "likes to have lots of space around it and between the lines" (J. Holmes, personal communication, 30 June, 2009). For this publication, the challenge was to achieve that space while also ensuring that the type would remain at a legible size.

Andrew said that "John also came up with the clever way of presenting the title" (R. Andrew, personal communication, 9 July, 2009), which can be seen below.

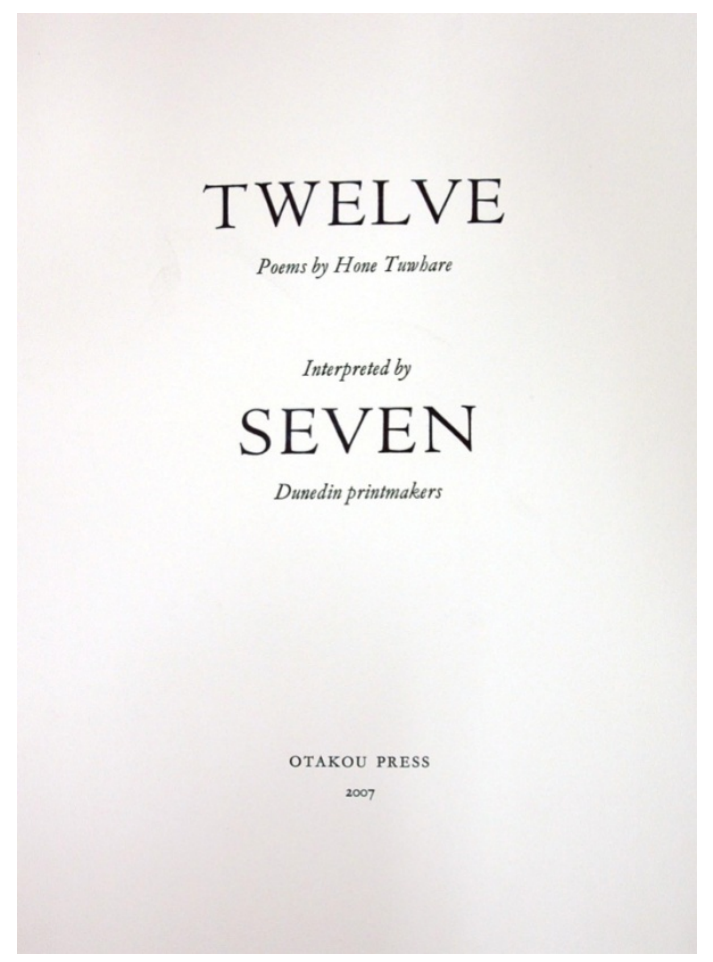

Figure 10: Title page for Twelve Poems (2007) 
The original plan was to bind the printed sheets together and present the publication as a book in codex form. However, Holmes felt the 'buyers' might end up wanting to frame the images so it was decided to keep the pages separate but house them together in a box (J. Holmes, personal communication, 30 June, 2009). Don Tobin, at the University of Otago Library Bindery, produced the box from archival, acid free card and Holmes produced the title label (Kerr, 2007).

\section{The use of the Otakou Press Room:}

Although the Otakou Press was used during this Programme, Holmes printed the majority of the text from his home. Due to work and travel commitments, Holmes worked on the project part-time and it was much easier for him to fit the printing around his work commitments if he was working on the publication from home. Holmes also felt that he "could do a better a better job" working from his own space (J. Holmes, personal communication, 30 June, 2009).

It was not only the Printer in Residence who utilised his own equipment. As it turned out, only four of the printmakers utilised the Otakou Press room to print even some of their images (Inge Doesburg, Olav Neilsen, Jenna Packer and Mary McFarlane).

The first of the printmakers to use the Otakou Press facilities became faint with the ink fumes and the lack of ventilation in the print room. To ensure the printers were not at risk of enhaling any toxins, the Chemistry Department staff undertook tests of the air in the print room during the printing process. To do this, Andrew wore a monitor that tested the fumes she was inhaling while she printed in the press room and to everyone's relief the test results were positive (R. Andrew, personal communication, 9 July, 2009).

"The extractor system was checked and recalibrated and a Chemsearch Analytical Report was done. The results showed no cause for concern" (Andrew, 2008 p.2). 


\section{The process of interpretation:}

The process of interpreting a poem as an image was a new experience for some of the printmakers. Neilsen had never interpreted a poem through his printmaking before and he said that it took him a while to "refine his ideas and work out what he was going to do with the poem" (O. Neilsen, personal communication, July 31,2009 ). He found that his initial ideas were quite literal, such as, "Hone Tuwhare in his house with rain on the roof or the skin" (0. Neilsen, personal communication, 31 July, 2009). In the end however, Neilsen found it best to use his own connection with the poem as the inspiration for his interpretation (see figure 11).

"...so I drew a picture of where I was when I first read the poem, which was in a tent at Christmas with the rain pouring down - it all seemed so appropriate.... It is a really simple idea but something most Kiwis can relate to" (0. Neilsen, personal communication, 31 July, 2009).

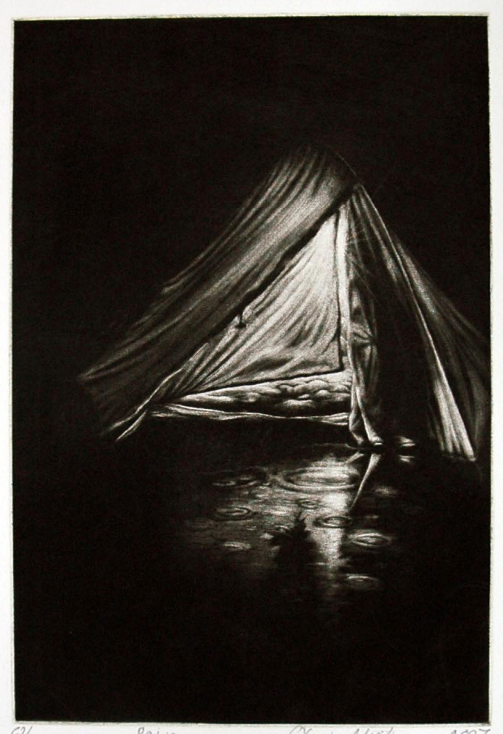

Figure 11: Olav Neilsen's interpretation of Hone Tuwhare's poem Rain. 
Inge Doesburg was another contributing printmaker to this publication, and although not discussed in regards to this publication in particular, like Neilsen, she referred to the need to portray her personal experience of the text:

"Psychologically, it is a different way of dealing with a visual image. You don't want the image to be a picture of the text - you aren't regurgitating what has been said already.... instead you are interpreting your feeling about the text and it is possibly quite different from what the text is actually telling you..... it's not so much an illustration as an addition to the text. It adds to the reader's / viewer's experience" (I. Doesburg, personal communication, 15 July, 2009).

All in all, Doesburg found this process "very rewarding" and felt that in some respects the experience had relaxed" the way she regards her "own artistic process" (I. Doesburg, personal communication, 15 July, 2009).

As has been highlighted, the seven printmakers were given free rein over the way they chose to interpret their chosen poem. They were also had full control over the printing techniques they wished to employ, as a means of enabling them to portray a unique and personal connection with the poem.

Neilsen had initially planned to use copper plate because of the detail, colouring and textures that could be achieved in the prints. However, the metal proved too soft for producing multiple copies of a high quality. The compromise was to use stronger brass plates and Neilsen was so impressed by the outcome that he has continued to use them, even for one-off images (O. Neilsen, personal communication, 31 July, 2009).

\section{The collaborative nature of the 2007 PiR Programme:}

Although it was more convenient for the Programme's participants to work from their own studios, it did affect the level of group collaboration. In contrast to the 2005 and 2006 Programmes, interaction between the Printer in Residence and 
participating printmakers was confined to two group meetings at the beginning of the Programme.

"We did our own thing really. We only got together once or twice, got ideas from each other and I told them what I could do........ I wasn't in the press room very often and most the printmakers did their work in their own studios" (J, Holmes, personal communication, June 30, 2009).

That said, Doesburg and Neilsen expressed a positive view towards the Programme and the opportunity it provided to collaborate on a group work. Doesburg felt that there was some sense of community among the printmakers and it was expressed in the finished product:

“... we didn't get to print altogether, as we did own work separately, but I do think there is a commonality coming through in the works. And some artists did print together like Kathryn [Madill] and Mary [McFarlane] and myself and Jenna [Packer]" (I. Doesburg, personal communication, 15 July, 2009).

"... it [the collaborative aspect of the Programme] was still there in that the printmakers were communicating with one another.... and the artists did talk about how much they enjoyed the collaborative side. ..... when I've run into any of them they ask if there will be another project they could be involved in" (R. Andrew, personal communication, 9 July, 2009).

For Andrew, one of the most enjoyable aspects of managing this PiR Programme was the opportunity to be the 'clean hands' for those printmakers that utilised the Otakou Press. She found it a great experience because it enabled her to "learn more about the printing process and about them [the printmakers] as artists" (R. Andrew, personal communication, 9 July, 2009). 


\section{The outreach component of the 2007 PiR Programme:}

Interviews and Programme documentation suggest it was a struggle to meet the outreach objectives outlined in the initial proposal. In preparation for the proposed workshop sessions, Andrew negotiated a schedule with the various printmakers for using the press room. This was emailed to the English, Design and Art History Departments so they could arrange class visits. However, it soon became apparent that the schedule was not being followed and class visits had to be abandoned.

"I don't think any of the printmakers except for one, once, ever arrived on schedule. Due of this, advertising the schedule to the Departments was abandoned because it was essentially a hollow promise" (R. Andrew, personal communication, 9 July, 2009).

Andrew believed the "lack of place based activities" (R. Andrew, personal communication, 9 July, 2009) negatively affected the Programme's ability to promote the Otakou Press and attract the numbers visiting the press room (Andrew, 2008 p.3).

The despite these disappointments, there was still an eagerness to perform some sort of outreach and this was done in the form of a public talk in the Humanities Divisional Common Room, October 10, 2007:

"Among the 30 attendees were Keith Maslen and Shef Rogers, both deeply involved with print and the Otakou Press. Four artists (Olav Neilsen, Simon Kaan, Jenna Packer and Bridgitte Kammlein - Marilyn Webb's assistant) and the printer shared their experiences of the creative process throughout the project" (Andrew, 2008 p.3).

"Jenna Packer spoke incredibly eloquently about the process of creating an image and the link between it and the poem - and that was very interesting to a number of the English academics because it was a completely different 
way of looking at words and interpreting them" (R. Andrew, personal communication, 9 July, 2009).

\section{Pricing the 2007 PiR publication:}

The report of this PiR Programme by Andrew (2007) notes that some of the printmakers believed the pricing of the publication was too low "in relationship to their profiles and their works worth" (Andrew, 2007, p.3). For Andrew this was one of the biggest challenges of running the Programme and one she knows Kerr has also faced since the Programme has been operating (R. Andrew, personal communication, 9 July, 2009):

"They [the printmakers] have quite a lot of difficulty in realising that the Programme is a different concept. We are not selling individual pieces [of art work]. It's about creating something that would never have been created otherwise and using group synergy to do it. It's not about the money side of it - it's about providing people with the opportunity to buy things they would not be able to otherwise...... it is not about creating a collector's entity, it's about the process" (R. Andrew, personal communication, July 9, 2007).

\section{Promotion of the publication:}

The 2007 PiR publication was publicised internally; via the University's Marketing and Communications Division, the OU Library listserv and the University Staff Bulletin and externally, through national groups such as LIANZA and on the University Library homepage (Andrew, 2008 p.2).

A short but favourable review of Twelve Poems (2007) also appeared in the Christchurch's Weekend Press (24/11/07) but by then all copies of the publication been sold. A wazgooze to celebrate both the completion and success of the 2007 Programme was held in the large Central Library Staff Room on November 15. 
Hone Tuwhare was able to see the finished publication, despite ill health, and was pleased with the result - he even signed some copies (D. Kerr, personal communication, June 30, 2009).

\section{Who purchased the 2007 PiR Publication?}

Library holdings on Te Puna indicate that Twleve Poems (2007) was purchased for library collections throughout the New Zealand and they include: Massey University Library, Auckland University of Fine Arts Library, Wellington City Libraries, Auckland Public Library and Dunedin Public Library. The purchase list indicated that a significant proportion of the purchasers were also University or University Library staff.

\section{Summary:}

The 2007 PiR Programme was the first to involve eight participants on a project and a number of challenges arose from this unique situation. Andrew experienced difficulties encouraging all seven printmakers to use the Otakou Press facilties and initial goals to allow for class visits and practical sessions had to be abandoned. Due to the numbers involved, the scheduling of even practical tasks, such as "getting all the printmakers in with their prints," became a challenge (R. Andrew, personal communication, July 9, 2007):

'.... and no one was aware that John [Holmes] was making a colophon and it came in after it was all collated.... Luckily Donald was back by then and was able to make sure it got placed where it was supposed to be" (R. Andrew, personal communication, July 9, 2007).

Since the printmakers and Printer in Residence opted to work from their own spaces, there was not enough on site activity to foster the levels of outreach or collaboration experienced on other Programmes. Despite this, two printmakers involved in this Programme were positive about the experience and believed a sense of community with the other printmakers did exist (I. Doesburg, personal 
communication, 15 July, 2009; O. Neilsen, personal communication, July 31, 2009).

Although there were a number of challenges involved in co-ordinating such a large group of participants, the 2007 PiR Programme achieved its proposed goals and a high quality, hand-made edition (receiving favourable reviews) was completed. 


\section{What themes have emerged from the data gathered?}

As is evident from the case studies, several key themes emerged during the data gathering and analysis phase of this research - they are discussed in greater depth below:

\section{Collaboration within the PiR Programme:}

Collaboration is a pervasive theme throughout the PiR Programme's short history and is perceived as essential to the success of the Programme by those interviewed.

For Kerr, this collaborative component is "one of the best things to come out of the programme.... The tussling, the creative juices that flow, or don't flow and that you've got to resolve something with the techniques and supplies you've got" (D. Kerr, personal communication, June 30, 2009).

Collaboration also operates at the broader level of the Programme's support by the University. As is outlined in the section 5 of this study (The University of Otago's Bibliographic Press and the Printer in Residence Programme), the PiR Programme is supported by a three way partnership of the Library, English Department and Design Studies Department. Although the PiR Programme has not required the funding support set up by this collaborative relationship, Kerr still considers the support it provides to the Programme as very important, and ensures all parties are consulted about each Programme proposal (D. Kerr, personal communication, June 30, 2009).

Although Kerr often comes up with the ideas for each Programme (not necessarily by choice), he encourages a collaborative process among the Programme's participants over the design and production of each publication. This collaborative process tends to vary from Programme to Programme due to the unique characteristics of each project. For instance, the 2005 and 2008 Programmes included no printmakers and of benefit to both Programmes was the flexibility this afforded in the face of change. 
Loney chose to work on Open Sky (2008) alone and this seems to have given him the flexibility to adjust his initial plans for the publication in terms of its content and its design:

“.... And Joan Dutton came into the printery soon after my arrival with a small sheaf of unpublished typewritten haiku, or short poems based loosely on the haiku form. This was entirely unexpected, and meant I had to look again to see how these new words might alter the selection of lines I had already made.... Within 24 hour of Ms Dutton's visit I had a new text to print" (A. Loney, personal communication, August 5, 2009).

All of the printers and printmakers interviewed for this study, referred to the collaborative process of producing the PiR publications as a highlight of their involvement in the Programme:

"The design of the publication is collaborative in that you have to think of someone else as well and so you are working together for the greater good" (I. Doesburg, personal communication, 15 July, 2009).

"You can beaver away for years and feel that you are a lone voice in the wilderness, but to have someone say what you are doing is valid, or 'we'd like you to be involved' is really nice... it makes you feel part of a community" (I. Doesburg, personal communication, July 15, 2009).

“... [artists and printmakers] don't necessarily understand the constraints of the handpress and setting print. However, it is good to have that handson involvement with them. If an artist is contributing to a book it is good that they have some sort of idea of the whole process - a hands on contribution rather than just ideas." (T. McLeod, personal communication, July 6, 2009).

Holmes and McLeod referred to some of the disadvantages a of a collaborative of process. Holmes said group collaboration can extend the decision making 
process, and that can be a problem if there is a looming deadline on ordering paper, for example. However, Holmes also felt that it was important to let that decision making process run its course to ensure the correct decisions were made (J. Holmes, personal communication, June 30, 2009). McLeod, who was also supportive of a group collaboration process, felt that it was equally important to ensure it had a structure and direction to it to ensure the publication's design didn't go off track (T. McLeod, personal communication, July $6,2009)$.

\section{The outreach component to the PiR Programme:}

All of the PiR Programme proposals viewed for this study stated that the Printer in Residence was expected to hold seminars and practical sessions that demonstrate the letterpress printing process (Kerr 2005a; Kerr 2006; Kerr 2007; Kerr 2008). This outreach was the most important aspect PiR Programme for Kerr because through these talks and seminars students became aware of the Otakou Press and the historical process of printing books by hand:

"...We should show them [students] how the machines operate - show them that there was a life before computers and the delete button. We can show them that printing is an honourable tradition. It is not easy. It can be tedious and hard work but it is also fun.... I remember a lass seeing some of Tara's work, which he had bought down [from Auckland] as examples of what could be done, and she said 'the man's changed my life. If I only I had known about this before.' The machines have a huge impact on people" (D. Kerr, personal communication, June 30, 2009).

"...... it is important to have an understanding of printing right back to Gutenberg's invention of movable type - that there was a whole other method to book making before computers that lasted 500 years, and involved setting individual letters and the spaces in between by hand.... It is very important that people understand how information was 
disseminated right from Gutenberg's day" (T. McLeod, personal communication, July 6, 2009).

Dr Shef Rogers felt that he, and the English honours students he taught, benefited from the talks given by each Printer in Residence and also through direct observation of the Printer's at work:

"I was able to watch Alan Loney more than some of the others and was particularly interested in his method of holding the paper to the tympan and in dampening the paper. I have also benefitted from seeing John Holmes' Excel spreadsheet calculations of points and layout for each page before he sets, and from learning to sew modest bindings on Brendan's books, though they were not technically PIR projects. It is always fun being around and helping out where one can" (S. Rogers, personal communication, August 3, 2009).

Holmes and McLeod also commented that the location of the Otakou Press contributed to a more indirect awareness of the PiR Programme and the letterpress printing process:

"People come in to see what is going on, they can look through the window and see what is happening, see the process. Not a lot of students come in surprisingly but Library staff and other people who look at the Special Collections exhibitions often come round" (T. McLeod, personal communication, July 6, 2009).

“...It is there [the handprint process]if people know what they are looking at but I know a lot of people probably don't know what they are looking at when they see these ornate presses, and then occasionally, fussy old people doing funny things in there. That's why I liked to hang up what I'd been doing so people could see" (J. Holmes, personal communication, June 30, 2009). 
During many of the Programmes, visitors were encouraged to enter the press room and ask questions while the Printer was working. In most cases the Printers didn't mind this situation because, as O'Brien put it, "it broke up the hard work involved in getting the projects done" (B. O'Brien, personal communication, July 8,2009$)$. However, it could also be a challenge if they were involved in tasks that required full concentration. McLeod, for example, often found he had to return to the press room in the evening (T. McLeod, personal communication, July 6, 2009).

In order to get Open Sky (2008) completed, Kerr found that Loney "was firm about establishing times when people could talk to him so he could have periods of uninterrupted work. That was a good learning experience for us because although it is good to have people drop by with an interest in what is going on, it can stop work and cause interruption" (D. Kerr, personal communication, June $30,2009)$.

All in all, the Printers in Residence and printmakers interviewed for this study felt the outreach activities were a positive experience - for themselves and the students who attended.

"I teach, so I enjoy that side of sharing skills...... I have bought in my own students from the art school and they were really taken with it. Donald also gave a talk about the books [PiR publications] which provided a really good connection" (I. Doesburg, personal communication, 15 July, 2009).

As outlined above, this outreach aspect is an important aspect of the PiR Programme overall. However, as is visible from the case studies, the level to which this has been achieved varies from programme to programme. The 2007 Programme seems to be the most underperforming, with Andrew giving it " 2 out of 10 " in terms of outreach and in terms of spreading awareness of "the print room and the printing process" (R. Andrew, personal communication, July 9, 
2009). Although none of the intended class visits/workshops eventuated, "John [Holmes] posted the pages he printed in the print room so people could see what was being done" (R. Andrew, personal communication, July 9, 2009) and a successful talk was given by the Printer in Residence and some of the printmakers once the publication was completed.

\section{The 'hand-crafted' book versus the mass produced book:}

The term 'hand-crafted' was used by virtually all the study participants when describing the characteristics and quality of the PiR publications in comparison to readily available mass produced books.

During the interviews, Kerr, Holmes, McLeod and O'Brien referred to the many tasks that determine the hand-crafted look and feel of a book: the planning and design, the folding and ripping of large sheets of paper, the type-setting, the inking, printing and drying of each page before they are collated and then stitched into a handmade cover (J. Holmes, personal communication, June 30, 2009; T. McLeod, personal communication, July 6, 2009; D. Kerr personal communication, June 30, 2009).

Performing these steps by hand produces qualities that distinguish private press editions from mass produced books, and they are the uniqueness of each copy and the physical feel of the book which McLeod referred to as "that tactile impression that you get from the letterpress that can't be achieved by litho or digital printing" (T. McLeod, personal communication, July 6, 2009).

"Often as hand-printer you aim to have everything printed as cleanly as possible so that it almost at the standard of a machine printed thing, but if you are going to do it that way you might as well get a machine to do it. It is the small imperfections and evidence of the printer's hands that make it special..... guess I could have made a machine [litho or computer based] version of it [Pine, 2005] but the process of inking, wiping and brushing the type to get texture of the ink on the page was very important to the feel 
of the work. I think if I produced the poems on a machine I would have lost the effect that the artist [Hotere] would want" (B. O’Brien, personal communication, July 8, 2009).

When Elliot saw the printed version of his illustrations for Hunting of the Snark (2006), he was pleasantly surprised to find that none of them had come out the same because it "gave each one an individual quality" (D. Elliot, personal communication, July 31,2009 ).

From his experience of contributing illustrations to larger commercially produced publications, Elliot felt that the visual qualities associated with handcrafted books have recently been mimicked to attract the eye of consumers, especially in the area of Children's literature. As an example, Elliot referred to the look of the Lemony Snickett series (D. Elliot, personal communication, July 31, 2009).

However, even though the digital printing process can mimic the 'look' of handcrafted publications, it will not be able to mimic the 'feel' of the handprinted page or the imperfections that give each hand-crafted edition its own unique character (T. McLeod, personal communication, July 6, 2009; D. Elliot, personal communication, July 31, 2009).

Another distinction between the handprinting and digital printing is that the handprinting process always involves working within the limitations of the equipment and type available (McLeod, 2009; O'Brien, 2009; Holmes, 2009; Loney, 2009; Kerr, 2009). When faced with this situation in regards to the Otakou Press, McLeod, O'Brien and Holmes chose to utilise some of their own type to achieve the design they wanted. Loney (2009) however, made the deliberate decision to work within the limits of the Otakou Press's resources to: a) produce a book that only he could make, and b) could only have been made at Otakou Press (A. Loney, personal communication, August 5, 2009). 


\section{Art collector's edition or private press book?}

Of the participants asked in this study, all felt that the terms fine printing or book arts could be applied to the PiR Programme and its associated publications. A web search (on "book arts" and programmes) reveals that the objectives of the PiR Programme place it comfortably amongst the many book arts programmes listed worldwide. The skill of printers and printmakers also make the PiR publications excellent examples of fine printing when compared to hobby private press outputs.

Yet despite these shared similarities, Kerr has steered the PiR Programme away from these associations:

"I am more comfortable with seeing the Programme as part of the private press letterpress tradition, and regarding the publications as limited edition private press books" (D. Kerr, personal communication, June 30, 2009).

McLeod could also see the PiR Programme as part of "that history of producing examples of fine printing" (T. McLeod, personal communication, July 6, 2009) but he felt that the term 'private press' was more accurate because it is traditionally associated with letterpress printing. In contrast, fine printing could be applied to all other types of printing (T. McLeod, personal communication, July 6, 2009).

Although the artists, printers and printmakers involved in the Programme so far are also respected in the local art or book collector market, this is not the intended audience for the PiR publications. And for Kerr, the publications are not the most important outcome of the Programme:

"The publication is almost a by-product; using the presses and educating people in how the presses work are just as important. You want to satisfy the one hundred people who have bought the product but it [the PiR Programme] is not just about the book as a commodity" (D. Kerr, personal communication, June 30, 2009). 
A similarity between the PiR Programme and movements like the livre d'artist (Drucker, 2000) is that they both "offered the possibility to produce work which they [the artists] wouldn't or couldn't normally produce themselves" (Drucker 2000, p.378; D. Elliot, personal communication, July 31, 2009; B. O’Brien, personal communication, July 8, 2009; I. Doesburg, personal communication, 15 July, 2009; O. Neilsen, personal communication, July 31, 2009).

“.... most of the illustrations I do are for children's book, and although this is still a children's book, it's getting a different audience and a sense of quality to it. This is where I would like to be all the time if I could... to have my work put in a more fine art context rather than popular book and general publishing" (D. Elliot, personal communication, July 31, 2009).

However, unlike livre d'artiste, the PiR Programme is not profit driven, it is not a product of the art industry, the publications tend to utilise unpublished material, are not directed at the art market (Drucker, 2009) and lastly, the images in PiR publications tend to be secondary to the text by performing an illustrative function (Adamowicz, 2009) .

“The $[\mathrm{PiR}]$ books stand up as literature in their own right. People don't have to look at them as collector's items or art; they fulfil all the criteria of what a scheme like this should do (B. O'Brien, personal communication, July 8, 2009).

In summary it seems that although the PiR publications display the craftsmanship that could make them popular items on the art market, it is not the intention of the PiR Programme to produce art works. 


\section{Future considerations for the PiR Programme:}

The interview participants involved in more than one PiR Programme were asked whether they felt the PiR Programme was facing any challenges or constraints. The issues they raised are discussed below:

\section{The future management of the PiR Programme:}

Although the PiR Programme has the support of the University Library, English and Design Studies departments; the organisation, running and success of the Programme has, for the most part, been the responsibility of Donald Kerr.

"It's all down to Donald [Kerr]. His position, his contacts and his enthusiasm for this is remarkable. He is a huge asset. He has created the type of collaborative environment that gets people continually involved" (D. Elliot, personal communication, July 31,2009 ).

"...it is his contacts, his identification of really current, salient points" that make the publications so popular. (R. Andrew, personal communication, July 9, 2009)

Kerr is happy with the way the PiR Programme is operating at the moment (as were the other interview participants in this study) but he questioned whether leaving the running of the Programme to one person was sustainable in the longterm. Kerr felt that a team-based approach would be more suitable and would provide the necessary staffing resources to allow the Programme grow and evolve (D. Kerr, personal communication, June 30, 2009).

"I hope that the Programme continues and isn't just left to hang on one person. I would be great if a team take it over - if others could have a greater input suggesting content and texts..... It needs a team if it is to grow (i.e. longer residency periods, or classes and instruction to interested people). It needs more resources than just one person" (D. Kerr, personal communication, June 30, 2009). 
Although hopeful that the Programme would continue to evolve, Kerr was also aware that such plans would require additional staffing - something that may not be a priority for the Library in the current economic climate.

Developing 'robust' policy and procedures for the PiR Programme:

As stated previously, the PiR Programme has managed to remain self-funding in that the sales from each Programme publication have covered printer's fees, accommodation, travel and the required printing materials. However, Andrew pointed out that what wasn't covered by each Programme was the Library staff time that was diverted from other library operations (including Special Collections), to allow each Programme to operate successfully (R. Andrew, personal communication, July 9, 2009). This additional staff support could take the form of providing additional coverage in Special Collections (freeing up Kerr to manage the Programme) or assisting in preparations for each Programme (such as ripping paper).

As a result, each year Kerr must submit a proposal for the PiR Programme that requires approval from the University Librarian and the Library's Executive Management Group. To date, no PiR proposal has been declined but both Andrew and Kerr referred to "a period of uncertainty every year when we wonder whether the next one [PiR Programme] will be approved" (R. Andrew, personal communication, July 9, 2009).

Although extremely supportive of the PiR Programme, Andrew expressed some concern in relation to the Programme's documentation, feeling that some of the uncertainty experienced each year could be lessened if the PiR Programme was to develop "robust procedure that could stand up to scrutiny" (R. Andrew, personal communication, July 9, 2009). Part of this documentation included a structured business plan and set of selection criteria.

As has been highlighted previously in this study, the recruitment of the Printer in Residence for each Programme has tended to be an informal affair, and this has 
been successful in large part due to Kerr's prior connections with the participants. However, if the Programme is to recruit printers from outside New Zealand, a much more structured selection and recruitment process may need to be in place.

At the time of this study Andrew and Kerr were in the process of reworking the documentation relating to the selection criteria and the expected outcomes to be included in the contract with each Printer in Residence. It is interesting to note that at present there are no selection criteria, or documentation, relating to the recruitment of the printmaker(s) for each PiR Programme.

The Programme's residency period:

At present the length of each PiR programme is approximately five weeks However, there was some discussion during the interviews over whether the Programme would benefit from lengthening this.

At the end of the 2005 Programme, O'Brien recommended that the PiR Programme should have a longer residency period (B. O'Brien, personal communication, July 8,2009 ). Although confident at the beginning of the Programme, O'Brien found it impossible to complete the two publications planned without further extending his residency and then making a subsequent trip to Dunedin. Apart from the PiR pilot in 2003, this was the only PiR Programme to attempt to produce two publications.

Kerr also referred to lengthening the residency period for the Programme in the future. For him, extending the residency period could make the programme more attractive to overseas printers who might be reluctant to travel to New Zealand and take up such a short residency (D. Kerr, personal communication, June 30, 2009). This opinion was influenced by a proposal from the American printer Gabriel Rummins:

"Some years ago the great guru of the iron printing press, Gabriel Rummins, was in Dunedin. He fell in love with the place and he sent me a 
proposal that would have him in the press room for nine months creating four books (which would sell because he is the guru, so it would cover the costs). He would also run a course and instruct people in using the presses" (D. Kerr, personal communication, June 30, 2009).

Although Kerr would like to think that a lengthened residency could be possible in the future, he felt that at present there were just not enough resources (especially in terms of staffing to support longer residences). This opinion was also voiced by Andrew.

“...I couldn't handle nine months, even six months, there just isn't enough resources to monitor the thing. The 4-5 week period is about as much as I can handle at the moment but I would like to see it grow" (D. Kerr, personal communication, June 30, 2009).

"Any plans to lengthen the period of the PiR Programme would require completely different staffing. As a library I think there would need to be that desire to put a lot resources into the PiR Programme, and at the moment, I am not sure there is that desire" (R. Andrew, personal communication, July 9, 2009).

The limited number of skilled private press printers in New Zealand:

All of the Printers in Residence interviewed in this study referred to the small pool private printers in New Zealand and whether this could place constraints on the future of the PiR programme, or at least limit the variety of people involved in the Programme.

Looking back at past Programmes it is clear that the PiR Programme has depended on the return of printers such as McLeod and Holmes. Kerr acknowledged this situation and felt that may be some fresh faces were needed. However, he also felt that the printers being utilised were highly skilled and because they were well experienced with the Otakou Presses, some of the risks associated with the completion of each new Programme were lessened: 
"Maybe we should break the mould sometimes and bring in someone else so we don't have that reliance on 'those printmakers, or these printers,' but unfortunately there aren't that many good handcraft printers around, and the printers and printmakers we have used are very very good... they also know the press's foibles and their constraints, and the limited resources available to them in the print room" (D. Kerr, personal communication, June 30, 2009).

Although Kerr is aware of other private press printers in New Zealand, there was a concern that they are somewhat "untested" when it comes to producing publications to a strict deadline or utilising press equipment that is not their own (D. Kerr, personal communication, June 30, 2009). The need for applicants to provide samples of their work would be a necessary aspect of the standard selection criteria and procedure that Andrew advocates for the Programme (R. Andrew, personal communication, July 9, 2009).

Despite (or maybe because of) the short residency period offered, Kerr has been approached by interested printers outside New Zealand - primarily in Australia. He hoped that this would become a regular reality in the future but as with the 2008 Programme, the costs associated with the printer's travel would need to be absorbed by the publications produced (if the Programme was to be selffunding).

\section{Perceived success and value of the PiR Programme:}

As previously outlined, the objectives of the PiR Programme overall are to promote the facility that is the Otakou Press; to educate people in the process of letterpress printing and produce a handprinted book on a specified theme. So far, all the PIR Programmes have met these objectives to varying degrees. (Even the 2007 Programme managed to provide some form of outreach activity through an open seminar). 
The perceived value of the PiR Programme was expressed by all the participants in this study. At the broadest level, the Programme was seen to contribute to the regions private press culture by broadening awareness of the Otakou Press facility and the letterpress printing process in general. Of those participants who were aware of the history of the Otakou Press, all appreciated Kerr's aim to continue Maslen's intentions for the press room facility by incorporating instruction with the production of a publication. Kerr reiterated this and said that "despite the change in name, it is still a continuance of what was started by Keith Maslen" (D. Kerr, personal communication, June 30, 2009).

Keith Maslen expressed his encouragement of the PiR programme during a speech to mark the press room's name change in 2005:

“... the Bibliography Room once had times of rich activity, and I am delighted to think that good times will come again, perhaps in ways that I never thought of or could not have bought to pass" (K. Maslen, personal communication, December 13, 2003).

O'Brien and McLeod felt that the Otakou Press would, along with other bibliographic presses operating in New Zealand, play an important part in ensuring that letterpress printing process of a high quality continues. Both printers referred to 'the handful' of private presses in New Zealand's history that focused on producing editions of local content to a high standard (such as Caxton Press, Pelorus Press and Pear Tree Press) and both felt the university bibliographic presses were in the best position to ensure that continues ( $T$. McLeod, personal communication, 6 July, 2009; B. O’Brien, personal communication, July 8,2009 ); especially since setting up a private press is now much harder due to the scarcity of resources :

"there are really no parts for the old presses now - they were phased out in the 1950s and 1960s" (T. McLeod, personal communication, 6 July, 2009). 
O'Brien felt that the funding and support given to local private printers, through residencies such as the PiR Programme, could become more important, especially as it gets harder and harder to run a private press: "even people like Tara [McLeod] need support and funding to carry on projects" (B. O’Brien, personal communication, July 8, 2009).

Kerr's promotional strategy of targeting New Zealand libraries through listservs (D. Kerr, personal communication, June 30,2009) has allowed the publications to reach a wider audience than was necessarily anticipated. In addition, their comparatively low price has made it possible for a wider audience interested in private press books (including small libraries) to become purchasers of a New Zealand limited edition.

At the level of the University of Otago Library, the PiR Programme was perceived as having raised the profile of the Library and its Special Collections throughout the University community (R. Andrew, personal communication, July 9, 2009). The PiR Programme has also featured in the Library's Annual Reports (2003, 2004, 2006 and 2008) as an example of the Library's success and wider community activity.

At the level of the individual participants, the PiR Programme was viewed as a valuable opportunity to become involved in producing publications that might never have had produced otherwise (D. Elliot, personal communication, July 31, 2009, I. Doesburg, personal communication, 15 July, 2009; O. Neilsen, personal communication, July 31, 2009). O'Brien and Elliot referred to the difficulties involved in setting up these types of projects on an individual basis and that "it really needs the co-ordinating centre which is Donald [Kerr] and the University Library" (D. Elliot, personal communication, July 31, 2009).

His residencies at Otakou, Wai-te-ata and Holloway Press had provided O'Brien with the opportunity to work with artists and poets on projects that may not have been done otherwise (B. O'Brien, personal communication, July 8, 2009), as 
well as the security of working on a project where the funding was not his responsibility - allowing for a bit more scope for creativity and experimentation (B. O'Brien, personal communication, July 8, 2009). O'Brien also referred to the promotional side the PiR Programme in this regard (B. O'Brien, personal communication, July 8,2009 ). He found it a relief to not have to worry about the promotion of the publication and spoke of the printer's nightmare "of no one buying what you've printed." 


\section{The lifecycle of PiR publications}

This chapter explores the PiR Programme in terms of Adams and Barker's (1993) model of a book's lifecycle.

\section{A New Model for the Study of the Book:}

The model published by Adams and Barker (1993) is a modified version of Robert Darnton's Communication Circuit Model, published in 1982 and revisited in 2007 (Darnton, 2007). Although Adams and Barker use the term the 'bibliographical document,' which allows for a consideration of other material produced by printing firms (Darnton, 2007 p.502), their model concentrates primarily on books. Essentially the model outlines the five events (publication, manufacture, distribution, receipt and survival) that occur during a book's 'life' (its production and function or usage) and the social, economic, political, legal, religious and intellectual pressures that can affect these events (Adams and Barker, 1993; Finkelstein and McCleery, 2005; Howsman, 2006).

The following chapter discusses the events outlined above in relation to the PiR Programme's publications. The data gathered during this study suggests that PiR publications experience (or will experience) similar events in their life-cycle. However, in comparison with today's commercial publishing, it would seem that many of these events become blurred because they are taking place in the same location and involve the same group of people. In contrast, the same events might take place in other parts of the world with regards to commercially published books (Greco, 2005).

\section{Publishing:}

The desire of the author or publishing agent to see a piece of text copied and transmitted to others is the first event in a book's lifecycle (Adams and Barker, 1993). In the case of PiR Programme, Kerr is the publishing agent. He uses the criteria of readability, local significance, and timeliness to select (or commission - 
in the case of the 2009 PiR Programme) texts, and most often utilises previously unpublished material.

The perceived profit of the texts selected for publishing is also part of the first stage in Adams and Barker's model (1993). For the PiR Programme the perceived profit is 'non-commercial'. The measure of success is the ability of the completed publication (and the Programme associated with it) to raise awareness of the Otakou press and the letterpress printing process in general. Monetary profit is not an aim of the PiR programme because it operates on a cost recovery basis within a non-profit making institution (the University Library). If the PiR Programme did not remain self-funding (which was not expected when the Programme was piloted) the three way partnership of the University of Otago Library, English Department and Design Studies Department is designed to cover any remaining costs.

In addition, the publishing stage includes decisions based around the preservation of the book and the information being transmitted (Adams \& Barker, 1993, p.16). Commercial publishers tend to address is issue by producing copies on mass utilising cost-effective materials (Greco, 2005). However due to its small print run, the PiR Programme focuses on the longevity of each publication by utilising high quality long lasting materials.

\section{Manufacture:}

Stage two involves decisions over the look and feel of the book. In commercial publishing (and non-commercial to a lesser degree), all aspects of the book's manufacture; the design, layout, materials and technologies utilised ultimately determine the items retail price (Adams \& Barker, 1993).

The design and manufacture of a book can be completely separated (physically) in the commercial printing process. In contrast, the design and manufacture of the PiR publications is merged into one process. Both phases are the primary role of the Printer in Residence and both take place in the print room - sometimes at the same time (as was seen during the 2006 PiR Programme). With the exception 
of the cards and feet for the 2006 publication and the polymer blocks for 2005 publications, no aspects of the manufacture are outsourced.

Much like commercial publishing, Kerr feels that the inclusion of illustrations in the PiR publications can enhance the text and increase the saleability of the publication (D. Kerr, personal communication, 30 June, 2009). However in terms of the overall manufacture of the PiR publications, the printmakers and artists seem to play a greater role in determining the type of image, its layout in the publication and collaborate with the Printer in residence in overall design of the publication.

The binding of the PiR publications has progressively become the responsibility of the University Library Bindery. Initially the Bindery only provided the necessary materials to the Print in Residence but since 2005 publication, all the enclosures have been produced by the Bindery with the design determined by the Printer in Residence and printmakers.

The PiR Programme utilises paid and volunteer labour. The Printer in Residence is paid a printer's fee, and all his travel, accommodation and meals are paid for. The artists / printmakers involved in each publication are paid a printers fee, and an author's fee is negotiated for the use of any published or unpublished text. So far, the PiR programme has been able to cover these labour costs from the sale of its publications. Voluntary labour has come from those with an interest in the PiR Programme and letterpress printing in general. Bindery staff from the Dunedin Public Library helped sewed the pages of PINE (2005) and University and Otago Polytechnic staff and students often volunteer to rip paper and collate pages. This concrete support of the Programme through volunteer labour is important to the Programme's running and much appreciated by Kerr (D. Kerr, personal communication, 30 June, 2009). Additional labour not covered by publication sales are the Library staff hours involved which are paid by the University Library. 


\section{Distribution:}

Adams and Barker refer to this as the "dynamic phase" in which the book serves its function of communicating the content (Adams and Barker, 1993 p.22). A variety of businesses and services worldwide can be involved in a book's distribution including: wholesalers, retailers, advertising/promotion agents, book reviews (Adams and Barker, 1993; Greco, 2005). And as Adams and Barker (1993) point out, there is also a secondary form of distribution which included libraries and second hand book stores.

The process of distribution within the PiR Programme is much simpler because the publications are purchased and distributed from the site of their manufacture. There are no wholesalers or retail outlets involved in their distribution (although they are transported to buyers if they are unable to be collected in person).

Kerr takes advantage of as much free advertising as possible to promote each PiR Programme (University of Otago email distribution lists and Staff Bulletin, library and book arts listservs). Publications likely to receive wider national or international interest (such as Hunting of the Snark (2006), Twelve Poems (2007) and PINE (2005) have been publicised via radio and newspaper.

Although a simpler and less costly process, in comparison to commercial publishing distribution processes, promotion of the PiR publications still involves the skill of being able to determine the market for the each publication and target that audience.

\section{Reception:}

From the information gathered in this study, it is difficult to accurately gauge this event in relation to the PiR publications. Of those included in this study, the recipient lists and interviews suggest that the PiR Programme had a dedicated following, orders prior to completion were not uncommon and there was often no need for a book launch as all copies sold quickly (R. Andrew personal 
communication, July9, 2009; I, Doesburg, personal communication, July15, 2009; D. Kerr personal communication, June 30, 2009). Recipient lists indicate that PiR publications tend to be purchased by University of Otago staff and individuals and libraries in the Otago area. However publications with a stronger national and international interest were Hunting of the Snark (2006), PINE (2005) and Twelve poems (2007).

As part of his promotion strategy, Kerr tends to target libraries as a means of ensuring that the PiR publications reach a wide audience despite the small number of copies produced (D. Kerr, personal communication, 30 June, 2009). A search on New Zealand's National Bibliographic Database, Te Puna, indicates that tertiary and public library collections nation-wide hold PiR Publications in their collections. Although libraries play a role in the distribution and reception phase of commercially mass produced books, the significance of this role is greater in relation to the PiR publications - for many they will be the only means of accessing these publications.

\section{Survival (the book as an artefact):}

This final phase in a book's life-cycle refers to the survival of the text (the ideas) and the physical object (Adams and Barker, 1993). When a book has performed its function of transmitting the ideas in the text, it becomes at risk of damage or destruction through neglect. However, as particular editions get more and more scare, it is not uncommon that remaining copies are 'rediscovered' as physical objects of value due to their rarity rather than their content (Adams \& Barker, 1993 p. 32). It is also during this phase that early or limited editions start to be regarded as artefacts of the society and period in history which produced them.

The PiR Programme has only been operating since 2003 so it is difficult to discuss the survival phase in the lifecycle of these publications. However, the preservation grade materials used in their production suggests that the publications are intended to remain in good condition of over a long period which, would help ensure that: a) the content remains accessible over a long 
period of time, and b) the publications can act as artefacts - physical representations of the PiR Programme and its activities and goals. In addition to the materials used in their publication, the significant number of PiR titles being held in the restricted library collections nation-wide also enhances their longterm survival.

The socio-economic forces affecting the life cycle of a book:

The events in occurring in the lifecycle of a book are considered to operate within the context of a society's social, cultural, economic, political and religious values these factors influence and shape the production of the text and its publication (Adams and Barker's, 1993).

In terms of the PiR Programme, Otago's social, cultural, academic and literary history is reflected in the subject matter chosen for publication. And despite being insulated against commercial market pressures in terms of pricing, legislation surrounding copyright and authorship must be adhered to.

The participants in this study expressed the benefits of institutional support for a Programme such as this. However, any external pressures affecting the University of Otago as a whole will ultimately feed through to the Programme via the Library or the supporting academic Departments. Changes within the Library could also affect future support for the PiR Programme. For example, five of the interview participants questioned whether the current Library management had the same the support for the Programme as the management in place when the PiR Programme was established in 2003.

\section{Summary:}

The events in a books lifecycle, as outlined by Adams and Barker (1993), clearly apply to the PiR Programme and the publications produced. In comparison with commercial printing and publishing, differences are apparent within each of these events. 
Unlike large-scale commercial printing, the stages of publication, manufacture and distribution take place in the same location and often involve the same group of people. The Printer in Residence also plays a much more significant role in the lifecycle of a PiR publication (through its design and manufacture), compared with a printer in a commercial printing context.

The external socio-economic forces that influence each stage of a book's life cycle (Adams and Barker, 1993) also affect the PIR Programme. However, in terms of economic or market pressures, the Programme is buffered by the University of Otago Library and supporting academic departments. 


\section{Conclusion:}

The objective of this study was to gain a holistic understanding of the PiR Programme via the Programme's archived documentation, the publications it has produced and the experiences and perceptions of those involved. The historical case study approach was best suited to this type of study because it aims to gain an in-depth understanding of all areas of the unit of study through an analysis of relevant primary and secondary resources. To gain a holistic understanding of the PiR Programme, guided interviews were conducted with eight people involved in the yearly Programmes since 2003, and written accounts were also contributed by two others.

The PiR archives provided an overview of the development of the Programme and its objectives: to promote an awareness of the Otakou Press and the process of printing using the handpress. This is done through the classes and talks organised as part of the Programme and the publications it produces. Interviews with the study's participants reinforced that these objectives were deeply influenced by the history of the Otakou Press from which it operates.

Case studies of the 2005, 2006 and 2007 PiR Programmes provided an insight into the process of producing PiR publications. They also highlighted the uniqueness of each Programme while also portraying the procedural aspects common to all PiR Programmes.

An analysis of the data gathered for this study revealed that; collaboration was a major theme throughout all aspects of the Programmes operations; outreach via class visits to the Otakou Press or talks given by the Printer in Residence (and any other participants) were considered a vital component of any PiR Programme; and although the PiR publications have hand-crafted qualities that would make them items of interested in art or book collector markets, Kerr is adamant that the publications be accessible (via their pricing) to anyone with an interest in books. 
Of those interviewed as part of this study, all felt it was important that the PiR Programme continue. Through the PiR Programme, publications have been produced that would not have been made otherwise, and the participating printers, artists and printmakers and have been able to collaborate in ways they may not have been able to arrange otherwise.

In terms of the book life-cycle model developed by Adams and Barker (1993), the PiR Programme seems to pass through all the events outlined. However, unlike the commercial printing process, many of these events are carried out in the same location and by the same people. In addition, the publications created by each PiR Programme are not just a publication of the chosen text - they are also artefacts that represent a Programme and the activities of a group's collaboration.

It seems that the development of the PiR Programme has not marked a change in direction of the use of the University's press room, the Otakou Press. Instead it seems to have drawn on the press room's history as a teaching press and private press and attempted to combine these functions in one Programme. Renaming the Bibliography Room to the Otakou Press was also a means of connecting the operations of this university press room with the printing history of the Otago region.

In conclusion, the PiR Programme is a small yet unique aspect of New Zealand's private and bibliographic press history that should be the subject of further study. 


\section{References:}

Adamowicz, E. (2009). The livre d'artiste in twentieth-century France. French Studies, 63(2):189-198.

Adams, T. R. \& Barker, N. (1993). A model for the history of the book. In. N. Barker (Ed), A Potencie of life: books and society (pp5-39). London: British Library.

Andrew, R. (2008). Report on the Printer in Residence Programme 2007 Otakou Press Room, University of Otago Library. Dunedin, NZ: University of Otago Library.

Baxter, J. K. (2005). PINE trees in the key of $F$ and a rose in the key of $G$. Dunedin, N.Z: Bibliography Room, University of Otago.

Benton, M.L. (2007). The book as art. In S. Eliot \& J. Rose (Eds.), A companion to the history of the book (pp. 493-507). Malden, MA : Blackwell Publishing.

Book. (2009). In Oxford English Dictionary. Retrieved October 15, 2009, from Oxford English Dictionary Online:

http://dictionary.oed.com/cgi/findword?query type=word\&queryword=book\&f ind. $x=83 \&$ find. $y=14$

Brown, M. P. (1994). Understanding illuminated manuscripts: a guide to technical terms. Malibu, Calif.: Paul Getty Museum in association with the British Library

Burns, R. (2000). Introduction to research methods (4th Ed.). London: Sage publications.

Carroll, L. (2006). The hunting of the snark: an agony, in eight fits. Dunedin, N.Z.: Otakou Press.

Cave, R. (2001). Fine printing \& private presses: selected papers by Roderick Cave. London: British Library. 
Darnton, R. (1982). What is the history of books? Daedalus, 111(3), 65-83.

Darnton, R. (2007). "What is the history of books?" revisited. Modern Intellectual History, 4(3), 495-508, doi:10.1017/S1479244307001370

Cave, R. (1983). The private press. New York: R. R. Bowker Company.

Center For Book Arts. (2008). 2010 artist-in-residence workspace grant for New York emerging artists. Retrieved May 1, 2009 from

http://www.centerforbookarts.org/opportunities/2010workspacegrantapp.pdf

Eisenstein, E. L. (1979). The printing press as an agent of change: communications and cultural transformations in early modern Europe. Cambridge, UK: Cambridge University Press.

Finkelstein, D. \& McCleery, A. (2005). An introduction to book history. New York: Routledge.

Gall, J.P., Gall, M.D. \& Borg, W. R. (2005). Applying educational research: a practical guide (5 $5^{\text {th }}$ ed.). New York: Pearson.

Gaskell, P. (1965). Bibliographical press movement. Journal of the printing historical society, 1, pp1-13.

Gorman, G.E., \& Clayton. P. (2005). Qualitative research for the information professional: a practical handbook (2nd ed.). London: Facet.

Greco, A. N. (2005). The book publishing industry. Mahwah, United States: Lawrence Erlbaum Associates.

Griffith, P., Harvey, R. \& Maslen, K. (1997). Introduction. In P. Griffith, R. Harvey \& K. Maslen (Eds.), Book \& print in New Zealand: a guide to print in Aotearoa (pp. 11-16). Wellington, NZ: Victoria University Press. 
Hamilton Printmakers Arts Association. (n.d.). Exhibitions. Retrieved May 1, 2009 from http://www.theprintstudio.ca/exhibitions.html

Hays, P.A. (2004). Case study research. In K. deMarrais \& S.D. Lapan (Eds.), Foundations for research: methods of inquiry in education and the social sciences (pp. 217-234). Mahwah, NJ: Lawrence Erlbaum Associates.

Hotere, R., \& Manhire, B. (2005). PINE. Dunedin, N.Z: Otakou Press. Howsam, L. (2006). Old books and new histories: an orientation to studies in book and print culture. Toronto: University of Toronto Press.

Hughes, P. (2001). Alan Loney, Te Jenner and 'The love of Ibykos'. Turnbull Library Record, 34, 99-110.

Hughes, P. (2000). Bob Lowry and the Pelorus Press, 1945-53. In P. Griffith, P. Hughes \& A. Loney (Eds.). A book in the hand: essays on the history of the book in New Zealand (pp. 167-187). Auckland: NZ: Auckland University Press.

Ireland, P. (2003). A Shape to Part the Space: Joanna Margaret Paul 1945-2003. Art New Zealand, vol. 108, retrieved October 10, 2009 from: http://www.artnewzealand.com/Issue108/paulobit.htm

Kerr, D. (2005). Printer in Residence Programme - University of Otago Library. Dunedin, NZ: University of Otago Library.

Kerr, D. (2005a). Printer in Residence Programme Contract: University of Otago Library. Dunedin, NZ: University of Otago Library.

Kerr, D. (2006). Printer in Residence Programme Contract, University of Otago Library. Dunedin, NZ: University of Otago Library.

Kerr, D. (2006). Tis the season for a Snark. Unpublished manuscript. 
Kerr, D. (2007). Printer in Residence Programme Contract, University of Otago Library. Dunedin, NZ: University of Otago Library.

Letterpress Printers of the World. (2005). John Holmes, Frayed Frisket Press, Dunedin, New Zealand. Retrieved, May 1, 2009 from http://www.letterpressprinters.org/bios_031.htm

Loney, A. (2009, July). Limits of the book as object. Paper presented at the meeting of the Bibliographical Society of Australia and New Zealand Annual Conference, University of Queensland, Brisbane, Australia.

Loney, A. (2009b). 2008 Printer in Residence Programme - the book \& Ruth Dallas. Unpublished manuscript.

McGann, J. (2002). The socialization of texts. In. Finkelstein, D. \& A. McCleery (Eds.), The book history reader (pp. 39-46). London: Routledge.

McKenzie, D. F. (1999).Bibliography and the sociology of texts. Cambridge, UK: Cambridge University Press.

McLeod, T. (2007). The head the heart and the hand: private press printing in the digital age. Auckland, NZ: Pear Tree Press.

McLeod, T. (2006). The private press in New Zealand in the twenty first century. Script \& Print, 30(3), 134-137.

Manhire, B. (1970). Malady. Dunedin, NZ: Amphedesma Press

Maslen, K. (2005a). From Bibliography Room to Otakou Press. Unpublished manuscript.

Maslen, K. (2005b). The Bibliography Room Press 1961-2005: a short history and checklist. Unpublished manuscript. 
Minnesota Center for Book Arts. (2008). Minnesota Center for Book Arts' Artistsin-Residence Program. Retrieved May 1, 2009 from http://www.mnbookarts.org/artistsprograms/air.html

O’Brien, G. (1997). Hotere - out the black window: Ralph Hotere's work with New Zealand poets. Auckland, N.Z: Godwit Publishing Ltd.

Paul, J. M. (2005). Access to lilac. Dunedin, N.Z: Bibliography Room, University of Otago.

Paul, J. M. (2001). The cherry now. Wellington, N.Z: Fernbank Studio.

Paul, J. M. (1978). Imogen: poems. Eastbourne, N.Z: Hawk Press.

Pickard, A. J. (2007). Research methods in information. London: Facet Publishing.

Platt, D. (2001). The private letterpress: what can be gained from looking to the past? Endnotes, 12-14.

Ransom, W. (1929). Private presses and their books. New York: R. R. Bowker Company.

Richards, L. (2005). Handling qualitative data: a practical guide. London: Sage. Rousmaniere, K. (2004). Historical research. In K. deMarrais \& S.D. Lapan (Eds.), Foundations for research: methods of inquiry in education and the social sciences (pp. 31-50). Mahwah, NJ: Lawrence Erlbaum Associates.

Sellon, A. (2006). The New Zealand Snark. Knight Letter: official magazine of the Lewis Carroll Society of North America.

Shep, S. (2005). Historical Investigation. In G. E. Gorman, P. Clayton (Eds.) Qualitative research for the information professional: a practical handbook (pp.160-181). (2nd ed.). London: Facet.

Traue, J. E. (2001). The two histories of the book in New Zealand. Bibliographical Society of Australia and New Zealand. 25(1), 8-16. 
Tuwhare, H. (2007). Twelve poems by Hone Tuwhare; interpreted by seven Dunedin printmakers. Dunedin, N.Z.: Otakou Press.

Tuwhare, H. (1970). Come Rain Hail: Poems. Dunedin, N.Z.: Bibliography Room, University of Otago.

University of Iowa Center of the Book. (n.d.). Printer-in-residence: University of Iowa Canter for the Book. Retrieved May 1, 2009 from http://www.uiowa.edu/ ctrbook/news/printer_app.pdf

University of Otago Library. (2003, 2004, 2006 \& 2008). Annual report. Retrieved May 1, 2009 from:

http://www.library.otago.ac.nz/services/admin/index.html\#annual

University of Otago Library (2007). Printer in Residence Programme. Retrieved April 14, 2009, from:

http://www.library.otago.ac.nz/SpecialCollections/printers.html

University of Otago Library (2007). Printer in Residence Programme 2007, Otakou Press Room, University of Otago Library. Dunedin, NZ: University of Otago Library. University of Otago. (2002). Print culture in New Zealand: Introduction.

Retrieved April 14, 2009 from http://www.otago.ac.nz/nzpg/print/

University of Rhode Island,. (n.d.). New Leaves Press at the University of Rhode Island. Retrieved may 1, 2009 from

http://www.uri.edu/library/special collections/exhibits/Newleaves/dore.htm

Waite, N. (1997). Private Printing. In P. Griffith, R. Harvey \& K. Maslen (Eds.), Book \& print in New Zealand: a guide to print in Aotearoa (pp. 82-82). Wellington, NZ: Victoria University Press. 


\section{Appendix 1:}

Contents:

Printer in Residence publications 2003-2009 
Title: '... a great warm featherbed'

Printer: Tara McLeod

Contributors:

Name of Press: Bibliography

Room, University of Otago

No. of pages: 4

Details of illustrations: woodcut image of Brasch on cover

Principal typeface:

14pt Garamond bold

Paper: 120 gsm Sorbex

Binding: Hand sewn

Price:

Notes:

Letter to Hal \& Rosemary

Summers, England, 28 February 1958 from Charles Brasch, Heriot Row, Dunedin, N.Z.

Title: A haggis of verse Printer: Tara McLeod Contributors:

Name of Press: Bibliography Room, University of Otago

No. of pages: 14

Details of illustrations:

Principal typeface:

14pt Garamond bold

Paper: 120 gsm Sorbex

Cover 215 Sundance

Binding: Hand sewn

Price: $\$ 20.00$

Notes:

Collection of poems on various subjects from seven poets who have an association with

Dunedin.

Edited by Donald Kerr
Author: Charles

Brasch

Illustrator(s):

Publication Date:

August 2003

No. of illustrations:

1

Type of Press:

Vandercook

Proofing Press

Paper size:

$23 \mathrm{~cm}$ [height]

No. of copies: 50

Author:

Illustrator(s):

Publication Date:

September 2003

No. of illustrations:

Type of Press:

Vandercook

Proofing Press

Paper size:

$23 \mathrm{~cm}$ [height]

No. of copies: 50
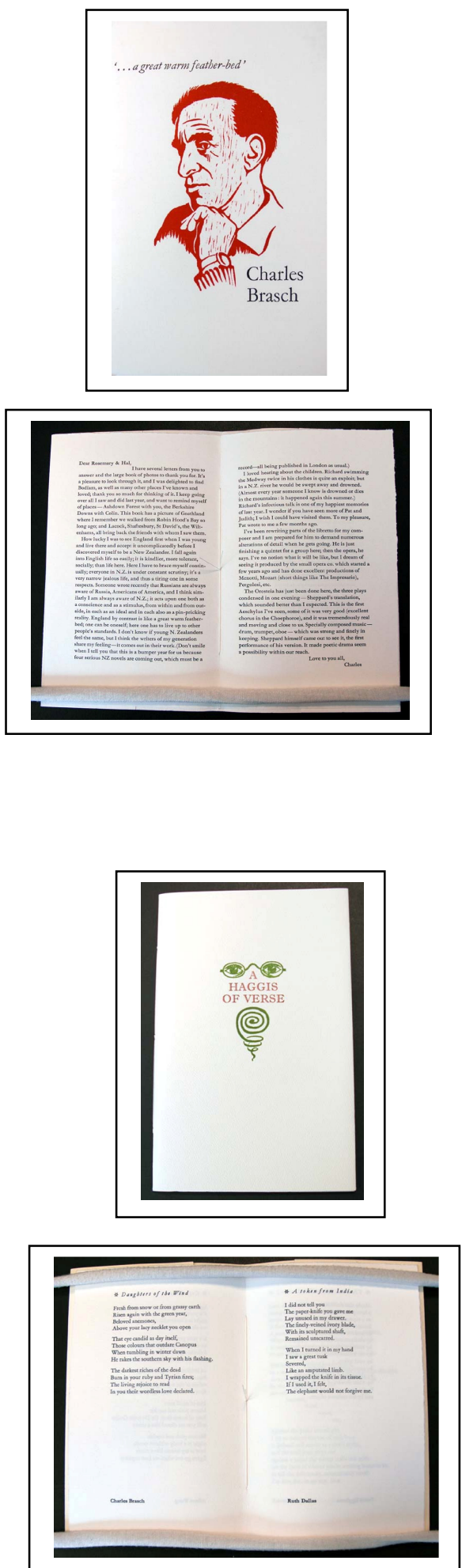
Title: Faces in the water

Printer: John Holmes

Contributors: Inge Doesburg Name of Press: Bibliography Room, University of Otago No. of pages: 17

Details of illustrations:

Woodcut images by John Mitchell; printed by Inge

Doesburg

Principal typeface:

14pt Garamond bold

Paper:

Fabriano Tiepolo 290gsm

Binding:

Conqueror Wine card folder with 2 ribbon ties attached to front and back covers, cream paper label on front printed in red within a black ruled border.

Price: $\$ 250.00$

Notes:

Title: Access to lilac

Printer: Brendan O'Brien

\section{Contributors:}

Name of Press: Bibliography

Room, University of Otago

No. of pages: 20

Details of illustrations:

All by Joanna Paul and printed from polymer blocks

Principal typeface:

14 point Garamond

Paper:

Binding:

Hand sewn; image on cover

Price:

Notes:

The poems have selected by Bernadette Hall, building on a core group gathered by Joanna herself under the title 'access to lilac'.
Author:

Brian Turner

Illustrator(s):

John Mitchell

Publication Date:

September 2004

No. of illustrations:

5

Type of Press:

Vandercook

Proofing Press

Paper size:

$38 \times 28 \mathrm{~cm}$

No. of copies: 60

\section{Author:}

Joanna Margaret

Paul

Illustrator(s):

Publication Date:

2005

No. of illustrations:

Type of Press:

Vandercook

Proofing Press

Paper size:

No. of copies: 100
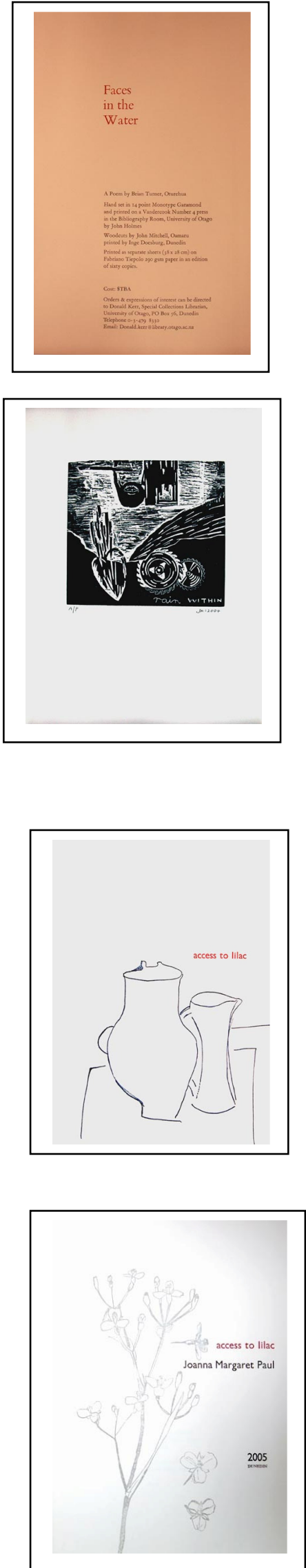
Title: PINE

\section{Contributors:}

Name of Press: Otakou Press

No. of pages: 20

Details of illustrations:

Principal typeface:

14 point Garamond for publication details

Paper:

Zerkall

Binding:

Hand sewn

Price: $\$ 800$ signed; $\$ 350$ unsigned Notes:

Artist's book of artwork by Ralph Hotere and poems by Bill Manhire. Poems rewritten by Ralph Hotere in August 2005 and printed from polymer blocks. Wood type rearranged by Brendan O'Brien in fashion of Hotere \& Manhire's earlier edition on 1974.

Title: The hunting of the snark; an agony, in eight fits

\section{Contributors:}

Inge Doesburg; Kathryn Madill;

Jenna Packer

Name of Press: Otakou Press

No. of pages: 20

Details of illustrations:

12 card characters; 1 original etching

Principal typeface:

12 \& 14 point Garamond

Paper:

off-white Zerkall; natural white Sundance felt and terracotta Bugra; Etching on Tiepolo Binding:

Publication Date: 2006

No. of illustrations: 13

Type of Press:

Vandercook Proofing Press

Paper size: height $20 \mathrm{~cm}$

No. of copies: 101
Printer: Tara McLeod
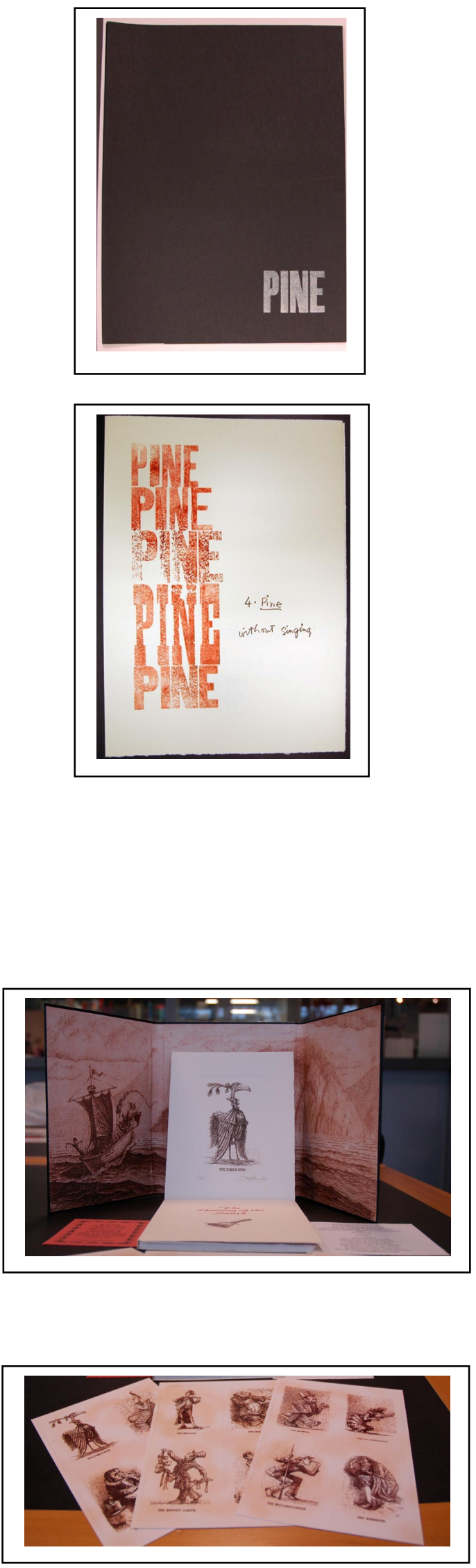

Price: $\$ 250.00$ 


\section{Notes:}

Kit ("Snarkopack") consists of 1 book ([20] p. ; 20 cm.), 3 sheets $(20 \times 13 \mathrm{~cm}$.) containing twelve card characters, one sheet of feet for mounting card characters, 1 original etching of a character $(19 \times 14 \mathrm{~cm}$.), rules card (19 $\times 14 \mathrm{~cm}$.), one bookmark $(21 \times 8 \mathrm{~cm}$. folded to $11 \times 8$ $\mathrm{cm}$.); all in folder (21 x $50 \mathrm{~cm}$. folded to $21 \times 21 \times 17$ $\mathrm{cm}$.) tied by cord.

Text printed by Tara McLeod; solar etching by Inge Doesburg, Jenna Packer and Kathryn Madill; binding by Don Tobin and University of Otago bindery; character card printers, Garry Porter and Graham Tohill at Wickliffe Press. -- Snarkolophon.

Title: Twelve poems by Hone Tuwhare; interpreted by seven Dunedin printmakers

Printer: John Holmes

\section{Contributors:}

Name of Press: Otakou Press

No. of pages: 21

Details of illustrations:

Seven original prints signed by the artists

Principal typeface:

14 point Monotype Garamond, 3 point leaded

Paper: Fabriano Tiepolo 290 gsm

Binding:

Loose portfolio sheets wrapped in Elephant Grey box

Price: $\$ 250.00$
Author: Hone

Tuwhare

\section{Illustrator(s):}

Webb, Marilynn. Nielsen, Olav. McFarlane, Mary. Doesburg, Inge.

Kaan, Simon.

Madill, Kathryn.

Packer, Jenna.

Publication Date:

October 2007

No. of illustrations:

7

Type of Press:

Vandercook

Proofing Press

Paper size:

Height $37 \mathrm{~cm}$

No. of copies: 95
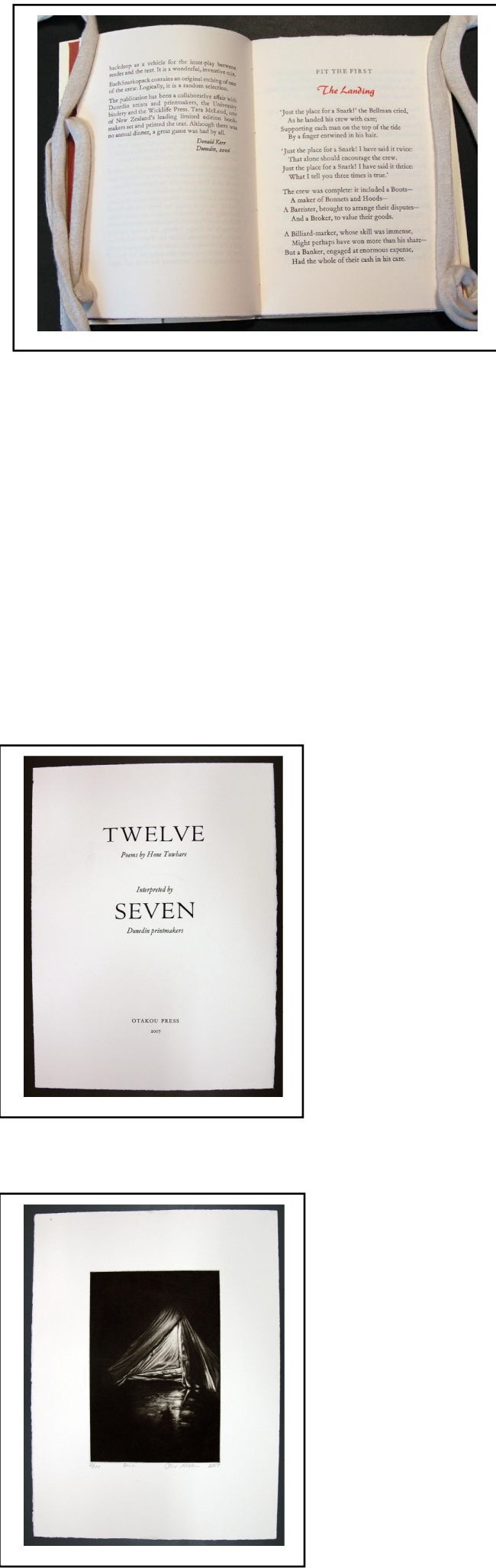


\section{Notes:}

The 12 poems originally appeared in Cone Rain hail, published in 1970 by the Bibliography Room, University of Otago.

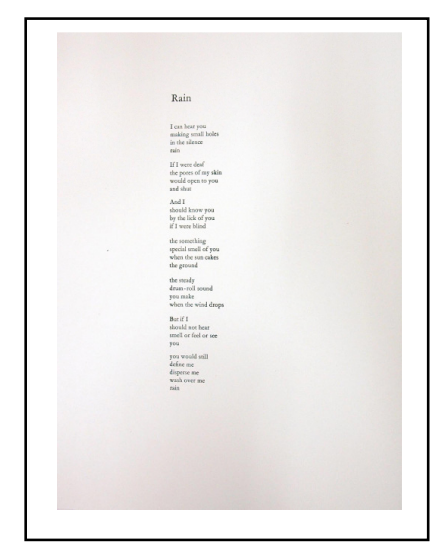

Title: Open sky : a homage to Ruth Dallas

Printer: Alan Loney

\section{Contributors:}

Name of Press: Otakou Press

No. of pages: 36

Details of illustrations:

Principal typeface:

14 pt Garamond / Plantin

\section{Paper:}

Damp Zerkall

Binding:

$1 / 4$ yellow linen, blue linen boards, title printed in silver on upper cover, fore- and bottom text edges untrimmed. Produced by University bindery.

Price: $\mathbf{\$ 2 0 0 . 0 0}$

Reprint of previously published poems, plus some unpublished haiku by Ruth Dallas. This book is edited, designed \& printed by Alan Loney. The visual elements are selected from material found in the Otakou Press studio by the printer.

T.p. printed in blue and grey. With a half t.p. printed with title in silver. Text printed in brown, blue, and grey type.

Author: Ruth Dallas

\section{Illustrator(s):}

\section{Publication Date:}

August 2008

No. of illustrations:

Type of Press:

Hopkinson \& Cope Albion handpress

no. 1928

Paper size:

$27.5 \times 19 \mathrm{~cm}$

No. of copies: 100
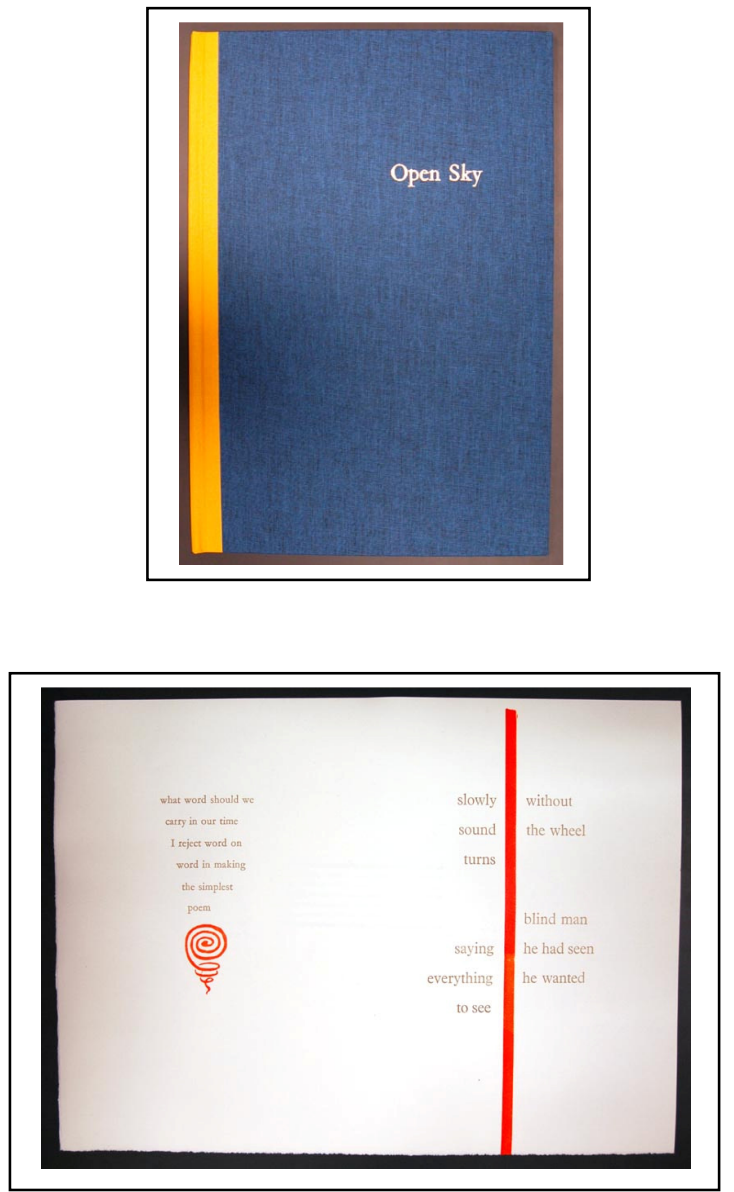
Title: O Lucy Man

Printer: Tara McLeod

Contributors:

Name of Press: Otakou Press

No. of pages:

Details of illustrations:

Relief etchings illustrating poems

Principal typeface:

14pt Garamond

Paper:

Zerkall cream 145 gsm

Binding:

Author:

Riemke Ensing

Illustrator(s):

\section{Publication Date:}

September 2009

No. of illustrations:

5

Type of Press:

Vandercook proofing press

Paper size:

No. of copies: 100

Price: $\$ 200.00$

Notes:

Poems written for Charles Brasch by Riemke Ensing to celebrate the $100^{\text {th }}$ anniversary of Charles Brasch's birthday.
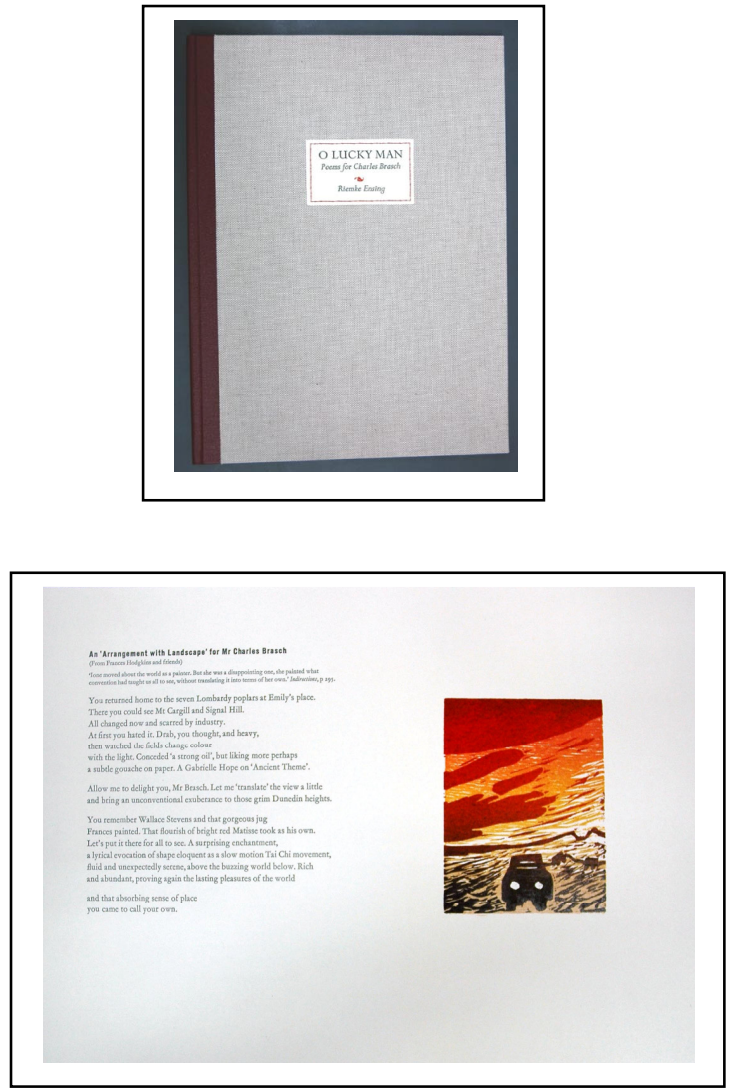
Appendix 2:

Contents:

Study objectives included in the Research Proposal 


\section{Study objectives outlined in the research proposal for this study}

The following research objectives were developed as part of the study's research proposal and were used to inform the data collection phase of this study. These objectives (and the associated research questions) were re-evaluated during the analysis phase of the study and pared-down to those outlined on page 24 .

\section{Objective one:}

To explore the historical context of the Otakou Press' development.

- What were the reasons, or objectives, behind the change in name from the Bibliography Room Press to the Otakou Press?

\section{Objective two:}

To investigate whether the Otakou Press is taking on a more book-arts focus through the PIRP than under its original guise as the Bibliography Room.

- How do the objectives of the Otakou Press compare with that of the former, Bibliography Room?

- How do the objectives of the Otakou Press compare, in general, with that of other bibliographic presses?

- What elements of the book-arts are found in the Printer-in-Residence publications?

- How do those with involvement in the Printer-in-Residence Programme perceive its contribution to book-arts in NZ?

\section{Objective three:}

To investigate the commercial, cultural, and intellectual context of each selected PIR publication in relation Adams and Barker's 'book centred model' (Howsman, $200633)$.

- How have the texts selected for a PIR publication been shaped by the design, format, production and marketing applied to them (Howsman, 2006)? 
- What are the processes and relationships involved in producing a PIR publication?

- How do these processes compare with other private press printing in general?

- Is there a perceived 'function' of a PIR publication, and if so, is it more aligned to book-art or bibliographic objectives? 


\section{Appendix 3:}

\section{Contents:}

Information provided to all interview participants:

Study information sheet;

Informed consent form;

Sample of the interview questions used in this study. 


\section{VICTORIA UNIVERSITY OF WELLINGTON \\ Te Whare Wānanga o te Û̉poko o te Ika a Mãui}

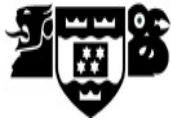

\section{SCHOOL OF INFORMATION MANAGEMENT \\ Information Sheet for participants in the research project \\ From bibliography to book-arts?: The Otakou Press Room's \\ Printer-in-Residence Programme}

The purpose of this study is to document the development of the Printer in Residence (PiR) Programme at the University of Otago and gain an in-depth understanding of the processes involved in producing the PiR publications. The most appropriate means of doing this is to gather the perceptions of those involved in the development and operation of the PiR Programme as a whole, and those Printers, Printmakers and Artists involved in the production of individual PiR publications.

Due to the time restrictions of this study, it will focus on the productions of five PiR publications:

- '--a great warm feather-bed' / Charles Brasch, 2003;

- A haggis of verse / poems on various subjects from seven poets who have an association with Dunedin, 2003.

- $\quad$ Faces in the water / poems by Brian Turner, woodcuts by John Mitchell, 2004

- $\quad$ PINE / Ralph Hotere, Bill Manhire, 2005

- $\quad$ The hunting of the snark: an agony, in eight fits / by Lewis Carroll, illustrated by David Elliot, 2006

- $\quad$ Twelve poems / by Hone Tuwhare, interpreted by seven Dunedin printmakers, 2007).

- $\quad$ Open sky: a homage to Ruth Dallas / a book by Alan Loney

Participation in this project will involve an interview with the Researcher, Paula Whitelock, and a list of questions indicative of what will be asked, will be made available before the interview date. The interview will be conducted face to face, or over the phone if necessary, at a date and time of your convenience between 30-06-09 and 31-07-2009. The interview will be recorded, with your approval, and notes may also be taken during the interview. The interview recordings will be transcribed by the Researcher - they will be securely stored, along with any associated notes, and made accessible only to the Researcher and Project Supervisor (Dr Sydney Shep).

Consent is also sought for the Researcher to ask follow up questions related to the interview, if clarification is required, or if a theme emergences from interviews with other participants which was not investigated during your interview.

As a research participant you can refuse to answer any interview questions and / or withdraw from the study before the data analysis phase of the study begins (10-08-09). If you chose to withdraw from this study, all information provided by you up until that point will be destroyed and excluded from this study. Please be aware that this study does not guarantee anonymity (as you will be named in the study), or confidentiality (as the information given during the interview will be attributed to you). That said, this study has been granted approval by the School of Information Management Ethics Committee at Victoria, University of Wellington on the grounds that no information that is of a sensitive nature (personally or commercially) will be included in this study. Any such information disclosed during the interview will be treated as confidential and will not be used. 
Please do not hesitate to contact me if you have any questions or would like any feedback about the information you have provided during the interview process. A copy of the interview recording, and any transcription notes made, can be sent to you on request. The section of the study discussing the findings related to your involvement in the PIR will also be made available, at the conclusion of this study, if you tick this option on the Informed Consent Form.

Since your interview will provide invaluable information about being involved in the PiR Programme, your permission is asked to store your recording as part of the PIR archives in the University of Otago's Special Collections collection (which has restricted access). Any instances where personal or commercially sensitive information is divulged would be edited from your recording before being stored as part of the PiR archives. If you are not comfortable with your interview being retained in this manner you can opt, in the Informed Consent Form, to have the recordings and associated notes destroyed after a period of two years - the recordings will be securely stored with restricted access during that time. During that two year period, the Researcher may refer to this information for publication in academic or professional journals and/or academic or professional conferences.

If you wish to participate in this study, please read through the Informed Consent Form, tick the statements you agree to, sign and date. It would be greatly appreciated if you contact me at your earliest convenience to organise a time to conduct an interview. Many thanks for your time and I look forward to hearing from you.

Kind regards,

Paula Whitelock (Researcher)

Email: whitelpaul@myvuw.ac.nz paula.whitelock@otago.ac.nz

Phone: 0800347826 (work) 034640714 (home)
Dr Sydney Shep (Project Supervisor)

Senior Lecturer, Library and Information

Services

Victoria University of Wellington

The Printer, Wai-te-ata Press

Email: Sydney.Shep@vuw.ac.nz

Phone: 08001162999 extn: 5784 
Please do not complete this informed consent form until you have read the information sheet related to this project. If you have any questions, please do not hesitate in contacting the Researcher, Paula Whitelock (email: whitelpaul@myvuw.ac.nz phone: 03464 0714)

In completing this form you are agreeing to take part in this research project as an interview participant. Please tick the box beside the statements below, if you agree with them, and sign below.

$\square$ I have read and understood the information sheet for this research project and consent to being an interview participant for this project.

$\square$ I understand that I will be identifiable by name in this research project and the information I give during the interview will be attributed to me, unless it is of a personal or commercially sensitive nature and I can point this at any time during the interview.

I consent to the interview being recorded and;

I consent to the recordings and notes to be retained as part of the Special Collections Printerin-Residence Archives in a secure collection with restricted access. In this instance, any aspects of the interview that divulges personal or commercially sensitive information will be edited from the recordings.

OR

I consent to the recordings and notes being destroyed after a period of two years (the recordings and notes will be securely stored during this time and will be accessible only to the Researcher and Supervisor during this time).

I consent to being asked follow-up questions related to the interview, if clarification is required or if a theme emergences from interviews with other participants which were not investigated in yours.

$\square$ I understand that this research paper will be deposited at the University Library and made available to Library users.

$\square$ I understand that the researcher may utilise information from this study for publication in academic or professional journals and academic or professional conferences.

$\square$ I understand that I am not expected to divulge any information that would be considered personally or commercially sensitive, or could distress and harm in any way. Any such information divulged during the interview will remain confidential and will not be used in this research project.

$\square$ I understand that I can refuse to answer any questions, engage in any activity, or provide any information that I am not comfortable with and/or could cause distress.

I would like a summary of the research finding to be sent to me.

I understand that I am free to withdraw from the research project at any time up until the data analysis phase of the research beginning 15/8/09. All information provided by you up until that point will be destroyed and excluded from this study

Name

Signed

Date: 


\section{A sample of the Interview questions for the INFO 580 Project:}

From bibliography to book-arts? The Otakou Press Room's Printer in Residence Programme

The questions listed below are indicative of what will be asked during the interviews with the key informants outlined in this application form. Each informant will be given a series of questions, selected from this list, which will as a guide or checklist for them and the researcher. The questions selected for each guide will be based on their relevance to the participant's PiR Programme experience.

\section{Otakou Press Room:}

- What is your understanding of the decision to change the name of the Bibliography Room to the Otakou Press Room?

- Could this change in name be marking a change in direction for this bibliographic press?

Printer in Residence Programme:

- What is your understanding of how the PiR Programme came about?

- What do you perceive to be the primary goals of the PiR Programme?

- Who is involved in the running of the PiR Programme?

- Please outline the steps involved in organising and co-ordinating a PIR project.

- Broadly speaking, how is the PiR Programme funded?

- Does the PiR Programme reflect the history and/or objectives of the Bibliography Room Press in any way?

- In what ways do you think of the PiR Programme as a collaborative effort? And how important is this collaborative aspect?

- What does the term, book arts mean for you? Do you feel it is a relevant term for the PIR publications? What does the term, print culture mean for you? Do you feel it is a relevant term for the PIR publications?

- In way ways do you think the PiR Programme, and its publications, have contributed to NZ's book history?

- What were your reasons for becoming involved in the PiR Programme?

- How would you describe your role, and influence, in the production of the publication(s) you've been involved in?

- How collaborative is the production process, and how did you find this type of process?

- What has it been like to be involved in such a Programme?

- How are the PIR publications marketed?

- What future goals do you have for the PiR Programme?

- Could you please describe a bit about your background as a printer and how you become involved in the Printer in Residence Programme (PIRP)? 
- Which of the PIR publications have you been involved in?

- How would you describe the role of the Printer in producing these publications?

- How would you describe the publications produced by the PIRP - what are their common characteristics?

- In terms of each of the PIR publications you have been involved in, what are your recollections of the experience and the production process? For example:

- What were the steps involved in creating the publication?

- How involved were you in the design and planning aspects of the publication?

- How much time did you spend with the Programme Manager (i.e. Donald Kerr), the Print-maker(s) involved and/or the Artist/Illustrator(s)?

- What were the challenges and the triumphs for each publication?

- How collaborative is the production process, and how important is collaboration when you are working with a Print-maker and/or Artist/Illustrator(s)?

- How would you describe the relationship between the illustrations and the printed text in each of the PIR publications you have been involved in?

- How does being involved with Programmes such as this differ from your own work as a Printer?

- Have you been involved in Programmes similar to the PIRP, and if so, what were they?

- In what ways do you feel that the PIR publications, you have been involved in, were a success?

- Please describe the education/outreach component you were involved as part of the PIRP?

- How important do you think this component is to the Programme? 
Appendix 4

Contents:

Glossary 


\section{Glossary:}

\section{Hand-press:}

A printing press in which the forme is inked, the paper is fed and removed, and the press is applied by hand. There are various transitional stages from the handpress to the printing machine in which one or more of these actions are performed automatically or partly mechanically. Source: Glaister, G. A. (1996). Encyclopedia of the book. New Castle, US: Oak Knoll Press.

\section{Letterpress:}

Printing done from raised types or blocks. A feature of letterpress printing is its crispness due pressure on the type tending to concentrate the ink at the edges of the letters.

Source: Glaister, G. A. (1996). Encyclopedia of the book. New Castle, US: Oak Knoll Press.

\section{Lithographic printing:}

A process of printing from a plane surface (as a smooth stone or metal plate) on which the image to be printed is ink-receptive and the blank area ink-repellent. Unlike letterpress printing plate, a lithographic plate can't be easily adjusted. Source: http://www.merriam-webster.com/dictionary/lithography

\section{Printing plate:}

As part of the hand printing system (such as letterpress printing), the printing plate carries the image or text to be printed. The plate can be an arrangement of set-up type; wood, metal, rubber, or plastic plate bearing an image, or a photographic plate (solar plate).

Source: Glaister, G. A. (1996). Encyclopedia of the book. New Castle, US: Oak Knoll Press. 


\section{Solar plate:}

A solar plate is a light sensitized steel backed polymer material which is exposed with U.V. light (sunlight) and developed with water. An image can be made directly on to the plate with opaque materials or by exposing the plate through a transparent film (such as acetate) with artwork on it. A positive transparency is for printing as an etching, and a negative transparency will produce a relief impression.

Source: http://www.nontoxic-printmaking.co.nz/techniques/solarplate.html 